\title{
Vanderson Cristiano de Sousa
}

Riqueza, abundância relativa e densidade de ninhos de meliponíneos (Apidae, Meliponini) em duas áreas de estágios sucessionais distintos de vegetação do Parque Estadual das Fontes do Ipiranga, São Paulo

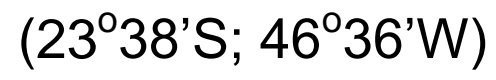

- Versão Corrigida -

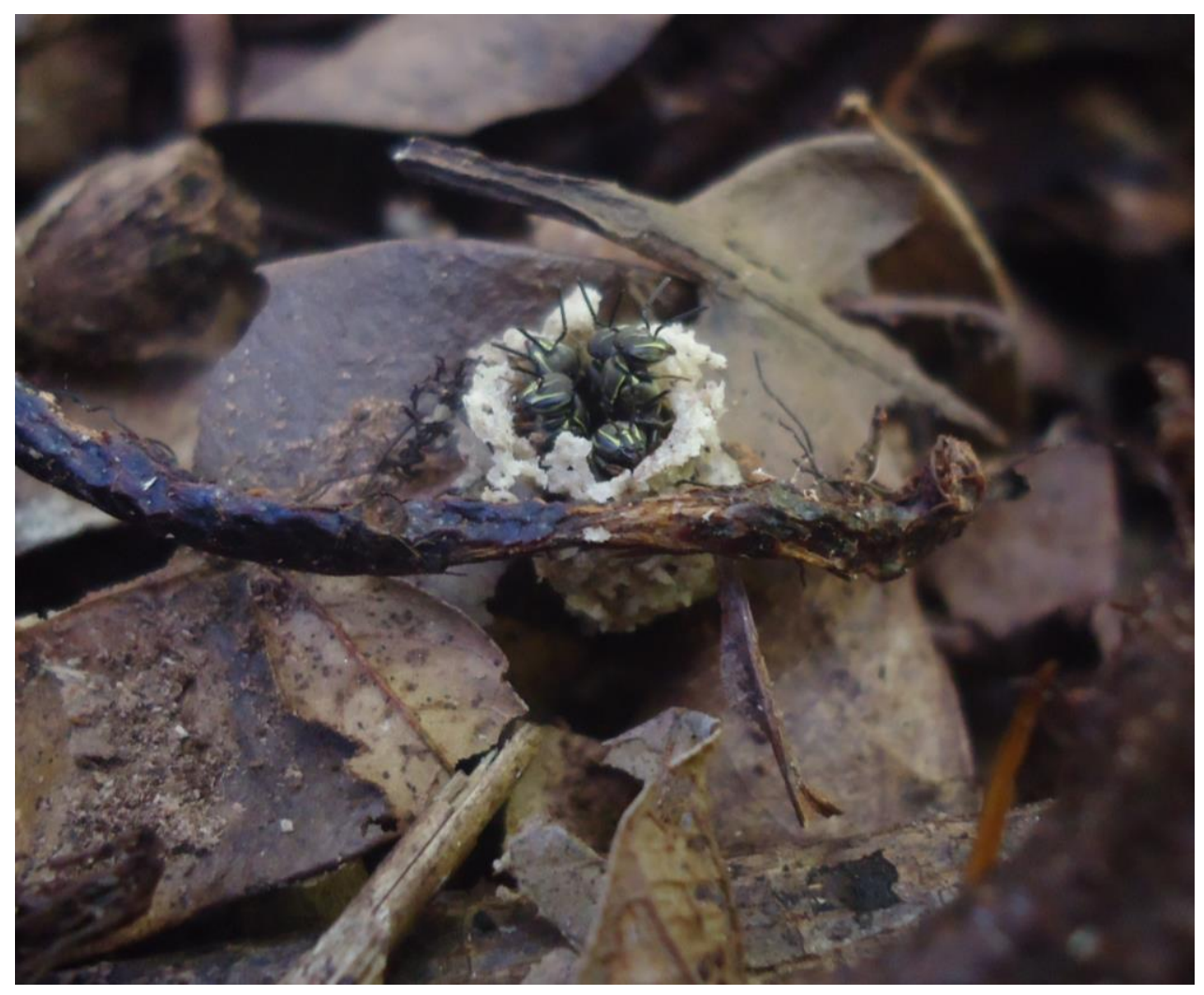

São Paulo 
Riqueza, abundância relativa e densidade de ninhos de meliponíneos (Apidae, Meliponini) em duas áreas de estágios sucessionais distintos de vegetação do Parque

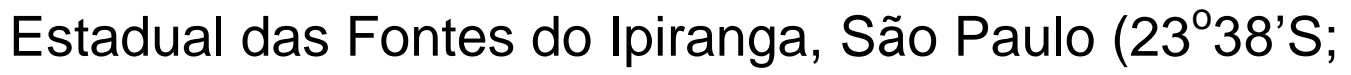
$\left.46^{\circ} 36^{\prime} \mathrm{W}\right)$

Dissertação apresentada ao Instituto de Biociências da Universidade de São Paulo, para a obtenção de Título de Mestre em Ciências, na Área de Ecologia.

Orientadora: Profa. Dra. Astrid de Matos Peixoto Kleinert.

São Paulo 
Ficha Catalográfica

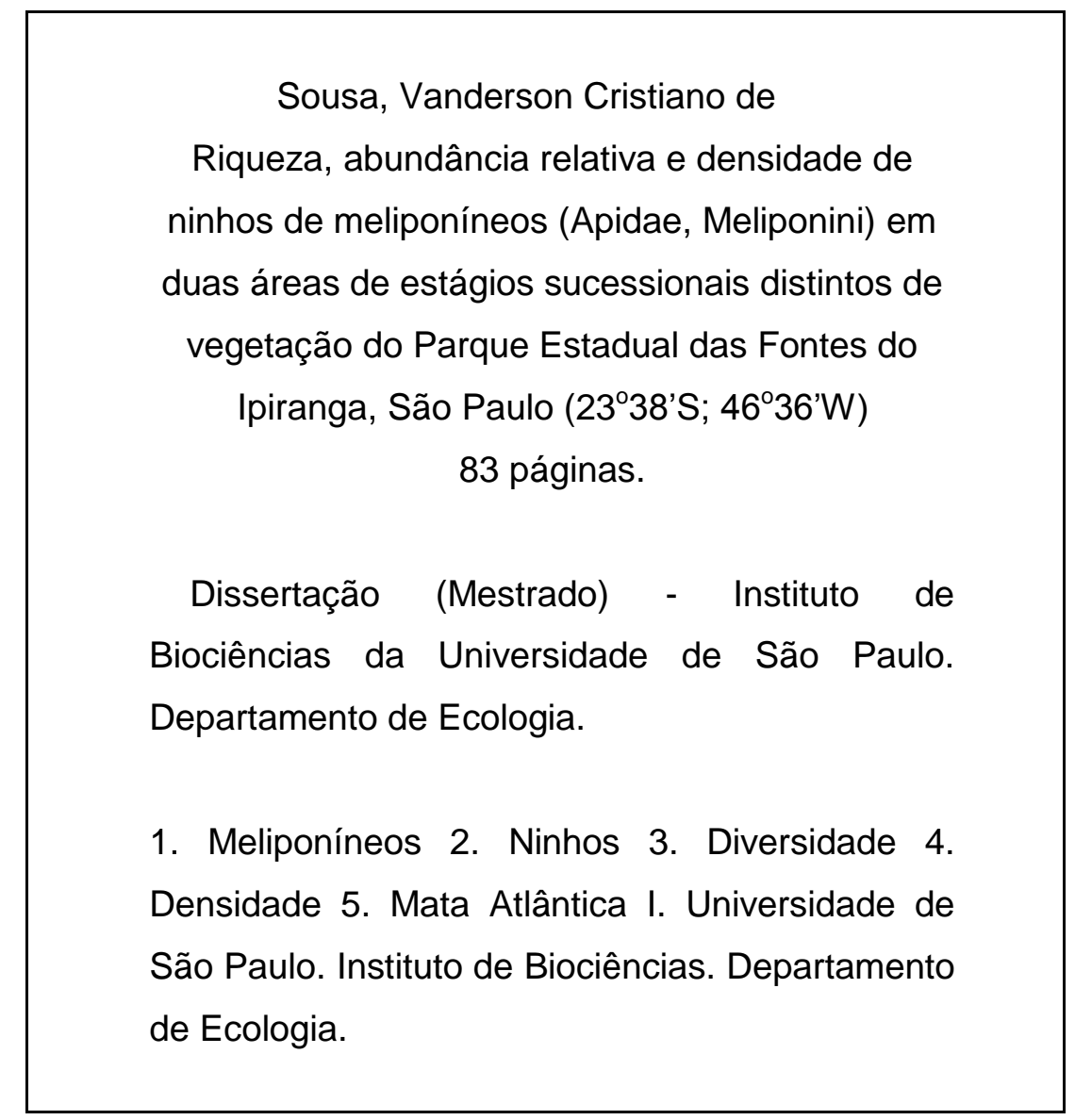

Comissão Julgadora:

$\operatorname{Prof}(a)$. Dr(a).

$$
\text { Prof(a). Dr(a). }
$$

Profa. Dra. Astrid de Matos Peixoto Kleinert 
Agradecimentos

À Profa Dra Astrid Kleinert, por toda orientação fornecida aos longos dos últimos anos, pelo apoio e pelas conversas construtivas, que vão além do meio acadêmico.

À Fundação de Amparo à Pesquisa de São Paulo (FAPESP) pela bolsa de estudo concedida (processo no 2011/03659-9).

Ao Prof. Roberto Shimizu e Prof. José Carlos Motta pelas valiosas contribuições e dedicação no Comitê de Acompanhamento do Projeto.

Aos colegas do Laboratório de Abelhas, pelas contribuições advindas de muitos em determinados momentos, em especial a Profa. Dra. Vera Lúcia I. Fonseca.

Por toda recepção, conversa e ajuda referentes aos mapas, vegetação, imagens de satélites e dados metereológicos, agradeço: à equipe do Instituto Jardim Botânico, em especial à Fatima Scaf e à Valeria; ao Instituto Geológico de São Paulo, em especial Antonio Carlos; à equipe do LASERE (Laboratório de Geografia Aéreo e Sensoriamento Remoto) da FFLCH USP; à equipe da Estação Metereológica do IAGUSP, em especial a Samantha.

À Fundação Parque e Zoológico do estado de São Paulo pela permissão em utilizar parte de sua área para esse estudo.

À Profa Dra Sívia M.R. Pedro, da USP-RP, que auxiliou na identificação das espécies Trigona braueri e Scaptotrigona bipunctata.

Ao amigo geógrafo Rodolfo Luz e ao Andre Luis do Laboratório de Abelhas, pelas ajudas referentes ao software Arcgis.

À ex-diretora Profa. Dra. Marta Mantovani, ao Arquiteto Paulo Bernadelli e ao atual diretor do Parque, o Prof. Dr. Fabio, pela autorização e apoio na pesquisa.

À Profa. Raquel Glezer (História FFLCH USP), vice-diretora do Parque Cientec, pelo apoio e incentivo ao longo dos últimos anos, bem como na orientação de alguns trabalhos que envolviam a população do entorno do PEFI, despertando em mim mais ainda o interesse pelo PEFI.

Aos funcionários do Parque Cientec pela atenção, preocupação e toda ajuda burocrática: Wandeth, Luciane, Regina, Irene, Inês, Patricia santos e, em especial Vera e Iraildes. Aos funcionários da equipe de segurança, em especial Humberto, Euclides, Fernando, Guilliano e Claúdio, por toda preocupação e atenção.

À Maria de Lourdes, do Parque Cientec, por acreditar e promover as atividades de educação que se desenvolvem no Parque Cientec e, em especial, pelo apoio na realização de palestras sobre abelhas voltadas aos funcionários e os visitantes do parque em geral.

Ao Prof. Dr. Waldir Mantovani e pela conversa esclarecedora sobre o plano de manejo e a escolha das áreas de vegetação do estudo.

À Profa. Rozely Ferreira pelas dicas valiosas sobre o PEFI e pela sua indispensável disciplina Planejamento em Serviços Ecossistêmicos. 
À Jenifer Carvalho Lopes pela ajuda na coleta de plantas e identificação das mesmas, além de ser amiga ao longo dos últimos anos nessa minha jornada pelo Instituto de Biociências.

Ao Julian Osuna e a Fernanda Luccas pela ajuda na coleta das abelhas. Ao técnico Paulo Cesar pela ajuda no levantamento em campo dos dados referentes à vegetação. $A$ todos aqueles que me prontamente me ofereceram ajuda e que eu acabei não precisando: Barbara, Adriana, Paola, Tamara e Andreia.

À Bernadete, à Socorro e à Vera do Departamento de Ecologia, sempre dispostas a ajudarem os alunos.

À Fabiana Pioker, que no últimos anos tem sido companheira das palestras e atividades referentes a divulgação sobre nossas abelhas sem-ferrão, "ilustres desconhecidas". Também agradeço pelas dicas referentes ao projeto.

Aos meus colegas da moradia da Universidade, o CRUSP, muitos corajosos lutadores do movimento estudantil, que fazem com que eu saiba que ainda têm muitos que sonham e lutam por um mundo socialmente melhor.

À Cinthya, fisioterapeuta, à Maria de Lourdes, à Alessandra, auricupunturista, à equipe do HU e Hospital das Clinicas, que estiveram presentes em minha vida a partir do dia 21 de outubro de 2011 e ao longo do ano de 2012.

Ao Lucas Paz, a Thais Lucena e Maíra Mesquita, meus eternos "Moacires, Filhos da Dor" pelos oito meses incríveis de 2012 nas águas gélidas e calorosas do espetáculo de dança-teatro aquático nas piscinas do CEPEUSP.

À toda comunidade da FFLCH USP por abrigar um estranho no ninho e propiciar uma nova maravilhosa jornada pelos caminhos das Ciências Sociais.

À Mariana Cremosa, membra da família que partiu em 2013, deixando saudades.

A cada abelha coletada de seu maravilhoso mundo para que nós possamos cada vez mais lutar pela sua preservação.

Aos eternos amigos, que fizeram parte de minha vida nos últimos 3 anos, me oferecendo forças, mesmo que indiretamente, para a realização desse projeto: Alessandra, Alexandra, Debora, Bruno, Silvana, Daiana, Diego, Clayton, Raquel, Rafael, Leandro Santos, Barbara, Luiz, Alan, Cleusa, Andrea Passos, Fabiana, Margaretha, João Paulo, Adriana, Paola, Paola Lá e Nelma.

À minha grande amiga Andrea Farias da biologia, que depois de oito anos de muita luta se despediu em 2013 de seus amigos e familiares. A grande Graça, sua mãe, que com muita força e fé foi mais que uma mãe para a Andrea e é um exemplo para todos nós.

À minha família, em especial à minha mãe Luzia Arba. 
"Não sou nada.

Nunca serei nada.

Não posso querer ser nada.

À parte disso, tenho em mim todos os sonhos do mundo.

(...)

Para uma rua inacessivel a todos os pensamentos,

Real, impossivelmente real, certa, desconhecidamente certa, Com o mistério das coisas por baixo das pedras e dos seres, $(\ldots)^{\prime \prime}$

Tabacaria, Fernando Pessoa

À Andreia Farias e à sua mãe Dona Graça... 


\section{SUMÁRIO}

\begin{tabular}{|c|c|}
\hline RESUMO .. & 1 \\
\hline ABSTRACT ............ & 2 \\
\hline 1.INTRODUÇÃO & 3 \\
\hline 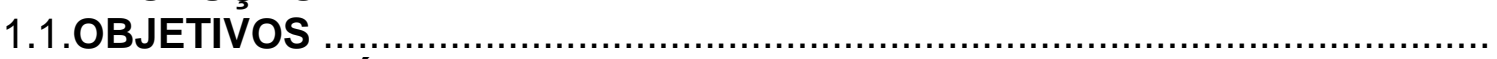 & 7 \\
\hline 2. MATERIAL E MÉTODOS & 9 \\
\hline 2.1 Área de Estudo ................ & 9 \\
\hline 2.2. A Vegetação do PEFI & 11 \\
\hline 2.2.1. Estágio sucessional secundário inicial (SI) - 100,50 ha (Plano de Manejo & \\
\hline do PEFI, 2005) & \\
\hline $\begin{array}{l}\text { 2.2.2. Estágio sucessional secundário tardio (ST) }-21,20 \text { ha (Plano de Manejo } \\
\text { do PEFI, 2005) }\end{array}$ & 13 \\
\hline 2.3. Local do estudo & 16 \\
\hline 2.3.1. Estágios sucessionais e a região do PEFI desse estudo ....................... & 16 \\
\hline 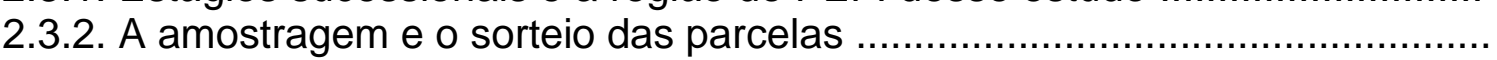 & 16 \\
\hline Perfis Florestais do PEFI (Peccinini, 2000) ....................... & 18 \\
\hline 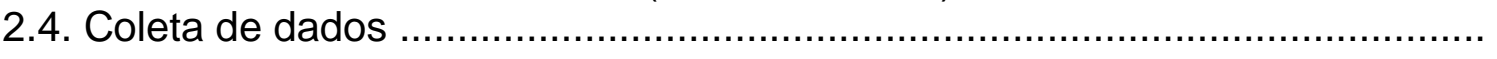 & 20 \\
\hline 2.4.1. Levantamento de ninhos & 20 \\
\hline ensurações das variáveis fitossociológicas das parcelas do estudo ......... & 21 \\
\hline 2.4.3. Variações microclimáticas entre os estágios sucessionais da vegetação ... & 22 \\
\hline 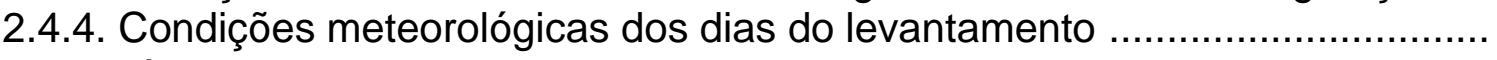 & 22 \\
\hline 2.5. Análise dos dados & 23 \\
\hline 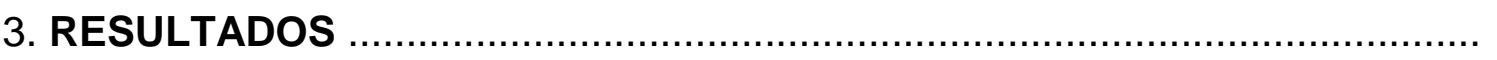 & 25 \\
\hline yios sucessionais & 25 \\
\hline 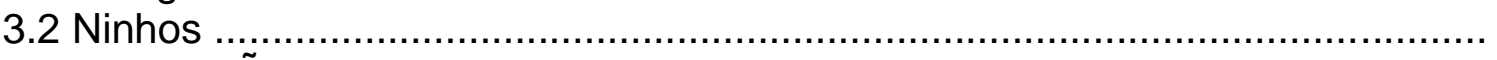 & \\
\hline & \\
\hline
\end{tabular}

4.1 Hipóteses

4.2 Espécies de meliponíneos

4.2.1 Paratrigona subnuda: abundância dos ninhos de solo

4.2.2 Trigona braueri: primeiro registro em São Paulo

4.2.3 Trigona spinipes: ninhos aéreos

4.2.4 Tetragonisca angustula: presente em área aberta e fora da área de amostragem

4.2.5 Abelhas do gênero Melipona: ausência

4.2.6 Apis mellifera: abundância igual à das espécies de meliponíneos que nidifciam em árvores

4.3 Posicionamento geográfico da entrada dos ninhos e direção dos ventos

4.4 Considerações finais

5. CONCLUSÕES

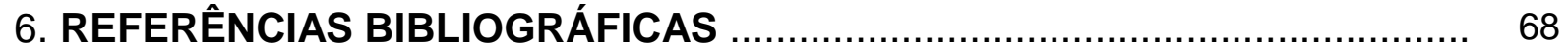

7. ANEXOS 
Riqueza, abundância relativa e densidade de ninhos de meliponíneos (Apidae, Meliponini) em duas áreas de estágios sucessionais distintos de vegetação do

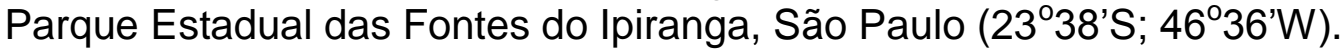

\section{RESUMO}

Os meliponíneos atuam como importantes polinizadores de espécies nativas nas regiões tropicais e subtropicais e apresentam uma grande relevância para as unidades de conservação. A disponibilidade de sítios de nidificação, conforme a oferta de diferentes substratos (cavidades em árvores e no solo, por exemplo), pode determinar a estrutura da comunidade de meliponíneos. Tendo como área de estudo o Parque Estadual das Fontes do Ipiranga ( $\left.23^{\circ} 39^{\prime} \mathrm{S}, 46^{\circ} 37^{\prime} \mathrm{W}\right)$, situado em meio de uma intensa urbanização na cidade de São Paulo - SP, este trabalho teve como objetivo principal o levantamento de ninhos de espécies de meliponíneos em duas áreas com fitofisionomias distintas: áreas de estágio sucessional secundário inicial (SI), com menor densidade de indivíduos arbóreos, e áreas de estágio secundário tardio (ST), com maior densidade de indivíduos arbóreos. Foram formuladas as seguintes hipóteses: 1) a riqueza e a diversidade de espécies de meliponíneos serão maiores nas áreas ST; 2) nas áreas ST, a maior disponibilidade de substratos para nidificação (ocos de árvores) implicaria em uma densidade maior de ninhos de meliponíneos, com o predomínio de espécies que nidificam em árvores; 3) nas áreas $\mathrm{SI}$, os valores de riqueza e de abundância relativa de espécies de meliponíneos que nidificam no solo serão maiores que os valores para as espécies que nidificam em árvores, pela baixa densidade de indivíduos arbóreos; 4) ninhos de espécies do gênero Melipona só serão encontrados nas áreas ST, por nidificarem em ocos de árvores com grandes CAPs (circunferência à altura do peito). No total, foram encontrados 14 ninhos, de 4 espécies, todas da subtribo Trigonina. A espécie Paratrigona subnuda, que nidifica no solo, foi a que apresentou a maior abundância relativa de ninhos $(n=11 ; 78,57 \%)$, com ninhos tanto em áreas $S I(n=2)$, como em áreas ST $(n=9)$. As demais espécies estiveram representadas por apenas um ninho cada: Trigona braueri $(n=1 ; 7,14 \%)$ em SI, Scaptotrigona bipunctata $(n=1 ; 7,14 \%)$ e Trigona spinipes ( $n=1 ; 7,14 \%)$, ambas em ST. As áreas ST apresentaram a maior abundância relativa de ninhos $(n=11,78,57 \%)$ e, ao contrário do que esperávamos, nessas áreas, a abundância de ninhos subterrâneos foi maior que a de ninhos de árvores, fossem eles de suporte ou de cavidades. Também não foram encontrados ninhos de espécies do gênero Melipona, como suposto. Os valores de diversidade foram praticamente os mesmos (baixos) para ambos os estágios ( $\mathrm{SI}$ - H' $\left.=0,60 ; \mathrm{ST}-\mathrm{H}^{\prime}=0,64\right)$. Já a riqueza e a densidade de ninhos foram significativamente maiores nas áreas ST $(S I-$ riqueza $=2$, densidade $=1,43$ ninhos $/$ ha; ST - riqueza $=3$, densidade $=5,24$ ninhos $/$ ha). A densidade de ninhos para toda a área de estudo (3,33 ninhos/ha) foi maior que a média encontrada para outros levantamentos realizados em áreas naturais.

Palavras-chave: meliponíneos, ninhos, diversidade, densidade, Mata Atlântica. 
Richness, relative abundance and nest density of stingless bees (Apidae, Meliponini) in two areas of vegetation in distinct successional stages of the Parque Estadual das

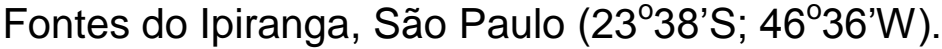

\section{ABSTRACT}

Stingless bees act as important pollinators of native species in tropical and subtropical regions and have a great relevance to conservation units. The availability of nesting sites, according to substrates' supply (cavities in trees and soil, for example), can determine the structure of stingless bees community. This study was conducted in the Parque Estadual das Fontes do Ipiranga ( $\left.23^{\circ} 39^{\prime} \mathrm{S}, 46^{\circ} 37^{\prime} \mathrm{W}\right)$, situated in the middle of an intense urbanization in São Paulo city - SP. The study aimed to survey the nest of species of stingless bees in two areas with different vegetation types: areas of initial secondary successional stage (SI), with a lower density of individual trees, and areas of late secondary stage (ST), with a higher density of individual trees. The following hypotheses were formulated: 1) richness and diversity of stingless bees species will be higher in the ST areas; 2) in these areas as well, the increased availability of nesting sites (tree hollows) will entail in a higher density of stingless bees nests with a predominance of species that nest in trees; 3) in the SI areas, richness and relative abundance of stingless bees species that nest in the soil will be greater than the values for species that nest in trees, due to the low density of individual trees; 4) nests of species of the genus Melipona will only be found in the ST areas due to their preference to nest in hollows of trees with large CAPs (circumference at breast height). In total, 14 nests of 4 species were found, all of them belonging to the subtribe Trigonina. Paratrigona subnuda, which nests on the ground, presented the highest relative abundance of nests $(n=11$, $78.57 \%)$, with nests in both SI $(n=2)$ areas, as in ST areas $(n=9)$. The other species were represented by only one nest each: Trigona braueri $(n=1,7.14 \%)$ in SI, Scaptotrigona bipunctata $(n=1,7.14 \%)$ and Trigona spinipes $(n=1,7.14 \%)$, both in ST. The ST areas had the highest relative abundance of nests $(n=11,78.57$ $\%$ ) and, contrary to what we had expected, in these areas, the number of underground nests was higher than of tree nests, whether they were supportive or cavities. Also contrary to our predictions, no nests of species of the genus Melipona were found. Diversity values were practically the same (low) for both stages (SI - H ' $\left.=0.60 ; \mathrm{ST}-\mathrm{H}^{\prime}=0.64\right)$. Richness and nest density were significantly higher in ST areas $(\mathrm{SI}$ - richness $=2$, density $=1.43$ nests $/$ ha; $S T$ - richness $=3$, density $=5.24$ nests/ha). The nest density for the entire study area (3.33 nests/ha) was higher than the average found in other surveys in natural areas.

Key words: stingless bees, nests, diversity, density, Atlantic Rain Forest. 


\section{INTRODUÇÃO}

A Mata Atlântica brasileira tem hoje uma abrangência estimada entre 1 e 1,5 milhões de $\mathrm{km}^{2}$, cerca de 7 a 8\% da floresta original (Galindo-Leal \& Câmara, 2005). Apresenta um rico complexo biótico de natureza florestal, apresentando altíssimos níveis de endemismo, além de representar um verdadeiro hotspot, com níveis excepcionais de biodiversidade (Schaffer \& Prochnow, 2002; Capobianco, 2004). No estado de São Paulo, restam 16\% de cobertura florestal natural de Mata Atlântica, sendo que muitas dessas áreas remanescentes são pequenas, isoladas, altamente perturbadas, e em contato direto com áreas urbanizadas e com grande proporção de espécies sucessionais secundárias (Viana et al., 1997).

As espécies de abelhas, que se alimentam de néctar e pólen, têm um papel fundamental na manutenção da biodiversidade de espécies vegetais, principalmente pela promoção da polinização cruzada (Santos, 2002). Estima-se que existam no mundo 20 mil espécies de abelhas (Pedro \& Camargo, 1999). Dentre os Apoidea, somente dois grupos são considerados exclusivamente eussociais: os Apini e os Meliponini (Kajobe \& Roubik, 2006). Os Meliponini pertencem ao grupo dos Apidae corbiculados e são conhecidos como abelhas indígenas sem ferrão (Michener, 2000; Silveira et al., 2002). Ocorrem em grande parte das regiões de clima tropical e subtropical do planeta (Nogueira-Neto, 1997; Heard, 1999; Martins et al., 2004), sendo que cerca de $75 \%$ das 550 espécies conhecidas são encontradas na América Neotropical. (Nogueira-Neto, 1997; Costa et al., 2003). No Brasil, estão representados por 412 espécies, pertencentes a 27 gêneros (Camargo \& Pedro, 2013). Estimativas realizadas no Estado de São Paulo indicam que nas regiões onde ocorrem, podem representar a maior biomassa de insetos que visitam flores (Michener, 1979). 
As colônias de meliponíneos apresentam um grande número de indivíduos, variando de algumas centenas a milhares de indivíduos, dependendo da espécie (Sakagami, 1982). Têm como características uma alta longevidade e uma baixa fecundidade (Eltz et al., 2003). Sua economia de forrageio é baseada no sistema de "refúgio", ou seja, as operárias forrageiam a partir de um local fixo, o ninho (Hubbell \& Johnson, 1977). Os ninhos são compostos, em geral, por uma rainha e operárias, além de machos, sendo que, na maior parte das espécies, as operárias podem produzir machos, sob determinadas circunstâncias (Imperatriz-Fonseca \& Kleinert, 1998; Roubik, 2006; Souza \& Kleinert, 2006).

Os hábitos de nidificação dos meliponíneos variam conforme as espécies. Algumas constroem ninhos aéreos, outras aproveitam cavidades subterrâneas abandonadas por outros insetos, como cupins e formigas, e a maioria nidifica em ocos de árvores vivas ou mortas (Nogueira-Neto et al., 1986; Roubik, 1989). Algumas espécies, como Tetragonisca angustula, acabam se adaptando muito bem ao meio antrópico, pois apresentam certa plasticidade em utilizar cavidades artificiais, como frestas em muros, paredes de concreto e edificações (Taura \& Laroca, 1991; Pereira, 2004; Zanette et al., 2005).

Geralmente, quando o número de indivíduos nas colônias aumenta muito, os meliponíneos formam outras novas pelo processo de enxameagem, porém, diferentemente das abelhas africanizadas, não são capazes de migrar sob condições desfavoráveis, sendo, portanto, suscetíveis às perturbações (NogueiraNeto, 1997; Roubik, 2006). Após a escolha da nova cavidade, as operárias abastecem primeiro o novo ninho com alimento e material de construção, vindos da colônia-mãe; o contato entre as duas colônias continua por dias, ou até mesmo meses, conforme a espécie (Nogueira-Neto, 1997; Roubik, 1989). Essa relação 
entre as colônias mãe e filha não permite que novos ninhos se dispersem para muito longe, não mais que algumas centenas de metros, mesmo que isso ocasione competição por alimento entre as duas colônias (Michener, 1979; Roubik, 2006).

Os tamanhos das cavidades nos ocos de árvores podem limitar o desenvolvimento dos ninhos de certas espécies, e a quantidade de substratos para nidificação podem ser um recurso limitante para os meliponíneos (Kerr et al., 1967; Hubbell \& Johnson, 1977; Oliveira et al., 1995; Samejima et al., 2004). A abundância de meliponíneos também está ligada à disponibilidade de alimento, pólen e néctar, como constatado em florestas da Malásia (Eltz et al., 2002). A redução de florestas tropicais em Sarawak, Malásia, diminuiu a densidade dos ninhos dos meliponíneos, pois esses estavam intimamente relacionados à densidade de árvores de grande porte, presentes em maior abundância nas florestas primárias, do que nas áreas perturbadas (Samejima et al., 2004).

Em estudos realizados no Brasil, espécies do gênero Melipona são relatadas apenas em ambientes naturais (Oliveira et al., 1995; Rêgo \& Brito, 1996; Brown \& Albrecht, 2001; Castro, 2001; Antonini, 2002; Mouga, 2004; Andena et al., 2005; Teixeira \& Viana, 2005; Serra et al., 2009), sendo muito raras ou ausentes em áreas urbanas (Taura \& Laroca, 1991; Pinheiro-Machado \& Kleinert, 1993; Carvalho \& Machini, 1999; Sousa et al., 2002; Souza et al., 2005; Sousa \& Kleinert, 2010), ou naquelas em que a vegetação natural foi completamente removida, substituída por pastagens e cultivos agrícolas (Pereira, 2004). Já no caso da subtribo Trigonina, algumas espécies fazem uso de cavidades artificiais existentes em ambientes urbanos, como aquelas dos gêneros Plebeia, Nannotrigona, Partamona e, principalmente, Tetragonisca angustula, popularmente conhecida como jataí (Pedro \& Camargo, 1999). Diferentemente das espécies maiores, que podem superar mais 
facilmente a distância entre os fragmentos, os meliponíneos de menor porte sofrem maior risco de mortalidade devido ao menor alcance de vôo (Araújo et al., 2004). As áreas verdes urbanas, como jardins e cemitérios, podem também servir como fontes alternativas de alimento para algumas espécies destas abelhas. Nos fragmentos florestais, assim como em algumas áreas urbanas, pode haver grande densidade de colônias, porém os índices de riqueza de espécies são baixos, com o predomínio de algumas poucas (Cane, 2001; Sousa \& Kleinert, 2010).

Em áreas urbanas, a riqueza de espécies é variável, indicando que diferentes graus de urbanização têm efeitos distintos na fauna de insetos local (Zanette et al., 2005; Andersson et al., 2007). No Brasil e, em particular, na área urbana de São Paulo, são poucos os estudos sobre comunidades de abelhas a partir de levantamentos de ninhos (Pinheiro-Machado \& Kleinert, 1993; Oliveira et al., 1995; Rêgo \& Brito, 1996; Castro, 2001; Teixeira \& Viana, 2005; Pereira, 2004; Souza et al., 2005; Kleinert, 2006). Os únicos levantamentos de ninhos de meliponíneos, realizados na grande São Paulo, foram feitos em áreas urbanas, e relatam densidades de 15,78 ninhos/ha (Pinheiro-Machado \& Kleinert, 1993) e de 10,51 ninhos/ha (Sousa \& Kleinert, 2010), valores superiores ao encontrado em áreas naturais de Mata Atlântica, 2,8 ninhos/ha (Silva et al., 2013). 


\subsection{OBJETIVOS}

Visto que a disponibilidade de substratos de nidificação pode determinar a estrutura e/ou a composição da comunidade de meliponíneos, com possíveis consequências para todo 0 habitat, este trabalho tem como objetivo realizar 0 levantamento de ninhos de espécies de meliponíneos, no Parque Estadual das Fontes do Ipiranga (PEFI)- São Paulo (SP), em duas áreas com fitofisionomias distintas: áreas de estágio sucessional secundário inicial (SI), com menor densidade de indivíduos arbóreos, e áreas de estágio secundário tardio (ST), com maior densidade de indivíduos arbóreos (Plano de Manejo do PEFI, 2005). Para esse fim, foram formuladas as seguintes hipóteses:

1) A riqueza e a abundância de espécies de meliponíneos serão maiores nas áreas de estágio secundário tardio (ST), onde os valores de diâmetro e de altura das árvores são maiores, do que das áreas de estágio secundário inicial (SI).

2) Nas áreas de estágio secundário tardio (ST), a maior disponibilidade de substratos para nidificação (ocos de árvores) implicará em uma densidade maior de ninhos de meliponíneos, com o predomínio de espécies que nidificam em árvores.

3) Nas áreas de estágio secundário inicial (SI), os valores de riqueza e de abundância relativa de espécies de meliponíneos que nidificam no solo serão maiores que os valores para as espécies que nidificam em árvores, devido à menor disponibilidade de árvores e ocos.

4) Ninhos de espécies do gênero Melipona serão encontrados somente nas áreas de estágio secundário tardio (ST), pelo fato dessas espécies 
nidificarem, preferencialmente, em cavidades de árvores com grandes CAPs (circunferência à altura do peito). 


\section{MATERIAL E MÉTODOS}

\section{1. Área de Estudo}

O Parque Estadual das Fontes do Ipiranga (PEFI), está situado entre os paralelos $23^{\circ} 38^{\prime} 08^{\prime \prime} \mathrm{S}$ e $23^{\circ} 40^{\prime} 18^{\prime \prime} \mathrm{S}$ e os meridianos $46^{\circ} 36^{\prime} 48^{\prime \prime} \mathrm{W}$ e $46^{\circ} 38^{\prime} 00^{\prime \prime} \mathrm{W}$, com altitudes médias entre 760 e 835 m (Fernandes et al., 2002). Parte de sua área está localizada na região sudeste do município de São Paulo, e outra parte se encontra no município de Diadema (Fig. 1). A área total do PEFI é de 526,38 ha e contém um fragmento florestal circundado por intensa urbanização, cuja vegetação classifica-se como floresta ombrófila densa e pertencente ao domínio de Mata Atlântica (Nastri et al. 1992 apud Barbosa et al., 2002).

O clima predominante é do tipo Cwb, segundo a classificação de Köppen, que indica clima temperado, com regimes de chuvas no verão e inverno seco; a temperatura média fica em torno de $18^{\circ} \mathrm{C}$, no inverno, e $22^{\circ} \mathrm{C}$, no verão (Santos \& Funari, 2002). A precipitação anual é superior a 1.500 mm (Santos \& Funari, op. cit). 

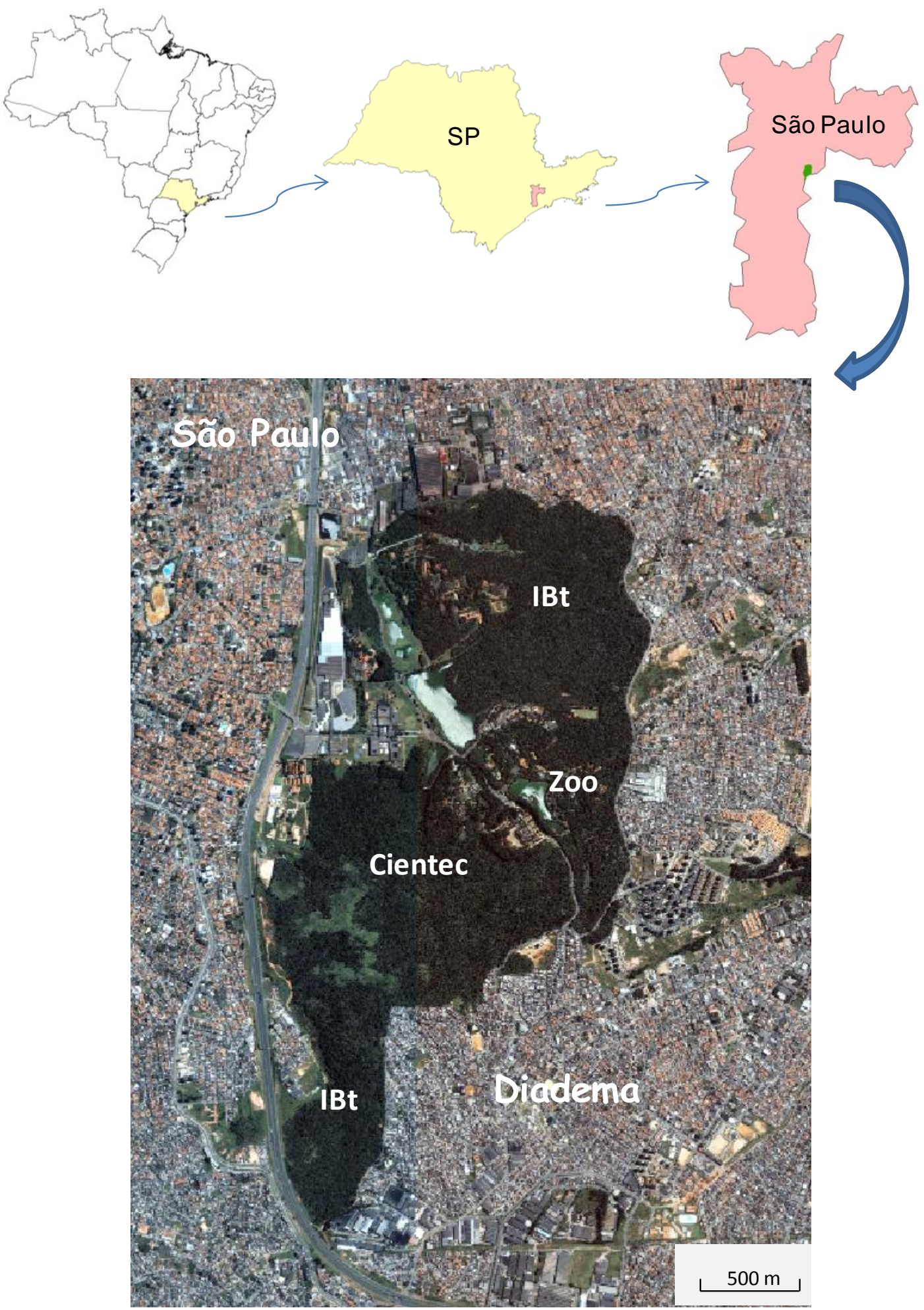

Figura 1. Parque Estadual das Fontes do Ipiranga e suas principais unidades administrativas (IBt - Instituto de Botânica; Zoo - Fundação Parque Zoológico de São Paulo; Cientec - Parque de Ciência e Tecnologia da Universidade de São Paulo). Fonte Imagem: Google Earth (20.06.2011). 
Originalmente denominado Parque do Estado, o PEFI foi criado em 1893, com a finalidade de preservar mananciais para o abastecimento de água. Em meio a uma intensa urbanização, o PEFI contribui com mais de $10 \%$ de toda área verde da metrópole paulistana, além de ser uma das principais reservas de fauna e flora da bacia hidrográfica do riacho Ipiranga (Barbosa et al., 2002; Mantovani \& Massambani, 2004). Também é classificado como parque setorial, com grande influência no lazer da região, devido às instituições que nele existem, como o Parque de Ciência e Tecnologia da USP (Parque Cientec), o Instituto Jardim Botânico, a Fundação Parque Zoológico do estado de São Paulo, além da Secretaria de Agricultura do estado de São Paulo e do espaço Centro de Esporte, Cultura e Lazer, administrado pela Secretaria de Assistência e Desenvolvimento Social.

Os fragmentos e áreas de mata mais próximos ao PEFI encontram-se a 25 km ao norte, no Parque Estadual da Serra da Cantareira (região norte da região metropolitana de São Paulo), ou a $17 \mathrm{~km}$ ao sul, nas matas da Represa Billings (Plano de Manejo do PEFI, 2005). Atualmente, possui áreas de floresta em diversos graus de conservação, apresentando-se como um mosaico de estágios sucessionais (Peccinini, 2000; Pivello \& Peccinini, 2002; Plano de Manejo do PEFI, 2005).

\subsection{A Vegetação do PEFI}

A área total do PEFI, obtida por análise de mapas, em nosso trabalho, foi de 519,03 ha, um valor bem próximo aos 526,38 ha estabelecido em um trabalho anterior (Nastri et al. 1992 apud Barbosa et al., 2002). A vegetação total do PEFI representa cerca de 359,40 ha $(69,24 \%$ da área do parque). Desconsiderando-se as áreas em que foram realizados reflorestamentos com pinheiros e eucaliptos, a 
vegetação cobre em torno de 332,24 ha $(64,01 \%$ da área total do PEFI). Estes valores são condizentes com o Plano de Manejo do PEFI (2005) que considera que as áreas de florestas cobrem cerca de $60 \%$ da área total do PEFI. Essa vegetação é formada por um complexo mosaico de diferentes estágios sucessionais, representando um contínuo que vai da séria pioneira, passando por áreas de secundário inicial, médio até atingir pontos com secundário tardio. Há poucos trechos contínuos de área de estágio secundário tardio e não há áreas originalmente preservadas no PEFI (Plano de Manejo do PEFI, 2005). Em alguns pontos, a identificação do estágio sucessional do local foi difícil devido, principalmente, ao mosaico extremamente recortado e à forte transição não discreta dos pontos de borda. Por isso, decidiu-se tomar medidas de CAP (circunferência à altura do peito), altura e densidade da vegetação para confirmar as diferenças fitossociológicas entre as áreas estudadas.

O mapeamento das fisionomias sobre as imagens de satélite obtidas com o Laboratório de Aerofotogeografia e Sensoriamento Remoto (LASERE), do Departamento de Geografia - FFLCH USP, foi realizado com o programa ArcGis 9.2®, e com o auxílio do mapa de vegetação do Plano de Manejo do PEFI (2005), permitiu verificar que: a) a área de estágio secundário inicial tem cerca de 100,50 ha (27,9 \% da vegetação total do PEFI; b) a área de estágio secundário tardio tem cerca de 21,20 ha (5,9\% da vegetação total do PEFI). 


\subsubsection{Estágio sucessional secundário inicial $(\mathrm{SI})$ - 100,50 ha (Plano de Manejo do PEFI, 2005)}

A vegetação nesse estágio (Fig. 2) é denominado de capoeirinha e é composta por espécies de arbustos e arvoretas heliófitas de crescimento rápido, com ciclos vitais que variam de dez a trinta anos. Há bosques com poucos estratos e poucas espécies exercendo um domínio na vegetação. Apresenta estrutura bastante variável, conforme sua composição em espécies e indivíduos; em geral, não atinge $10 \mathrm{~m}$ de altura. Porém, em determinadas áreas, há uma densidade maior de remanescentes de árvores de porte médio, em torno de $10 \mathrm{~m}$ a $12 \mathrm{~m}$, não alterando, entretanto, as condições de luminosidade favoráveis ao desenvolvimento de plantas heliófitas. Nas parcelas de estudo de área de secundário inicial, assim como apontado pelo Plano de Manejo do PEFI (2005), verificamos a grande descontinuidade no dossel, ou a ausência do mesmo, além da presença de muitas espécies de bambus e lianas, o que dificulta a regeneração nessa área, acarretando a morte de muitas espécies arbóreas.

\subsubsection{Estágio sucessional secundário tardio (ST) - 21,20 ha (Plano de Manejo do PEFI, 2005)}

A vegetação nesse estágio (Fig. 3) é denominada de capoeirão e composta por uma complexa fisionomia, sendo difícil definir os estratos na vegetação, além de conter uma elevada diversidade e riqueza florística. Pode apresentar áreas com riqueza superior à do clímax. Há um dossel mais contínuo, em torno de $15 \mathrm{~m}$ de altura, em geral, com plantas emergentes de até $18 \mathrm{~m}$. Também apresenta árvores de grande porte, com até $30 \mathrm{~m}$ de altura. Ainda há a penetração de luz no seu 
interior, favorecendo as espécies heliófitas. Devido às muitas perturbações (poluição atmosférica, competição com lianas, alta incidência de luz sobre os caules), há poucos trechos do PEFI cobertos por esta fitofisionomia. 


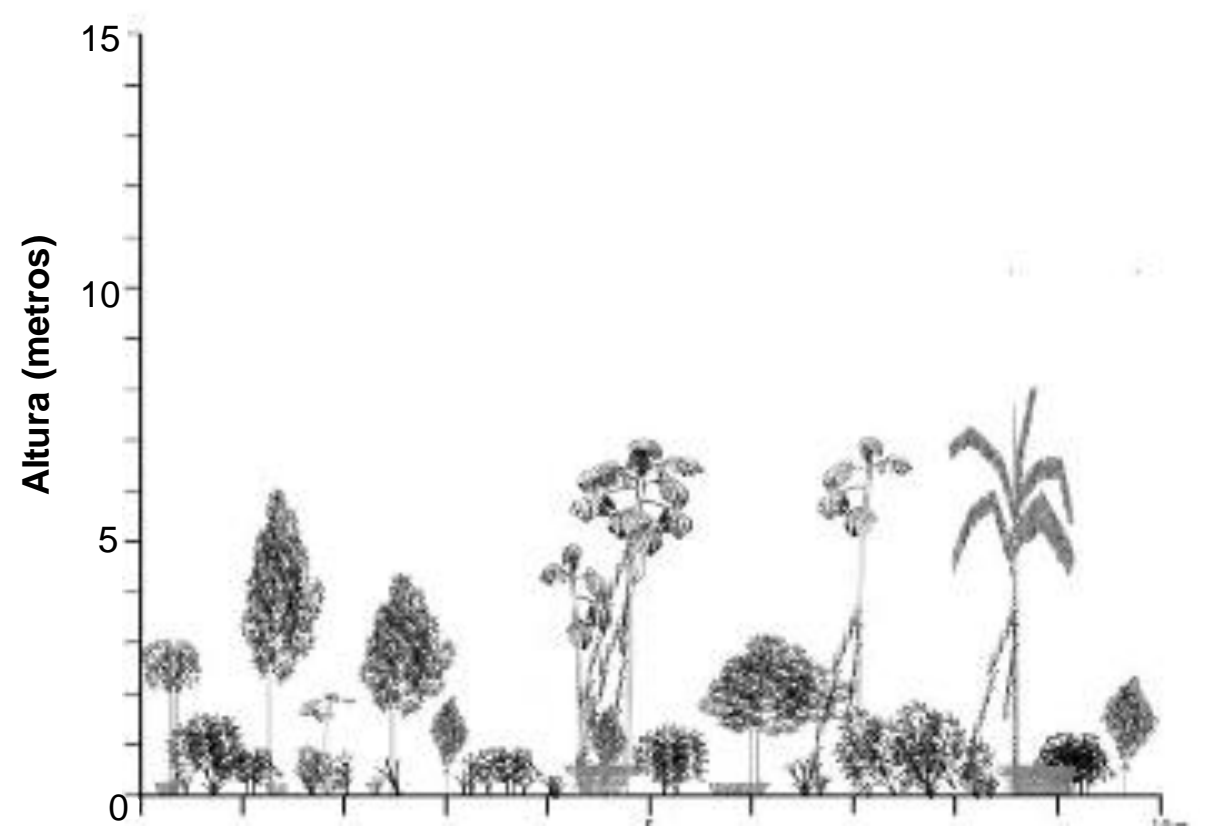

Figura 2. Perfil-diagrama do estágio sucessional secundário inicial da Floresta Ombrófila Densa.

Fonte: Plano de Manejo do PEFI, 2005.

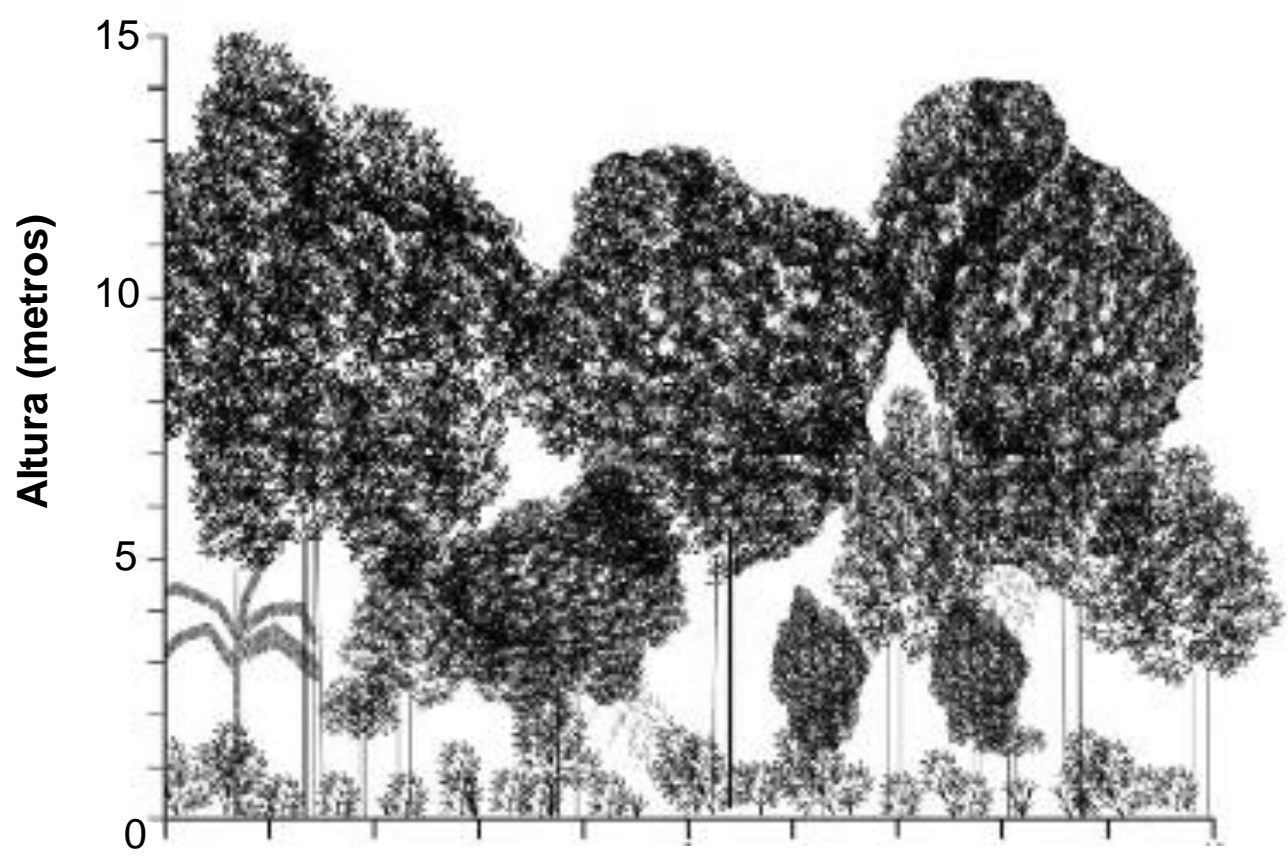

Figura 3. Perfil-diagrama do estágio sucessional secundário tardio da Floresta Ombrófila Densa.

Fonte: Plano de Manejo do PEFI, 2005. 


\subsection{Local do estudo}

\subsubsection{Estágios sucessionais e a região do PEFI desse estudo}

Para o estudo, foram comparadas a riqueza, a abundância relativa e a densidade dos ninhos de meliponíneos em duas categorias de habitats: áreas com vegetação em estágio sucessional secundário inicial (SI) (descrição item 2.2.1.; Fig. 2) e áreas com vegetação em estágio sucessional secundário tardio (ST) (descrição no item 2.2.2.; Fig. 3). Os fragmentos utilizados nesse estudo situam-se na região do Parque Cientec e no lado esquerdo da região do Parque Zoológico, na região central do PEFI (Fig. 4). Nessa região, concentram-se os poucos dos grandes fragmentos de área de estágio secundário tardio, além de grandes fragmentos de área de estágio secundário inicial.

\subsubsection{A amostragem e o sorteio das parcelas}

Foram amostrados no total 4,2 ha, sendo 2,1 ha nas áreas SI e 2,1 ha nas áreas ST. Em cada um dos tipos de área, foram sorteadas 21 parcelas de 0,1 ha (Fig. 4). Após realizarmos o desconto de áreas de bordas e limites com os estágios sucessionais adjacentes, seguimos com os procedimentos do sorteio das parcelas. As áreas de estágio secundário inicial, utilizadas para a realização do sorteio, estão localizadas em dois grandes fragmentos, totalizando 29,5 ha, no total, dos quais obtivemos 78 parcelas passíveis $(7,8 \mathrm{ha})$ de serem sorteadas. As áreas de estágio secundário tardio, utilizadas para a realização do sorteio, estão localizadas em seis fragmentos, totalizando 9,6 ha, no total, dos quais obtivemos 46 parcelas passíveis $(4,6 \mathrm{ha})$ de serem sorteadas. O sorteio das parcelas, previamente numeradas, foi realizado com o auxílio de uma ferramenta suplemento do software Microsoft Excel 2007 (PopTools). 


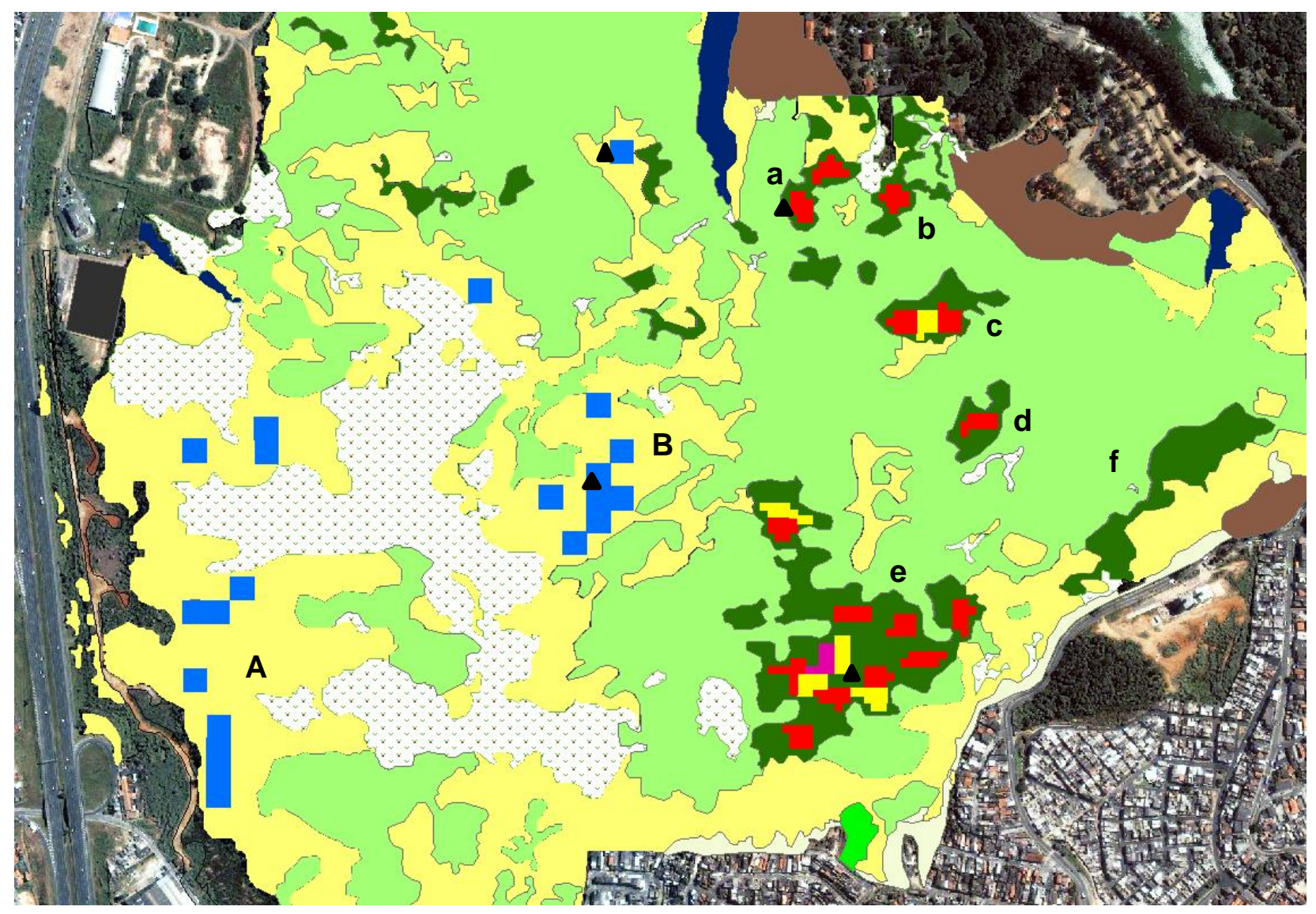

Estágio Primário

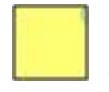

Secundário Inicial - parcelas em azul

Secundário Médio

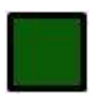

Secundário Tardio - parcelas em vermelho, amarelo e roxo.

Localização da instalação dos Data Loggers $(n=4)$

Figura 4. Localização das 21 parcelas sorteadas para o estudo em áreas com vegetação em estágio secundário inicial (fragmentos contínuos "A" e "B", com 78 parcelas passíveis de serem sorteadas) e também das 21 parcelas sorteadas em áreas com vegetação em estágio secundário tardio (fragmentos "a", "b", "c", "d", "e" e "f", com 46 parcelas passíveis de serem sorteadas). Com exceção do fragmento "f", que está localizado na área do Zoológico, todos os demais estão inseridos no Parque Cientec USP. 


\subsubsection{Os Perfis Florestais do PEFI (Peccinini, 2000)}

As 21 parcelas sorteadas das áreas $\mathrm{SI}$ encontravam-se nos dois perfis florestais considerados em piores condições de regeneração (Peccinini, 2000). Dessas, 10 estavam localizadas em áreas do tipo Floresta com Dossel Descontínuo/Degradada: com dossel presente em pequenas manchas de árvores, menores valores médios de altura das árvores e densidade abaixo de 0,06 indivíduos $/ \mathrm{m}^{2}$. As outras 11 parcelas localizavam-se em áreas do tipo Floresta com Dossel Heterogêneo e Porte Baixo: árvores com alturas baixas, mas com emergentes, área muito degradada, distribuição esparsa, sub-bosque pouco presente e estratificação simplificada, densidade de 0,13 indivíduos $/ \mathrm{m}^{2}$.

As 21 parcelas sorteadas das áreas ST encontravam-se em um perfil florestal considerado em melhor estado de regeneração (Peccinini, 2000) (Fig. 5). Esse perfil, Floresta com Dossel Homogêneo Denso, apresenta as seguintes características: áreas com copas de tamanho variável, densidade de 0,32 indivíduos $/ \mathrm{m}^{2}$, sub-bosque denso em regeneração, devido a um corte na década de 50 . 

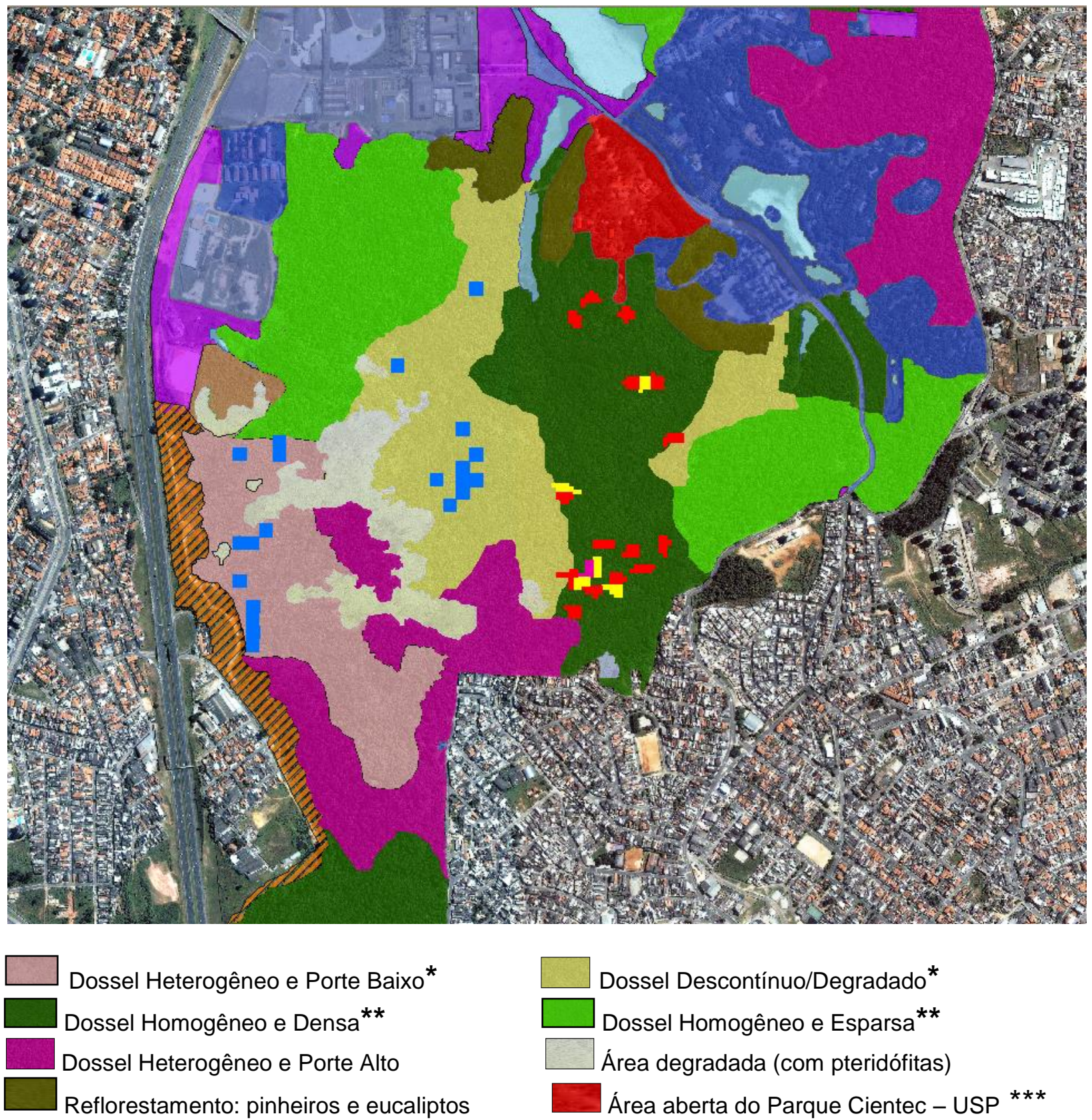

$$
\text { Parcelas ST ( } n=21) \square \text { Parcelas SI }(n=21)
$$

* Perfis de florestas e áreas em pior estado de regeneração.

** Perfis de florestas e áreas em melhor estado de regeneração

*** Área (6,85 ha) em que Sousa \& Kleinert (2010) realizaram um levantamento de ninhos.

Figura 5. Perfis florestais do PEFI e distribuição das parcelas do estudo ( $n=42)$. Fonte: adaptado de Peccinini (2000) 


\subsection{Coleta de dados}

\subsubsection{Levantamento de ninhos}

A coleta de dados foi realizada de outubro de 2011 a dezembro de 2013 por um coletor. Com um total de cerca de 1008 horas (média de 24 horas estudo total por parcela), alternou-se a busca de ninhos entre as áreas de SI e ST a cada semana, ou intervalo de dias. Cada uma das parcelas foi dividida em subparcelas menores, que foram inteiramente vasculhadas. Como critério de inclusão, foram verificadas todas as árvores com CAP superior a $15 \mathrm{~cm}$, ou seja, DAP (diâmetro na altura do peito) superior a quase $5 \mathrm{~cm}$, devido à probabilidade de encontrarmos ninhos de espécies menos exigentes, no que se refere ao diâmetro das árvores e/ou substratos, além de poderem servir de suporte para ninhos aéreos. Todas as árvores (das bases aos galhos), troncos caídos, cupinzeiros e buracos no solo foram observados. Toda a extensão do solo foi minuciosamente vasculhada. A inspeção das árvores altas foi realizada com o auxílio de um binóculo modelo Nikon (Action 7$15 \times 355.5^{\circ}$ at $\left.7 x\right)$.

Os ninhos encontrados foram identificados e sua localização precisa foi registrada com o auxílio do GPS Garmin map 62CS. Os dados de coordenadas geográficas foram processados no programa MapSource 6.10.2 Garmin $\AA$, RouteConverter $2.4 \AA$, e os ninhos mapeados no programa ArcGis $9.2 \AA$. As imagens de satélite do PEFI foram obtidas com o Laboratório de Aerofotogeografia e Sensoriamento Remoto (LASERE) do Departamento de Geografia - FFLCH, USP.

Foram registradas informações sobre o local do ninho, tipo de substrato utilizado, altura da entrada dos ninhos em relação ao nível do solo, posicionamento das entradas em relação aos pontos cardeais, CAP à altura do peito das árvores 
utilizadas como substrato. A arquitetura da entrada dos ninhos foi registrada, quando possível, com máquina fotográfica.

Foram coletados, quando possível, ramos para a identificação das espécies vegetais. O material está depositado no herbário do Departamento de Botânica do IBUSP.

De cada ninho encontrado, coletou-se cerca de 10 indivíduos para identificação específica. Para a coleta, utilizou-se aspirador entomológico para os ninhos com alturas acessíveis e rede entomológica adaptada em um cabo telescópico para os ninhos com alturas inacessíveis. As abelhas capturadas foram colocadas em frascos com acetato de etila e, em laboratório, montadas, etiquetadas e secas em uma estufa a $35^{\circ}-40^{\circ} \mathrm{C}$, por 24 horas. Após esse processo, foram acondicionadas em caixas entomológicas de polietileno e mantidas em gaveta entomológica, depositadas na Coleção Paulo Nogueira Neto (PNN), do Laboratório de Abelhas do Instituto de Biociências, Universidade de São Paulo.

A identificação dos espécimes foi realizada através da chave de Silveira et al. (2002) e comparação com os espécimes guardados na Coleção PNN. A Profa Dra Sílvia M.R. Pedro, USP-RP, confirmou a identificação das espécies Trigona braueri e Scaptotrigona bipunctata.

\subsubsection{Mensurações das variáveis fitossociológicas das parcelas do estudo}

Os valores de CAP, altura e densidade das árvores foram tomados de subunidades padronizadas correspondentes a $10 \%$ da área de cada parcela $\left(100 \mathrm{~m}^{2}\right)$. Estas subunidades consistiam de áreas retangulares de $33,5 \times 3 \mathrm{~m}$, dispostas em diagonal no centro das parcelas, orientadas no sentido sudeste. Em um estudo comparativo entre os métodos de quadrantes e parcelas na 
caracterização da composição florística e fitossociológica de um trecho de Mata Atlântica (floresta ombrófila densa), Aguiar (2003) observou que os dois métodos amostraram a composição florística e a estrutura fitossociológica da comunidade de maneira semelhante. Siqueira (1994) apud Aguiar (2003) aponta que, dos 63 trabalhos analisados entre os anos de 1970 a 1994, 51 deles empregaram o método de parcelas nos levantamentos de vegetação.

\subsubsection{Variações microclimáticas entre os estágios sucessionais da vegetação}

Para verificar se havia diferenças microclimáticas entre os estados sucessionais da mata (SI e ST), e entre os tamanhos dos fragmentos nesses estágios, utilizamos quatro registradores Data Logger (Fig. 4). Esses quatro aparelhos foram instalados para a tomada contínua de dados referentes à temperatura e umidade relativa a cada 20 minutos, diariamente. Os Data Loggers 1

e 2 foram instalados no "fragmento contínuo B" em áreas SI (Fig. 4): Data Logger 1, no centro de uma área menor, com cerca de 0,7 ha; Data Logger 2, no centro de uma área maior, com 14,5 ha. O mesmo ocorreu em áreas ST (Fig.4): o Data Logger 3 foi instalado no centro de um fragmento menor ("a"), uma área com 0,51 ha; Data Logger 4, no centro de um fragmento maior ("b”), uma área com 5,14 ha.

Os dados coletados também foram comparados com os dados obtidos pela Estação Metereológica do IAG USP, situada em área aberta do PEFI, Parque Cientec - USP (Fig.5)

\subsubsection{Condições meteorológicas dos dias do levantamento}

Realizou-se os levantamentos dos ninhos em dias com condições atmosféricas adequadas às atividades de vôos dos meliponíneos, isto é, com 
temperaturas acima dos $20^{\circ} \mathrm{C}$, entre os horários das 9:00 e 17:00 h, estendendo-se um pouco em alguns dias, nos meses de verão (Teixeira \& Campos, 2005; Hilário et al., 2007a; Figueiredo-Mecca et al., 2013). Os dias nublados, ou com chuvas, foram evitados pela dificuldade encontrada em buscas preliminares desse trabalho e de trabalhos anteriores (Sousa \& Kleinert, 2010). As atividades das abelhas são alteradas em dias com chuvas (Hilário et al., 2007b; Figueiredo-Mecca et al., 2013) pois, em geral, elas fecham as entradas dos ninhos, principalmente as espécies que nidificam em cavidades subterrâneas (Paratrigona subnuda). Iwama (1977) verificou que as temperaturas em que Tetragonisca angustula abre as entradas de seus ninhos, na cidade de São Paulo, situou-se entre 17 e $24^{\circ} \mathrm{C}$. A espécie Friesella schrottkyi é chamada popularmente de mirim-preguiça justamente por iniciar suas atividades apenas em dias com temperaturas elevadas. Ambas as espécies já tiveram seus ninhos encontrados em áreas abertas do PEFI (Sousa \& Kleinert, 2010)

\subsection{Análise dos dados}

As duas áreas com fitofisionomias distintas (SI e ST) foram comparadas quanto ao número de ninhos e de espécies, densidade dos ninhos, perímetro das árvores (quando encontrado ninhos). Para cada tipo de habitat, foram calculadas a riqueza $(S=$ número de espécies encontradas $)$, a diversidade $\left(H^{\prime}=\right.$ índice de Shannon), a equitatividade ( $\mathrm{J}=$ índice de Pielou) de espécies e a densidade de ninhos (número de ninhos por hectare). Para estimar o tamanho amostral, foi feita a curva de rarefação para as espécies registradas no local de estudo. Os índices de diversidade (H'), equitatividade (J') e a curva de rarefação foram calculados no programa PAST (Hammer et al., 2001). 
Todos os valores das variáveis relacionadas aos ninhos (número e densidade), aos dados fitossociológicos (densidade, altura e perímetro das árvores), além dos dados de temperatura, foram submetidos aos de testes KolmogorovSmirnov e Shapiro-Wilk (Zar, 1999) para confirmação ou não da normalidade das distribuições dos valores encontrados e ao teste de homogeneidade de variâncias de Levene (Zar, 1999). O nível de significância determinado foi de 0,05.

Para comparação da densidade, do número de ninhos e das diferentes variáveis fitossociológicas (médias de CAP, de altura e de densidade de árvores) das parcelas de estudo de ambos os estágios (SI e ST) utilizou-se o teste de MannWhittney. Para verificar quais variáveis fitossociológicas (médias de CAP, altura e densidade de árvores) foram efetivamente importantes para a ocorrência de ninhos de meliponíneos, utilizou-se o teste de correlação de Spearman $\left(r_{s}\right)$.

Para a comparação das médias de temperaturas entre os diferentes tamanhos de fragmentos e estágios sucessionais utilizou-se o teste não-paramétrico de Friedman. Para a verificacão de preferência por determinadas orientações geográficas na construção das entradas dos ninhos usou-se o teste de $X^{2}$ (Zar, 1999). As análises estatísticas foram processadas com o software Statistica for Windows. 


\section{RESULTADOS}

\subsection{ESTÁGIOS SUCESSIONAIS}

As duas fitofisionomias, secundário inicial (SI) e secundário tardio (ST), apresentaram diferenças estatisticamente significativas para os valores de densidade, CAP e altura das árvores (Tabela 1, Anexos 1, 2 e 3). Assim como as médias de altura $(\mathrm{H})$, as médias de CAP de todos os indivíduos arbóreos, como daqueles com CAP > $25 \mathrm{~cm}$, foram significativamente maiores nas áreas ST.

A densidade média de indivíduos arbóreos foi significativamente maior nas parcelas ST, embora essa diferença não tenha sido constatada quando se considerou apenas os indivíduos arbóreos com CAP $>25 \mathrm{~cm}$. 
Tabela 1. Valores médios com desvio padrão (s) e valores mínimos e máximos de densidade, CAP e altura dos indivíduos arbóreos dos estágios secundário inicial e tardio (SI e ST, respectivamente), e resultados dos testes de comparação entre os estágios.

\begin{tabular}{|c|c|c|c|c|c|c|c|}
\hline \multirow{2}{*}{ Variáveis } & \multicolumn{2}{|c|}{ SI $(n=21)$} & \multicolumn{2}{|c|}{ ST $(n=21)$} & \multirow{2}{*}{$U$} & \multirow{2}{*}{ Z } & \multirow{2}{*}{ p-level } \\
\hline & média $\pm \mathrm{s}$ & mín-máx & média $\pm \mathrm{s}$ & mín-máx & & & \\
\hline Densidade de árvores (indivíduos $/ \mathrm{m} 2)(\mathrm{CAP}>15 \mathrm{~cm})$ & $0,206 \pm 0,045$ & $0,13-0,28$ & $0,251 \pm 0,056$ & $0,15-0,37$ & 127 & $-2,36$ & 0,0183 \\
\hline Densidade de árvores (indivíduos/m2) (CAP>25 cm) & $0,125 \pm 0,043$ & $0,05-0,20$ & $0,153 \pm 0,048$ & $0,06-0,28$ & 151 & $-1,75$ & 0.0792 * \\
\hline CAP $(\mathrm{cm})$ de árvores com CAP $>15 \mathrm{~cm}$ & $36,34 \pm 7.83$ & $24,82-54,60$ & $41,66 \pm 7,17$ & $30,40-63,96$ & 129 & $-2,30$ & 0,0213 \\
\hline CAP $(\mathrm{cm})$ de árvores com CAP $>25 \mathrm{~cm}$ & $47,57 \pm 9,66$ & $31,45-62,74$ & $57,40 \pm 12.79$ & $38,64-91,17$ & 113 & $-2,70$ & 0,0068 \\
\hline Altura de árvores $(\mathrm{m})$ com CAP $>15 \mathrm{~cm}$ & $8,07 \pm 1,44$ & $5,58-11,22$ & $9,13 \pm 0,78$ & $8,01-11,26$ & 106 & $-2,88$ & 0,0040 \\
\hline Altura de árvores $(\mathrm{m})$ com CAP $>25 \mathrm{~cm}$ & $9,38 \pm 1,62$ & $6,26-13,08$ & $10,91 \pm 1,20$ & $8,64-13,54$ & 99 & $-3,06$ & 0,0022 \\
\hline
\end{tabular}

*- não significativa. 
As áreas ST apresentaram, geralmente, temperaturas ligeiramente mais baixas que as áreas SI. Não houve diferença estatisticamente significativa entre as temperaturas dos quatro fragmentos escolhidos para a medição das temperaturas: fragmentos pequeno e grande em SI; fragmentos pequeno e grande em ST (Tabela 2). As médias de temperaturas entre as quatro amostragens variaram em décimos de graus Celsius, tanto para a amostragem de todos os meses em conjunto (Friedman ANOVA $=2171,381 p=0,00000$ ), quanto para os dados analisados por semana, como os da última semana do mês de outubro de 2012 (Friedman Anova= 202,1565 p =0,00000) (Fig. 6). Comparando-se com os dados obtidos na Estação Metereológica do IAG/USP (IAG/USP, 2012), situada em área aberta do PEFI, as médias de temperaturas das áreas SI e ST mantiveram-se abaixo das médias das temperaturas da área aberta do PEFI (Fig. 7).

Devido a problemas técnicos, os dados de umidade relativa não puderam ser utilizados. Testes de controle evidenciaram muita variação de medidas entre os Data Loggers usados, devido à sensibilidade de seus sensores quando expostos em ambientes externos.

Tabela 2. Média e desvio-padrão dos dados de temperatura $\left({ }^{\circ} \mathrm{C}\right)$ nos diferentes fragmentos dos estágios secundário inicial (SI) e secundário tardio (ST).

\begin{tabular}{lcc}
\hline $\begin{array}{l}\text { Estágios e tamanho } \\
\text { dos fragmentos }\end{array}$ & $\begin{array}{c}\text { Média } \\
\text { out/12-mai/13* }\end{array}$ & $\begin{array}{c}\text { Média } \\
\text { 01 semana** }\end{array}$ \\
\hline SI pequeno (0,7 ha) & $19,75 \pm 3,27$ & $22,46 \pm 4,11$ \\
SI grande (14,5 ha) & $19,72 \pm 3,22$ & $22,39 \pm 3,94$ \\
ST pequeno $(0,51 \mathrm{ha})$ & $19,50 \pm 3,06$ & $21,99 \pm 3,75$ \\
ST grande $(5,14 \mathrm{ha})$ & $19,52 \pm 2,92$ & $22,10 \pm 3,30$ \\
\hline
\end{tabular}

*Total de 10.957 dados, 3.652 horas amostradas - fim de out/2012 a início de mai/2013.

Friedman Anova $=2171,381, p=0,00000$

**Total de 462 dados, 154 horas amostradas, 25 a 31/10/12.

Friedman Anova $=202,1565 p=0,00000$ 


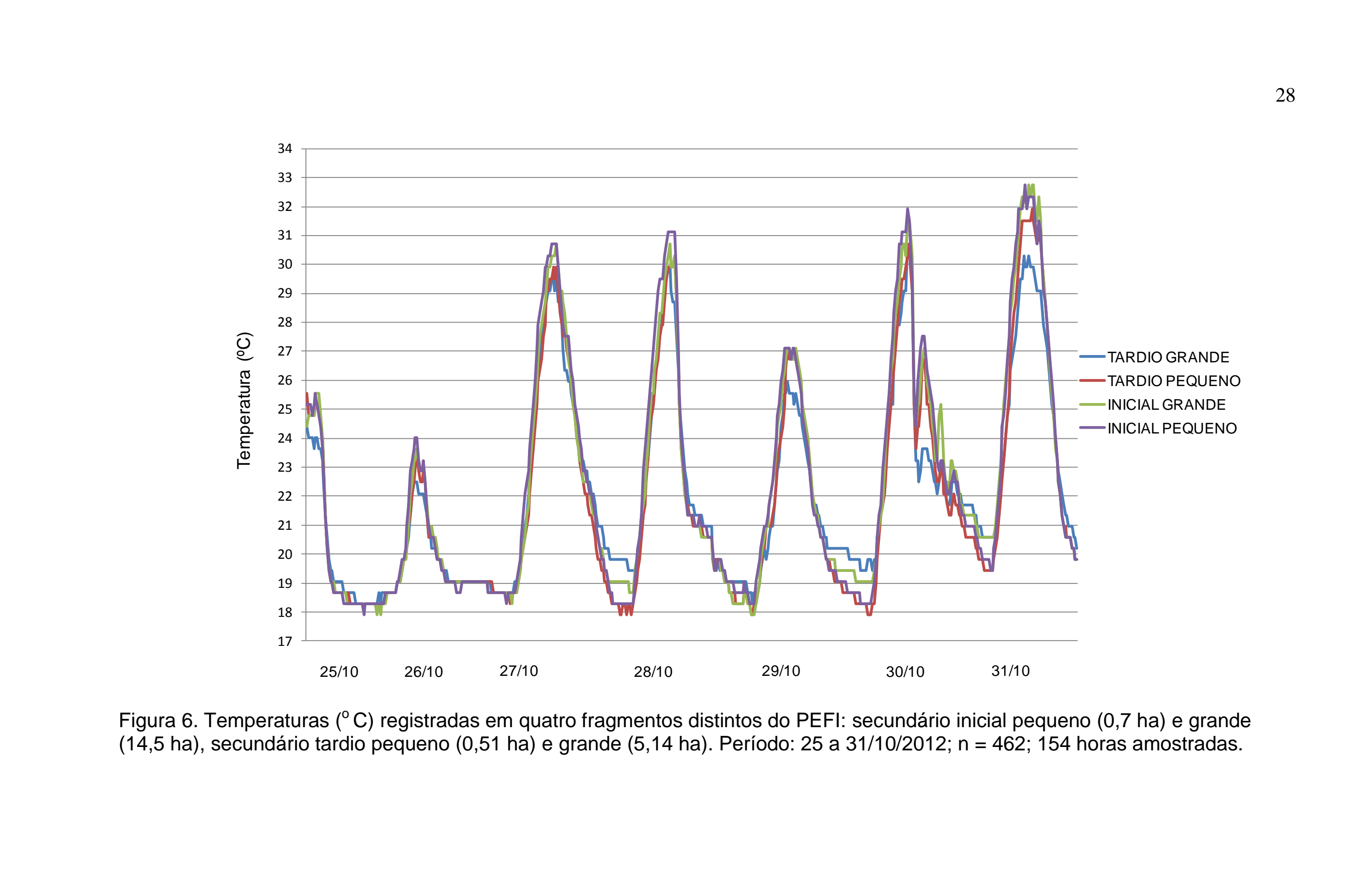




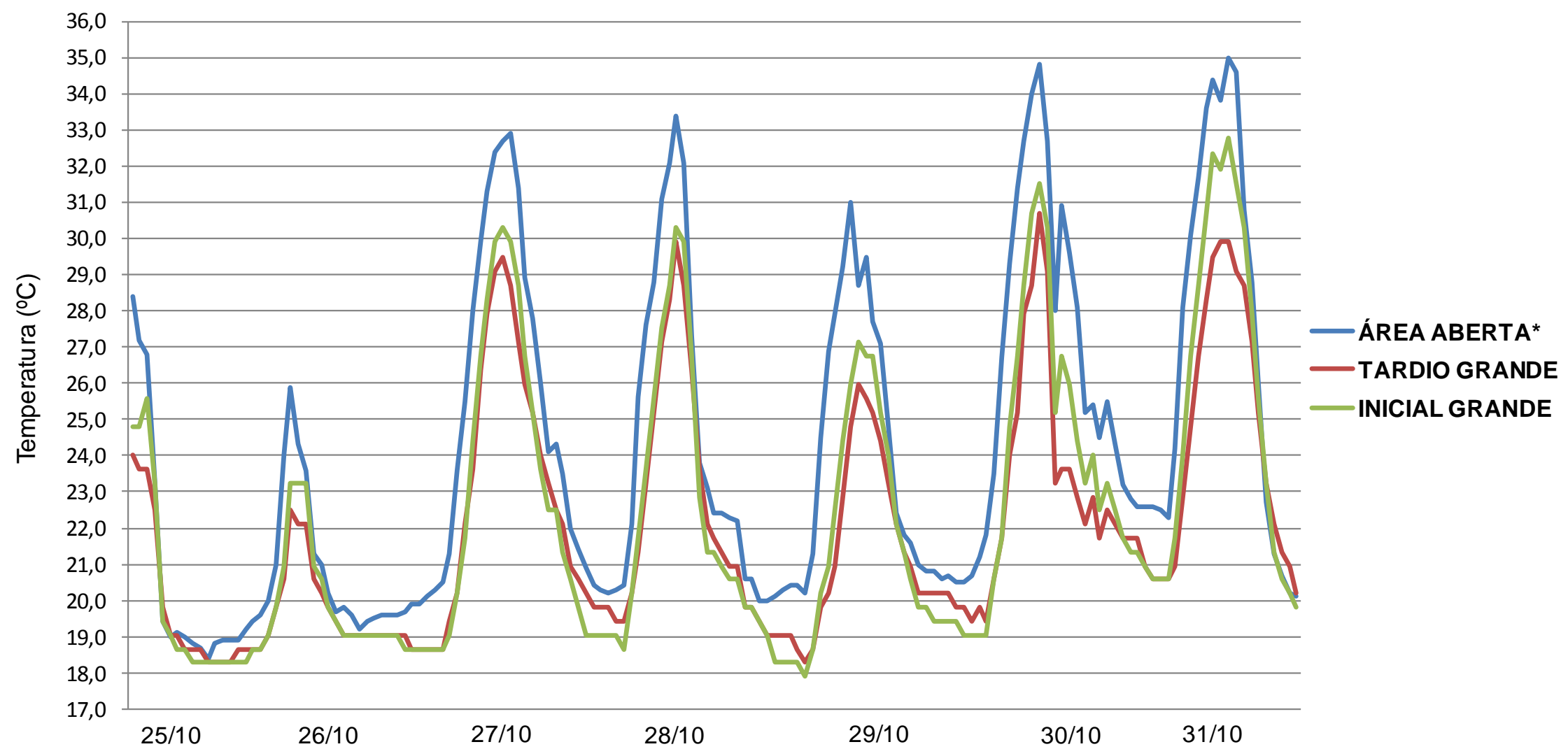

Figura 7. Temperaturas $\left({ }^{\circ} \mathrm{C}\right)$ registradas nos fragmentos secundário inicial grande $(14,5 \mathrm{ha})$, secundário tardio grande $(5,14$ ha) e em área aberta do PEFI (7,28 ha). Período: 25 a 31/10/2012. *Ârea aberta (urbanizada): Estação Meteorológica do IAG/USP. 


\subsection{NINHOS}

$\mathrm{Na}$ área de estudo, foram encontrados 14 ninhos de meliponíneos, pertencentes a 3 gêneros e 4 espécies, todos da subtribo Trigonina. Nas parcelas da área SI, foram encontrados 3 ninhos e nas ST foram encontrados 11 ninhos (Tabela 3 e Fig. 8). As espécies encontradas foram: Paratrigona subnuda (Moure, 1947), Scaptotrigona bipunctata (Lepeletier, 1836), Trigona braueri (Friese, 1900) e Trigona spinipes (Fabricius). Paratrigona subnuda foi a espécie que apresentou a maior abundância relativa de ninhos $(n=11 ; 78,57 \%)$. As demais espécies estiveram representadas por apenas um ninho cada: Scaptotrigona bipunctata $(n=1 ; 7,14 \%)$, Trigona braueri $(n=1 ; 7,14 \%)$ e Trigona spinipes $(n=1 ; 7,14 \%)$.

Também foram encontrados sete ninhos de meliponíneos fora da área de amostragem, como trilhas e pontos de passagem para se acessar as parcelas de estudo: a) em áreas de estágio secundário médio: Tetragonisca angustula (Latreille, 1811) $(\mathrm{n}=2)$; b) em áreas limítrofes entre os estágio secundário médio e SI: Scaptotrigona bipunctata $(n=1)$ e Trigona braueri $(n=1) ; c)$ em áreas de SI: Tetragonisca angustula (Latreille, 1811) $(n=1)$ e Trigona spinipes $(n=1) ; e)$ em área degradada (sem árvores, pois sofreu um incêndio em anos anteriores): Paratrigona subnuda $(n=1)$. Esses ninhos foram considerados somente para o registro de espécies.

A Fig. 9 mostra a distribuição espacial dos ninhos nos dois estágios sucessionais. Os Anexos 4 e 5 apresentam as coordenadas geográficas e os pontos de localização no mapa da Fig. 9 de todos os ninhos encontrados, bem como os estágios sucessionais das áreas onde foram localizados. 
Tabela 3. Número de ninhos encontrados na área de estudo, separados por espécies e estágios sucessionais da vegetação, e de ninhos encontrados nas trilhas, fora da área de amostragem.

\begin{tabular}{|c|c|c|c|c|c|}
\hline \multirow[b]{2}{*}{ Espécie } & \multicolumn{2}{|c|}{ Número de ninhos } & \multirow[b]{2}{*}{ Total $1^{*}$} & \multirow{2}{*}{$\begin{array}{l}\text { Ninhos fora } \\
\text { da área de } \\
\text { amostragem }\end{array}$} & \multirow[b]{2}{*}{$\begin{array}{l}\text { Total } \\
2^{* *}\end{array}$} \\
\hline & $\begin{array}{l}\text { Secundário } \\
\text { Inicial }\end{array}$ & $\begin{array}{l}\text { Secundário } \\
\text { Tardio }\end{array}$ & & & \\
\hline Paratrigona subnuda & 2 & 9 & 11 & 1 & 12 \\
\hline Scaptotrigona bipunctata & 0 & 1 & 1 & 1 & 2 \\
\hline Tetragonisca angustula & 0 & 0 & 0 & 3 & 3 \\
\hline Trigona braueri & 1 & 0 & 1 & 1 & 2 \\
\hline Trigona spinipes & 0 & 1 & 1 & 1 & 2 \\
\hline Total & 3 & 11 & 14 & 7 & 21 \\
\hline
\end{tabular}

*Total 1: somatória dos ninhos da área de amostragem; ${ }^{* *}$ Total 2: somatória incluindo ninhos que estão fora da área de amostragem

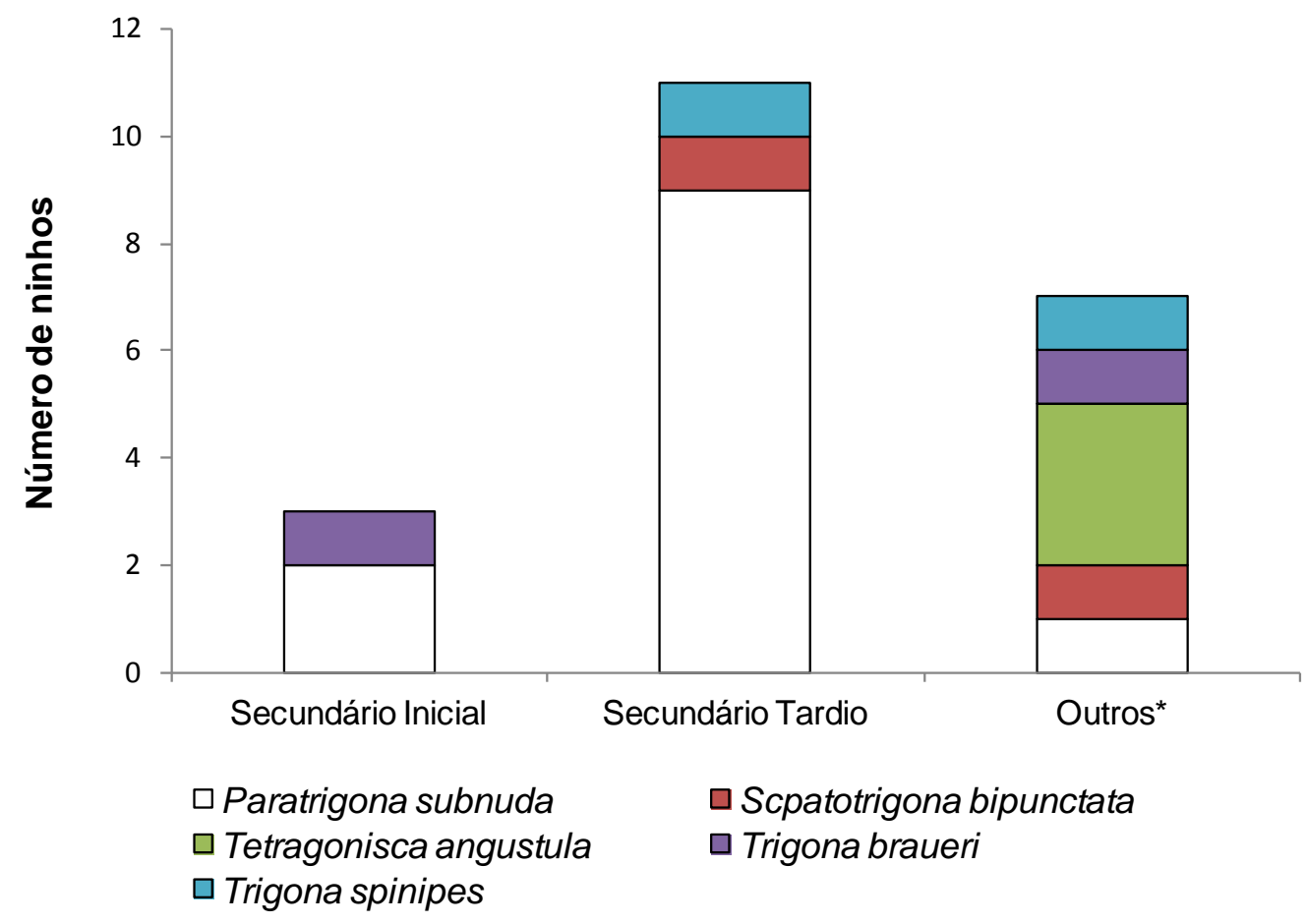

Figura 8. Número de ninhos por espécie e por estágio sucessional da vegetação encontrados no Parque Estadual das Fontes do Ipiranga, SP (2012-2013). *№ de ninhos outros - ninhos encontrados fora da área de amostragem. 


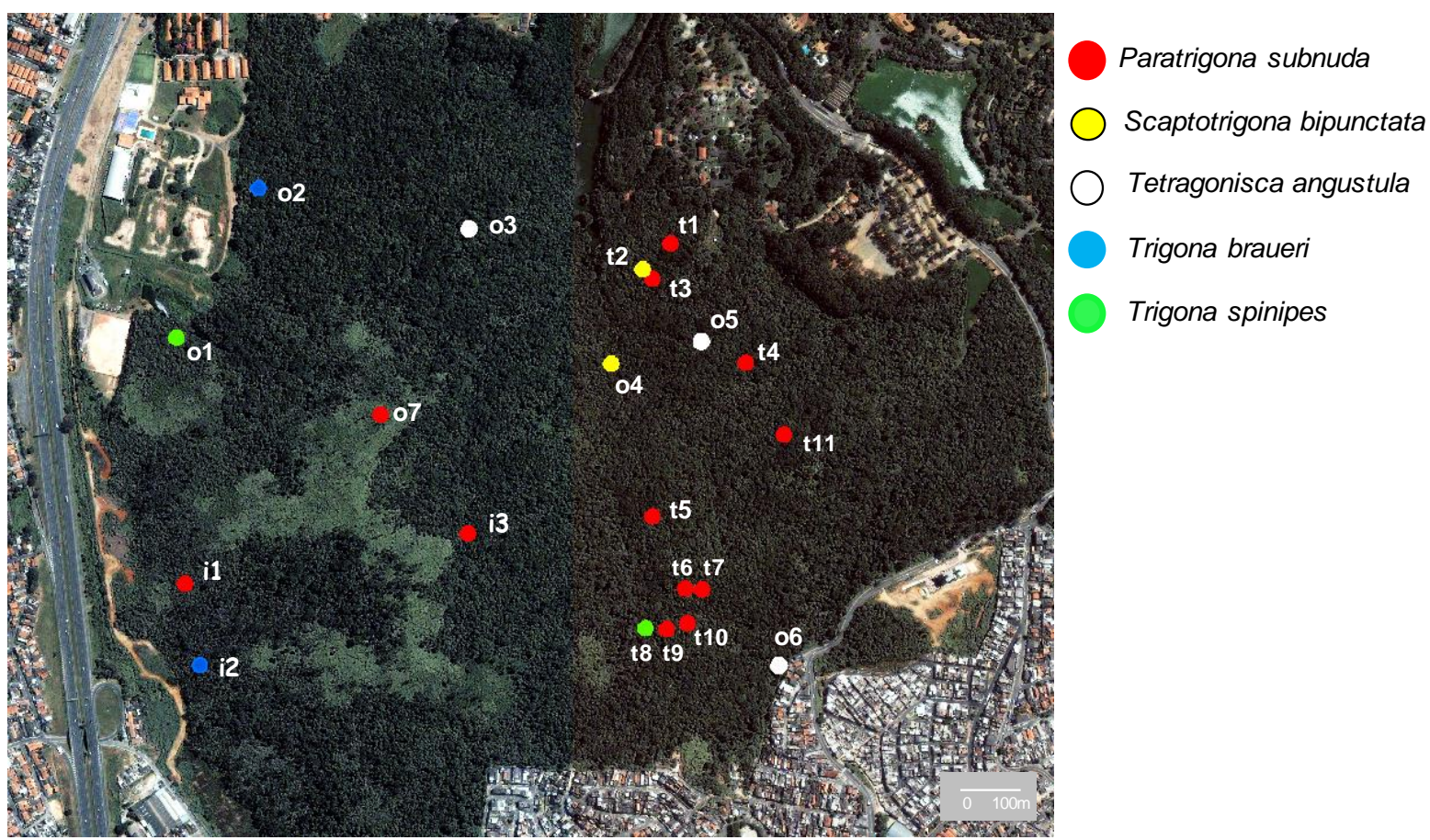

Figura 9. Distribuição espacial dos ninhos de meliponíneos encontrados no PEFI: i1 a i3: secundário inicial (SI); t1 a t11: secundário tardio (ST); 01 a 07: ninhos fora da área de amostragem).

A curva de rarefação não apresentou estabilização para nenhum dos estágios (Fig. 10). Isso indica que o número de parcelas estudadas ainda foi insuficiente. Porém, ao se fazer uma projeção com um aumento de $50 \%$ no número da parcelas estudadas, a curva de rarefação de espécies se estabilizaria nas áreas SI a partir da 26ํㅜ parcela (desvio padrão $<0.01$; desvio $=0$ a partir da 29ำ parcela, com estabilidade no número de espécies) e nas áreas ST a partir da 29ํㅜ parcela (desvio padrão=0, com estabilidade no número de espécies). Cabe ressaltar que essa projeção pressupõe uma taxa de encontro de ninhos e espécies, nas parcelas adicionais, semelhante à encontrada nas demais parcelas. A curva de acumulação de espécies também não apresentou estabilização para nenhum dos estágios (Fig. 11), indicando também uma insuficiência amostral. Porém, ao se fazer uma projeção com um aumento de $50 \%$ do número da parcelas estudadas, as curvas de acumulação 
de espécies se estabilizariam (com desvio padrão = 0, com estabilidade no número de espécies), tanto na áreas em SI quanto nas áreas em ST, a partir da 29ำ parcela. Nessa projeção, também estipulamos uma taxa de encontro de ninhos e espécies nas parcelas acrescidas seguindo a mesma proporção dos resultados das parcelas já estudadas.
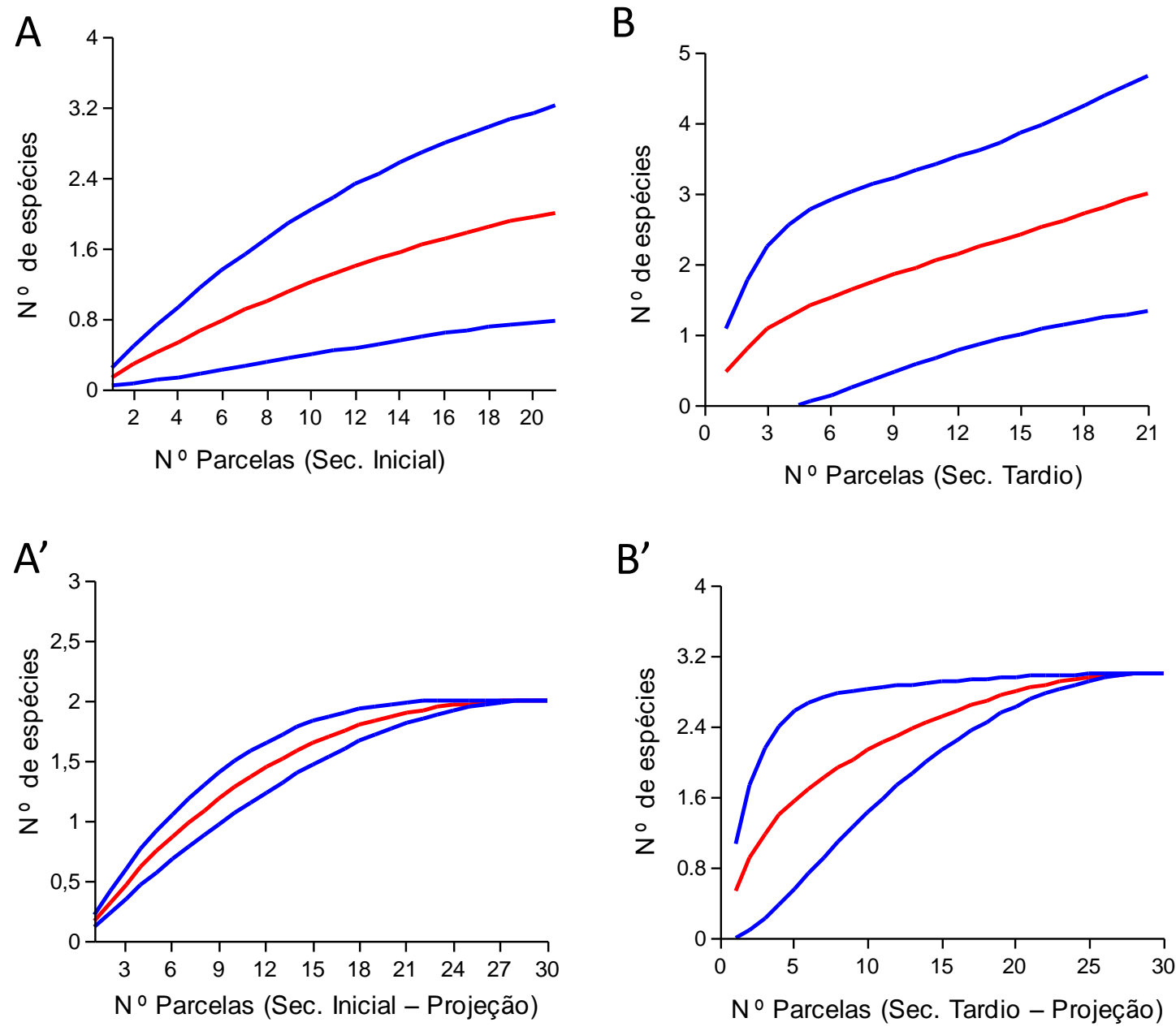

Figura 10. Curvas (A e B) e projeção de curvas ( $A^{\prime}$ e $\left.B^{\prime}\right)$ de rarefação de espécies (em vermelho) e intervalo de confiança de $95 \%$ (em azul) para as parcelas SI (A e $\left.A^{\prime}\right)$ e ST (B e B'). Para a projeção das figuras $A^{\prime}$ e B', manteve-se a mesma proporção de taxa de encontro de ninhos nos diferentes estágios. 
A

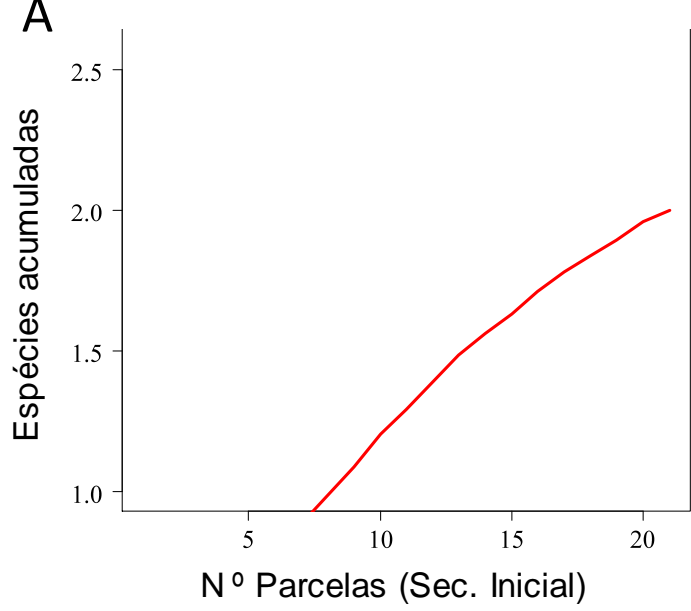

$A^{\prime}$

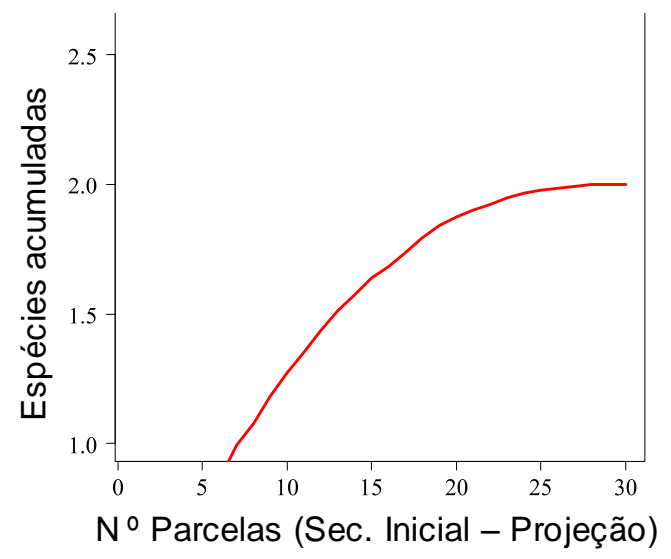

B

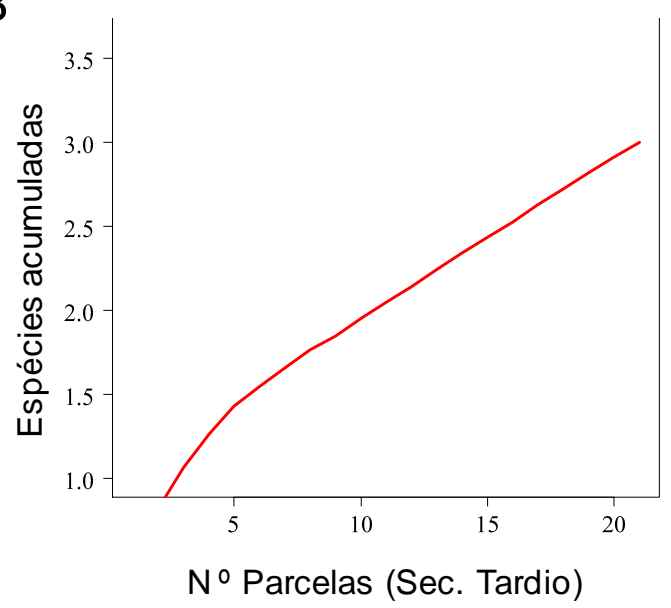

$\mathrm{B}^{\prime}$

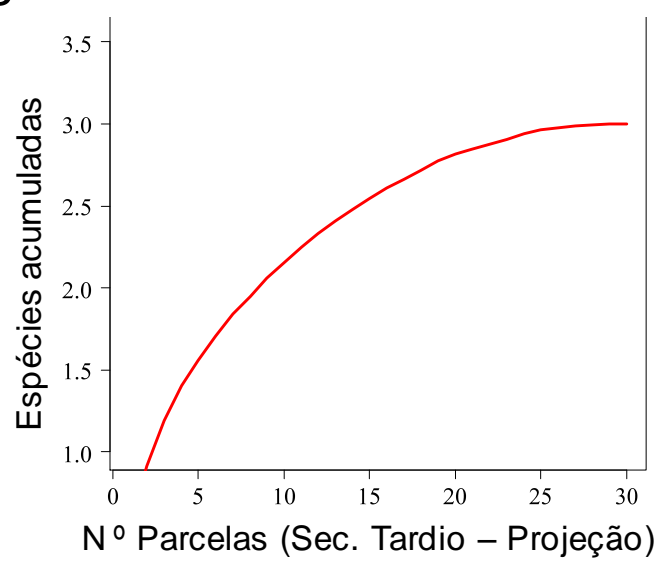

Figura 11. Curvas ( $A$ e $B$ ) e projeção de curvas ( $A^{\prime}$ e $\left.B^{\prime}\right)$ de acumulação de espécies (suficiência amostral) para as parcelas $S I\left(A\right.$ e $\left.A^{\prime}\right)$ e $S T$ (B e $\left.B^{\prime}\right)$. Para a projeção das figuras A' e B', manteve-se a mesma proporção de taxa de encontro de ninhos nos diferentes estágios. 
A média do número de ninhos por parcela em áreas ST $(0,52 \pm 0,68)$ foi significativamente superior à média verificada em áreas $S I(0,14 \pm 0,36)(U=154,000$; $z=-2,105 ; p=0,0353, n=21)($ Fig.12)

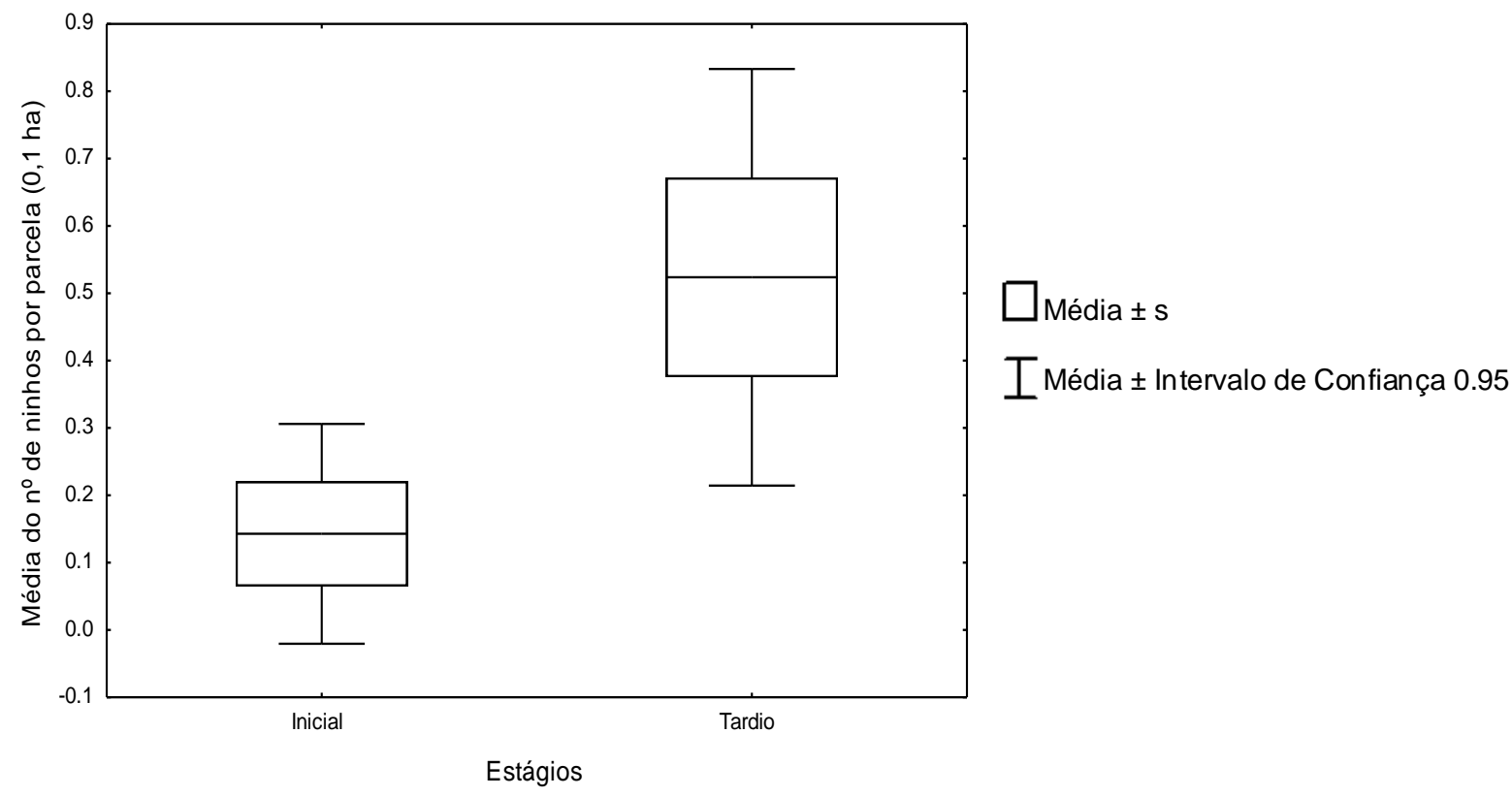

Figura 12. Média do número de ninhos por parcela $(0,1$ ha) em áreas de estágio secundário inicial e em áreas de estágio secundário tardio no PEFI, SP. 
Considerando-se a área total amostrada (4,2 ha), a densidade média dos ninhos foi de 3,33 ninhos/ha, com valores muito superiores nas parcelas ST $(5,24$ ninhos/ha) em comparação com as $\mathrm{SI}(1,43$ ninhos/ha) $(U=154,000 ; z=-2,105$; $p=0,0353, n=21$ ) (Fig.13; Tabela 4). A densidade média da espécie mais abundante, Paratrigona subnuda, também foi maior nas áreas ST ( $\mathrm{n}=9 ; 4,29$ ninhos/ha) em comparação com as $S I(n=2 ; 0,95$ ninhos/ha) $(U=156,000 ; z=-2,174 ; p=0,0297$; $n=21)$.

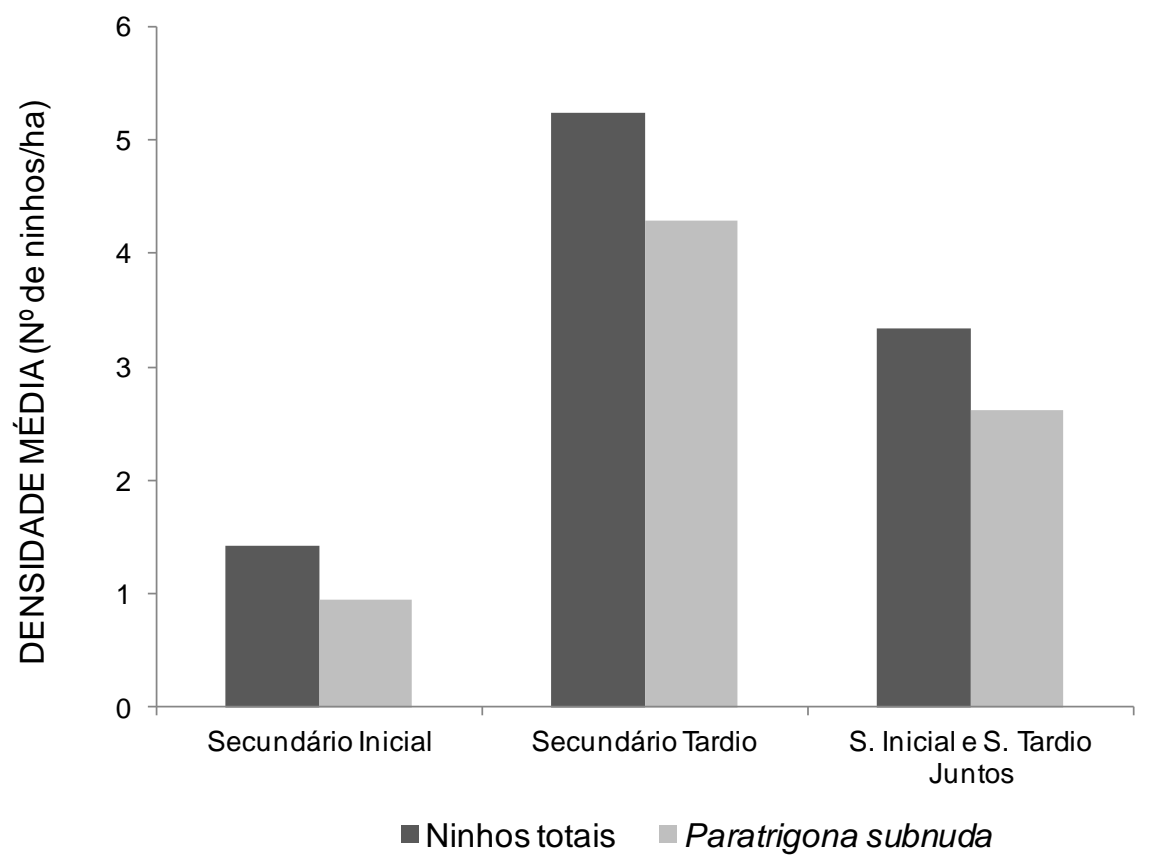

Figura 13. Densidade média dos ninhos de meliponíneos e da espécie mais abundante, Paratrigona subnuda, nas áreas SI (secundário inicial) e ST (secundário tardio) do PEFI, SP. 
O índice de diversidade $\left(\mathrm{H}^{\prime}\right)$ para toda a área amostrada foi igual a 0,7550 e a equitatividade (J'), 0,54. O baixo índice de diversidade é evidenciado pelo fato de apenas uma espécie (Paratrigona subnuda) representar 78,57\% da abundância relativa dos ninhos. O valor de equitatividade indica que a distribuição do número de espécies foi moderadamente heterogênea. Ao analisarmos os dados em separado, a fitofisionomia SI apresentou um valor de riqueza $(n=2)$ estatisticamente diferente de ST $(n=3)(U=156,000 ; z=-2,060 ; p=0,0390)$. A diversidade em áreas SI $\left(H^{\prime}=0,6365\right)$ foi semelhante àquela verificada em $S T\left(H^{\prime}=0,6002\right)$. $O$ valor superior de equitatividade em áreas $S I\left(J^{\prime}=0,92\right)$, quando comparado às áreas $S T\left(J^{\prime}=0,55\right)$, é devido ao pequeno número de ninhos e espécies encontradas (Tabela 4). 
Tabela 4. Quadro comparativo entre as fitofisionomias estudadas (SI e ST) no PEFI, SP, quanto à riqueza, diversidade (H'), equitatividade (J'), número e densidade de ninhos. Os dados de densidade apresentam a média e desvio padrão.

\begin{tabular}{|c|c|c|c|c|c|c|}
\hline & SI & ST & $\mathrm{SI}+\mathrm{ST}$ & $U$ & Z & Significância \\
\hline Área total (ha) & 100,5 & 21,2 & 121,7 & - & - & - \\
\hline Área amostrada (ha) (\% da área total) & $2,1(2,09 \%)$ & $2,1(9,91 \%)$ & $4,2(3,45 \%)$ & - & - & - \\
\hline Riqueza de espécies em árvores & 1 & 2 & 3 & - & - & - \\
\hline Riqueza de espécies subterrâneas & 1 & 1 & 1 & - & - & - \\
\hline Riqueza de espécies total & 2 & 3 & 4 & 156,00 & $-2,060$ & $0,03901 *$ \\
\hline Diversidade $\left(\mathrm{H}^{\prime}\right)$ & 0,6365 & 0,6002 & 0,7550 & - & - & - \\
\hline Equitatividade (J') & 0,92 & 0,55 & 0,54 & - & - & - \\
\hline № ninhos em árvores & 1 & 2 & 3 & 210,00 & $-0,592$ & 0,5539 \\
\hline № ninhos subterrâneos** & 2 & 9 & 11 & 156,50 & $-2,174$ & $0,02967 *$ \\
\hline № ninhos total & 3 & 11 & 14 & 154,00 & $-2,105$ & $0,0353 *$ \\
\hline Densidade de ninhos subterrâneos (ninhos/ha)* & $0,95 \pm 3,00$ & $4,29 \pm 5,97$ & $2,62 \pm 0,49$ & 156,50 & $-2,174$ & $0,02967 *$ \\
\hline Densidade de ninhos em árvores (no ninhos/ha) & $0,48 \pm 2,18$ & $0,95 \pm 3,01$ & $0,71 \pm 2,61$ & 210,00 & $-0,592$ & 0,5539 \\
\hline Densidade de ninhos total ( $\mathrm{n}^{\circ}$ ninhos/ha) & $1,43 \pm 3,59$ & $5,24 \pm 6,80$ & $3,33 \pm 4,97$ & 154,00 & $-2,105$ & $0,0353 *$ \\
\hline
\end{tabular}

* Significância $=p<0,05 ;{ }^{* *}$ - A única espécie encontrada nesse estudo nidificando no solo foi Paratrigona subnuda. 
Quanto ao substrato utilizado para a construção dos ninhos, podemos classificá-los em 3 tipos: a) ninhos subterrâneos ( $n=11,78,57 \%)$, como os de Paratrigona subnuda, que ocupam cavidades abandonadas do solo, como antigos ninhos de formiga; b) ninhos em ocos de árvores ( $n=2,14,29 \%)$, como os de Scaptotrigona bipunctata e Trigona braueri; c) ninhos aéreos $(n=1,7,14 \%)$, apoiados em galhos ou troncos de árvores, como os de Trigona spinipes. Devido ao baixo número de dados, para nossas análises, agrupamos os dois últimos tipos de ninhos em um grupo chamado "ninhos em árvores" (Tabela 4). Segundo Silva (2012), Trigona braueri também pode construir ninhos aéreos.

Analisando-se os dados de todas as parcelas $(n=42)$, observamos uma correlação positiva e significativa entre o número de ninhos e a densidade de todos os indivíduos arbóreos (CAP > $15 \mathrm{~cm})(\mathrm{r}=0,4171 ; \mathrm{p}=0,0060 ; \mathrm{n}=42)$ e também entre o número de ninhos e a densidade dos indivíduos arbóreos com CAP $>25 \mathrm{~cm}$ $(r s=0,4274 ; p=0,0048 ; n=42)$ (Fig. 14, Tabela 5). 
A

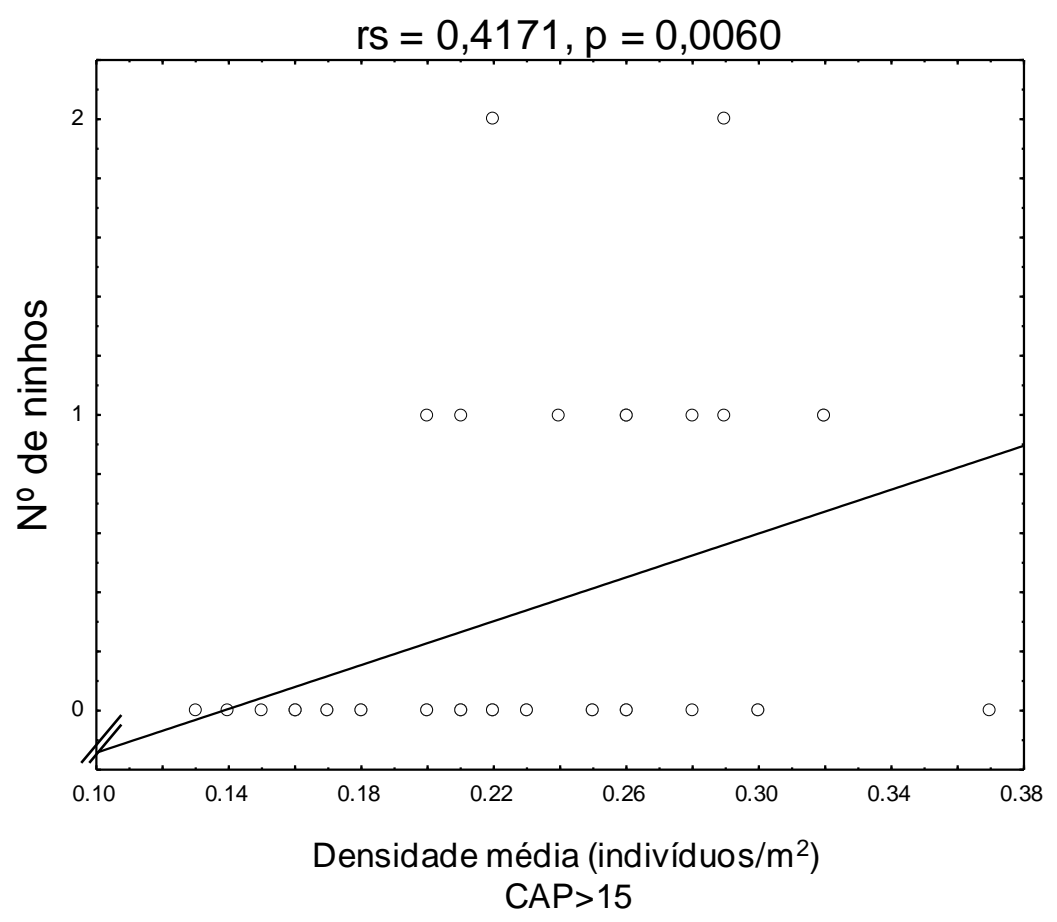

B

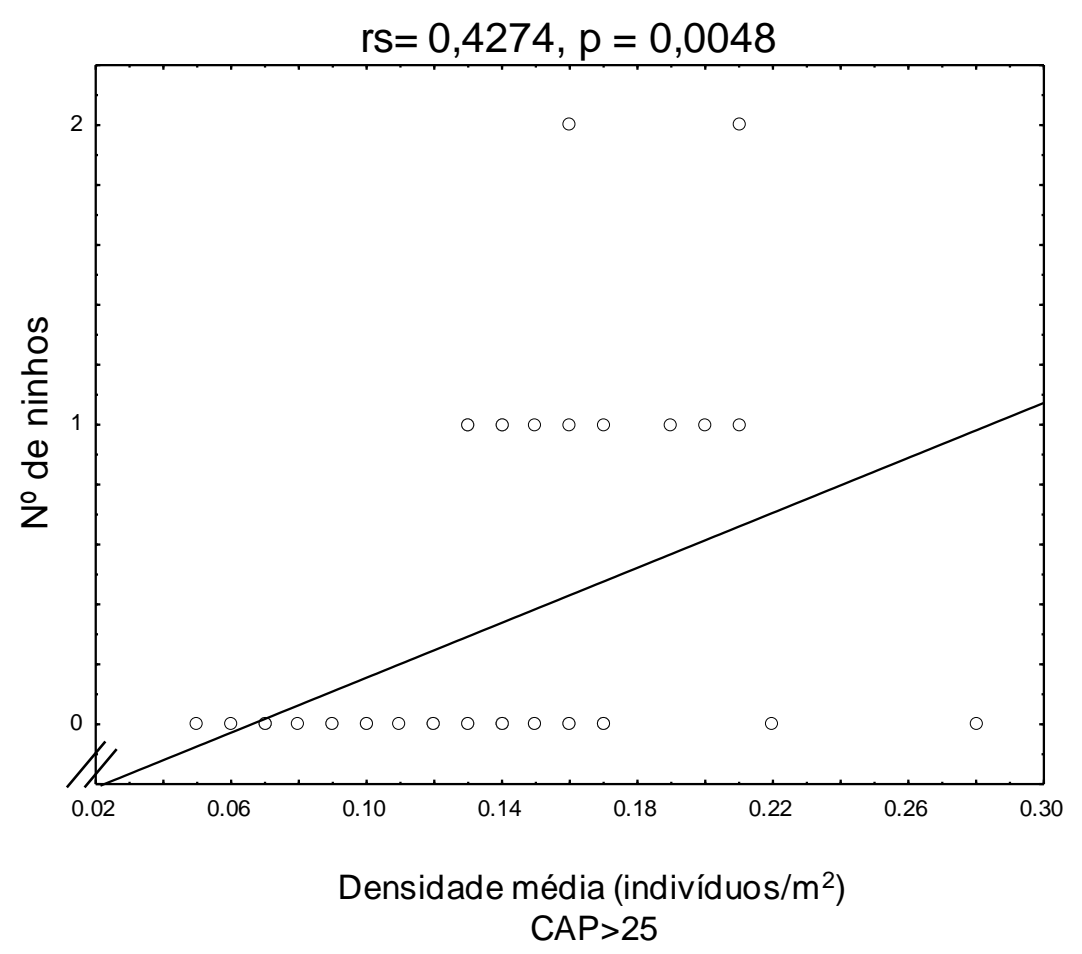

Figura 14. Correlação entre o número de ninhos de meliponíneos e a densidade média de todos os indivíduos arbóreos com $\mathrm{CAP}>15 \mathrm{~cm}(\mathrm{~A})$ e a densidade média dos indivíduos arbóreos com CAP>25 cm (B), no PEFI, SP. 
Tabela 5. Correlação (Spearman) entre o número de ninhos de meliponíneos (totais e separados por tipo de substrato) e as variáveis fitossociológicas de todas as parcelas do estudo $(n=42)$, das parcelas de estágio secundário inicial $(n=21)$ e de estágio secundário tardio $(\mathrm{n}=21)$. Em negrito, as variáveis que podem ter influenciado a ocorrência dos ninhos (correlação estatisticamente significativa).

\begin{tabular}{|c|c|c|c|c|c|c|c|}
\hline Parcelas & & $\begin{array}{c}\text { Densidade } \\
\text { CAP > } 15 \mathrm{~cm}\end{array}$ & CAP $>15 \mathrm{~cm}$ & $\begin{array}{c}\text { Altura } \\
\mathrm{CAP}>15 \mathrm{~cm}\end{array}$ & $\begin{array}{l}\text { Densidade } \\
\text { CAP >25 cm }\end{array}$ & CAP $>25 \mathrm{~cm}$ & $\begin{array}{c}\text { Altura } \\
\text { CAP }>25 \mathrm{~cm}\end{array}$ \\
\hline \multirow{6}{*}{$\begin{array}{l}T \\
O \\
D \\
A \\
S\end{array}$} & \multirow[t]{2}{*}{ Ninhos totais } & 0,4171 & 0,2153 & 0,1828 & 0,4274 & 0,1705 & "0,3935 \\
\hline & & $p=0,0060$ & $p=0,1709$ & $p=0,2465$ & $p=0,0048$ & $p=0,2803$ & $p=0,3299$ \\
\hline & \multirow[t]{2}{*}{ Ninhos em árvores } & 0,2066 & $-0,0343$ & 0,0420 & 0,2642 & $-0,0725$ & 0,0038 \\
\hline & & $\mathrm{p}=0,1893$ & $p=0,8292$ & $\mathrm{p}=0,7919$ & $p=0,909$ & $\mathrm{p}=0,6484$ & $p=0,9809$ \\
\hline & \multirow[t]{2}{*}{ Ninhos de solo } & 0,3271 & 0,3009 & 0,2281 & 0,3352 & 0,2641 & 0,2114 \\
\hline & & $p=0,0345$ & $\mathrm{p}=0,0529$ & $p=0,1463$ & $p=0,0300$ & $\mathrm{p}=0,0910$ & $\mathrm{p}=0,1789$ \\
\hline \multirow{6}{*}{$\begin{array}{l}\text { I } \\
\text { N } \\
\text { I } \\
\text { C } \\
\text { I } \\
\text { A } \\
\text { L }\end{array}$} & \multirow[t]{2}{*}{ Ninhos totais } & 0,5086 & 0,0000 & $-0,2023$ & 0,4288 & $-0,1124$ & $-0,2697$ \\
\hline & & $p=0,0185$ & $p=1,0000$ & $\mathrm{p}=0,3793$ & $\mathrm{p}=0,0524$ & $\mathrm{p}=0,6277$ & $p=0,2371$ \\
\hline & \multirow[t]{2}{*}{ Ninhos em árvores } & 0,2786 & $-0,0369$ & $-0,1108$ & 0,3708 & $-0,1846$ & $-0,1846$ \\
\hline & & $p=0,2214$ & $p=0,8737$ & $p=0,6326$ & $\mathrm{p}=0,0979$ & $\mathrm{p}=0,4230$ & $\mathrm{p}=0,4230$ \\
\hline & \multirow[t]{2}{*}{ Ninhos de solo } & 0,4042 & 0,0268 & $-0,1607$ & 0,2421 & 0,0000 & $-0,1875$ \\
\hline & & $\mathrm{p}=0,0692$ & $\mathrm{p}=0,9082$ & $p=0,4864$ & $p=0,2903$ & $\mathrm{p}=1,0000$ & $p=0,4156$ \\
\hline \multirow{6}{*}{$\begin{array}{l}\mathrm{T} \\
\mathrm{A} \\
\mathrm{R} \\
\mathrm{D} \\
\mathrm{I} \\
\mathrm{O}\end{array}$} & \multirow[t]{2}{*}{ Ninhos totais } & 0,1958 & 0,3241 & 0,2762 & 0,3314 & 0,0972 & 0,1746 \\
\hline & & $\mathrm{p}=0,3949$ & $p=0,1518$ & $\mathrm{p}=0,2255$ & $\mathrm{p}=0,1422$ & $\mathrm{p}=0,6750$ & $p=0,4492$ \\
\hline & \multirow[t]{2}{*}{ Ninhos em árvores } & 0,1613 & $-0,0268$ & 0,1072 & 0,1622 & $-0,0536$ & 0,0536 \\
\hline & & $p=0,4850$ & $\mathrm{p}=0,9082$ & $p=0,6438$ & $p=0,4825$ & $p=0,8176$ & $\mathrm{p}=0,8176$ \\
\hline & \multirow[t]{2}{*}{ Ninhos de solo } & 0,0963 & 0,4264 & 0,3015 & 0,2842 & 0,1797 & 0,2041 \\
\hline & & $p=0,6781$ & $p=0,0539$ & $p=0,1841$ & $p=0,2118$ & $p=0,4357$ & $p=0,3749$ \\
\hline
\end{tabular}


Analisando-se os ninhos quanto ao tipo de substrato utilizado para sua construção, diferentemente do que aconteceu com os ninhos de árvore (devido ao baixo número de ninhos, $n=3$ ), o número de ninhos de solo $(n=11)$ apresentou uma correlação positiva e significativa com a densidade de todos os indivíduos arbóreos ( $\mathrm{rs}=0,3271 ; \mathrm{p}=0,0345 ; \mathrm{n}=42$ ) e também com a densidade dos indivíduos arbóreos com CAP >25 cm ( $r s=0,3352 ; p=0,0300 ; n=42)$ (Fig. 15).

Analisando-se os dois estágios sucessionais, para as parcelas $S I(n=21)$, houve correlação positiva significativa entre o número de ninhos e a densidade de todos os indivíduos arbóreos ( $r s=0,5086 ; p=0,0185$ ) (Fig. 16). Não houve correlação significativa entre os tipos de ninhos (totais, subterrâneos e de árvores) e as demais variáveis. 
A $\mathrm{rs}=0,3271, \mathrm{p}=0,0345$

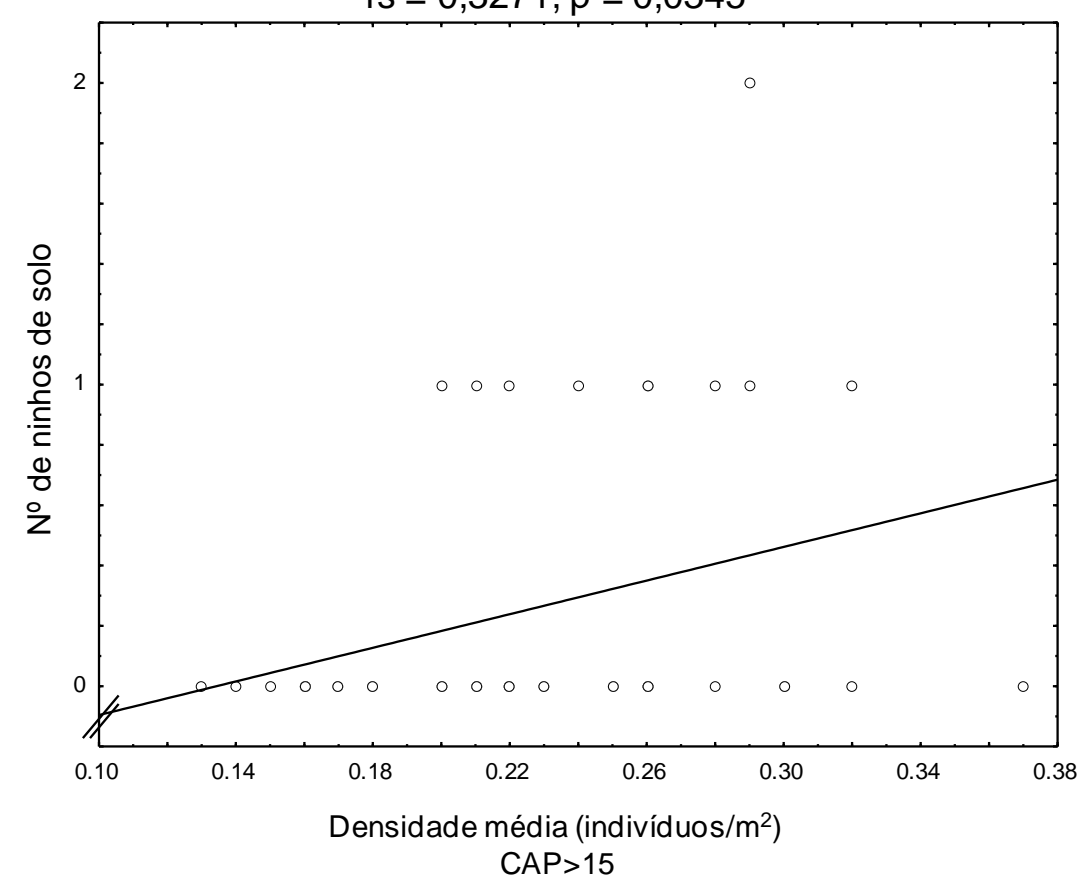

B

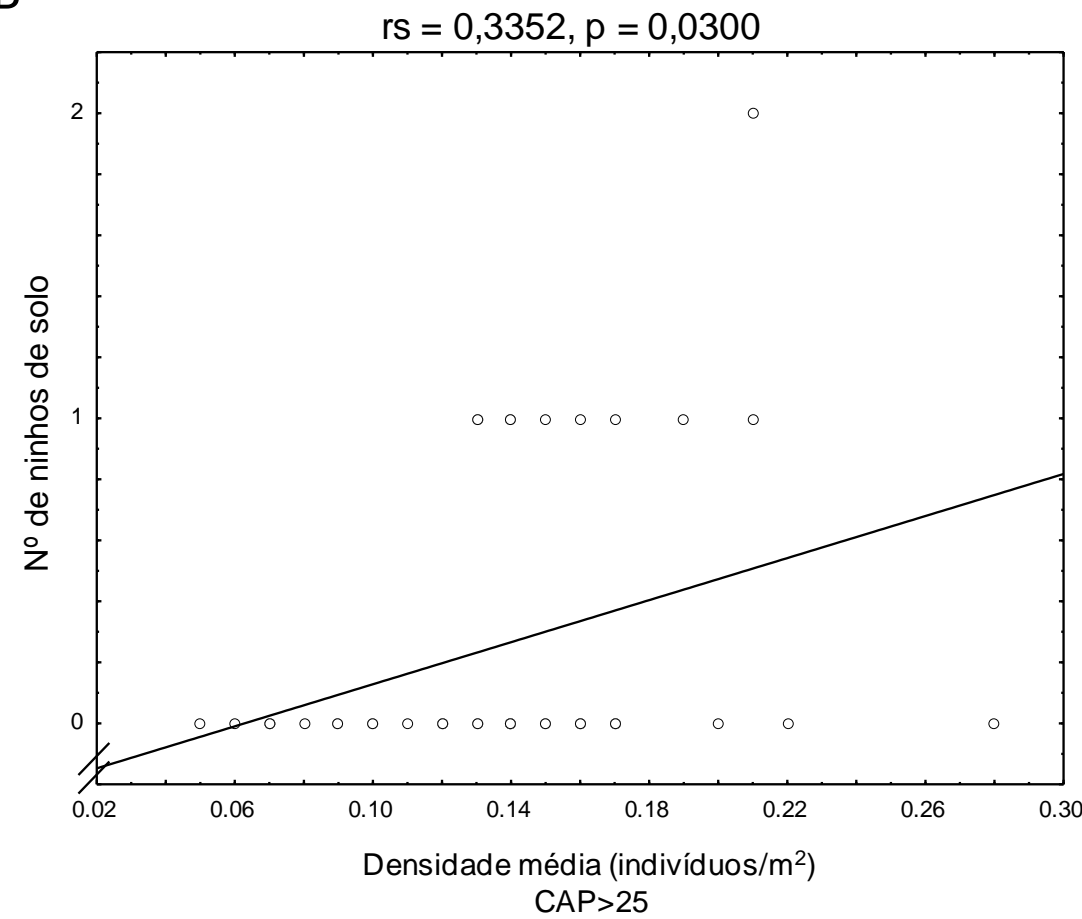

Figura 15. Correlação entre o número de ninhos de solo de meliponíneos e a densidade média de todos os indivíduos arbóreos com CAP $>15 \mathrm{~cm}(\mathrm{~A})$ e a densidade média dos indivíduos arbóreos com CAP>25 cm (B), no PEFI, SP. 
$r S=0,5086 ; p=0,0185$

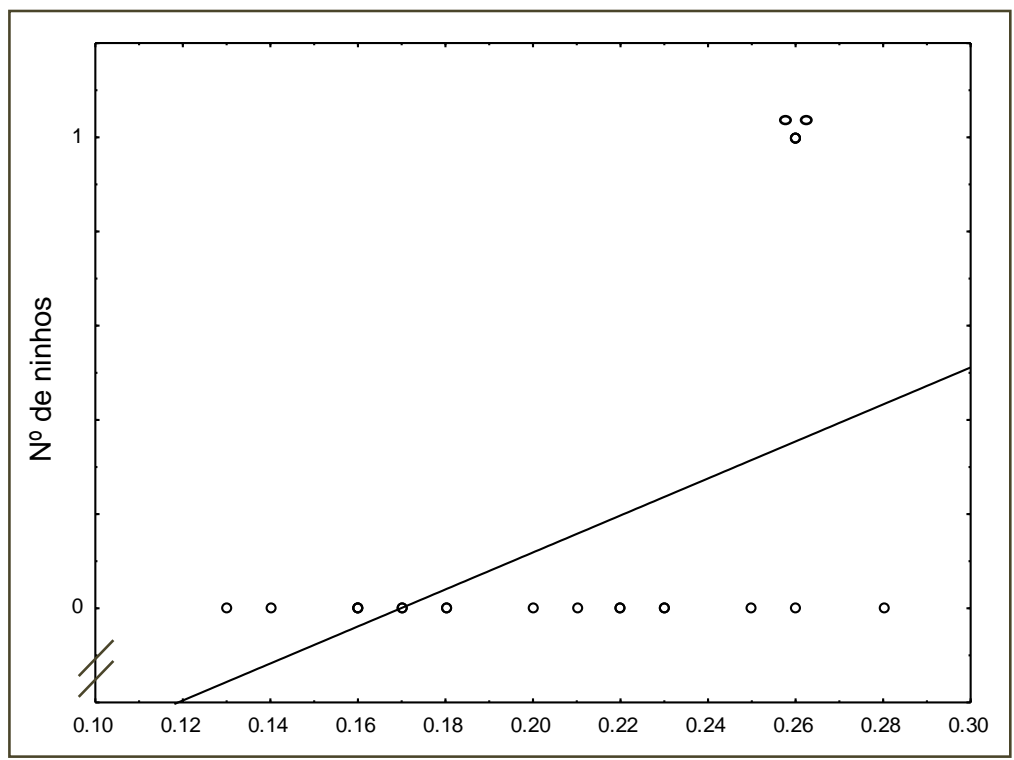

Densidade média (indivíduos $/ \mathrm{m}^{2}$ )

CAP $>15$

Figura 16. Correlação entre o número de ninhos de meliponíneos em área secundária inicial e a densidade média de todos os indivíduos arbóreos com $\mathrm{CAP}>15 \mathrm{~cm}$, no PEFI, SP.

As entradas dos ninhos de árvores (ninhos em cavidades e ninhos aéreos), situados dentro e fora da área de amostragem $(n=8)$, apresentaram uma tendência para se orientarem preferencialmente para o sentido noroeste e leste $\left(\chi^{2}=18, G L=7\right.$, $\mathrm{p}=0,012$ ) (Fig. 17). S. bipunctata apresentou a entrada de seus dois ninhos orientadas no sentido leste; $T$. braueri $(\mathrm{n}=2)$, orientadas no sentido noroeste; $T$. spinipes apresentou um ninho com entrada orientada no sentido noroeste; Tetragonisca angustula apresentou dois ninhos com entradas orientadas sentido leste e uma orientada no sentido norte. A Fig. 18 mostra a frequência (em \%) do sentido médio de onde proveio o vento nos anos de 2011 e 2012 e a média entre os anos de 1957 e 2012 (IAG/USP, 2012). Nenhum ninho encontrado apresentou entrada orientada para o sentido predominante dos ventos. 
Nas parcelas de estudo, foi encontrado apenas um ninho de Apis mellifera, em área ST, extinto alguns meses depois. A densidade de ninhos de Apis mellifera para a vegetação total, considerando-se todas as 42 parcelas estudadas (e o ninho recém - extinto), foi de 0,24 ninhos/ha. 


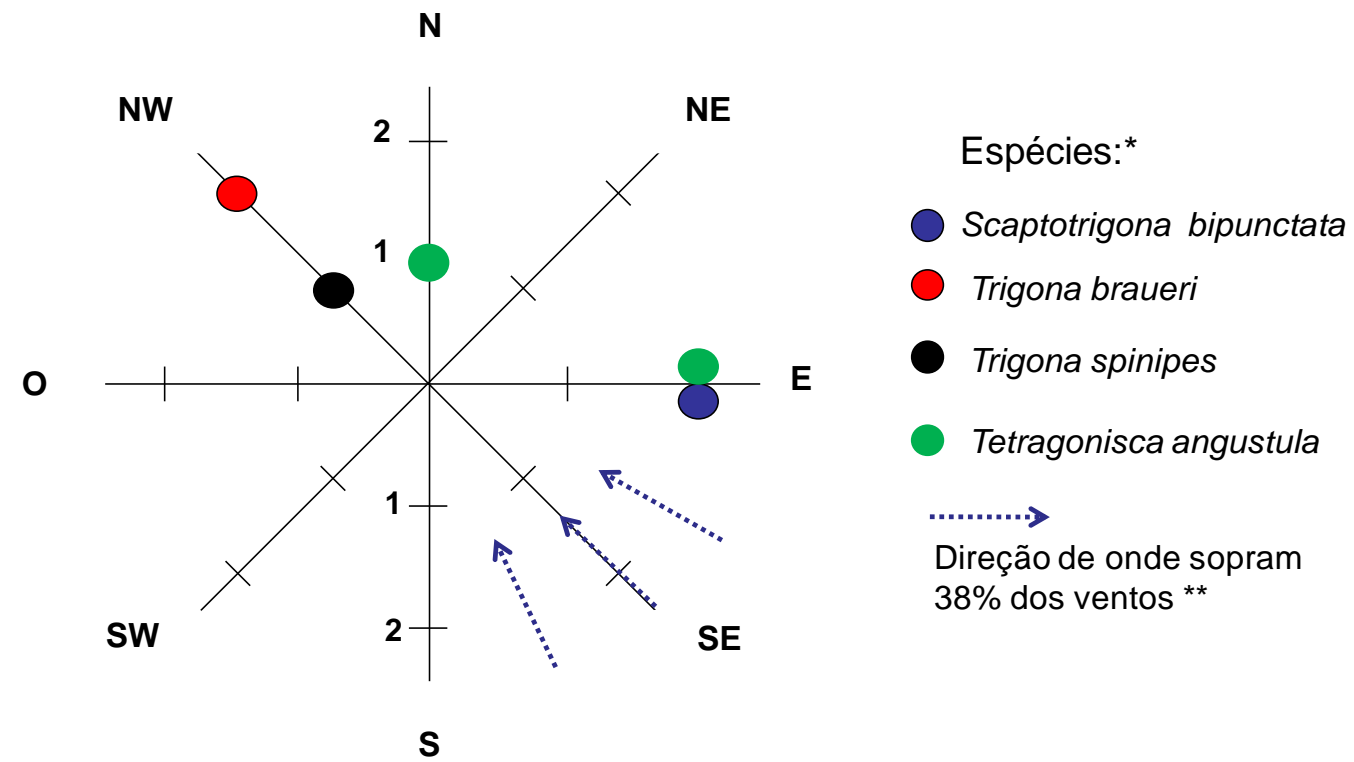

Figura 17. Números de ninhos de meliponíneos $(n=8)$ conforme a espécie*, encontrados em área de mata do $\mathrm{PEFI}$, plotados conforme o sentido de exposição de suas entradas. ${ }^{* *}$ - Dados do IAG/USP (2012).

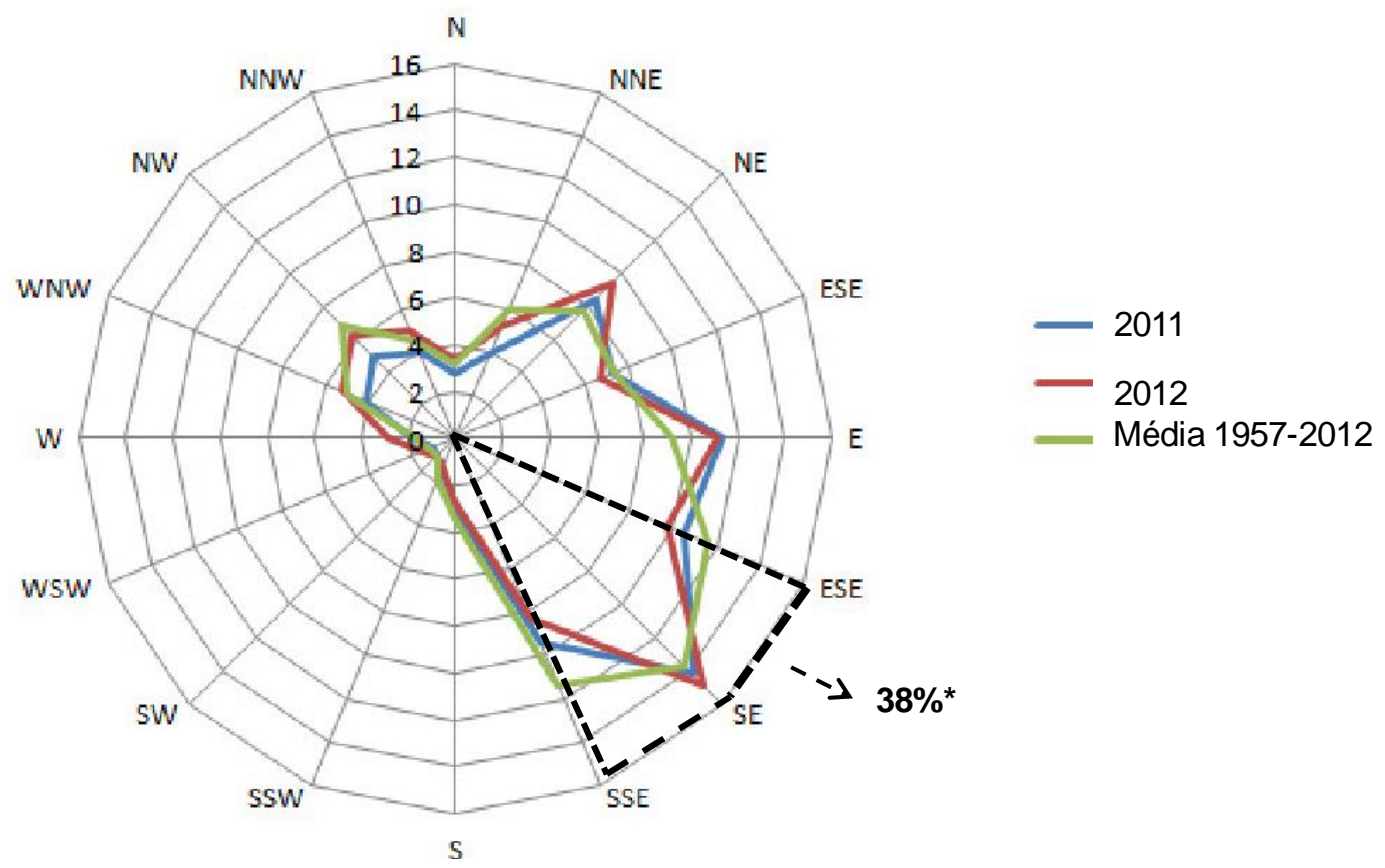

Figura 18. Frequência (\%) da direção média de onde proveio o vento nos anos de 2011 e 2012 e média de 1957-2012 no PEFI. *- Área hachurada indica que 38\% da direção média do vento provém de SSE, SE e ESE.

Fonte: adaptado de IAG/USP (2012). 


\section{DISCUSSÃO}

\subsection{Hipóteses}

A nossa primeira hipótese, que a maior oferta de substratos para nidificação nas áreas ST possibilitaria uma maior riqueza e abundância de ninhos de meliponíneos, em comparação com as áreas SI, foi corroborada. Entretanto, somente a primeira parte da segunda hipótese, que pressupunha uma densidade maior de ninhos em áreas ST, com predomínio de espécies que nidificam em árvores, foi corroborada em nossa área de estudo $(\mathrm{SI}=1,4$ ninhos/ha; $\mathrm{ST}=5,24$ ninhos/ha). Nessas áreas, a riqueza de espécies que nidificam em árvores ( $n=02$ espécies) foi maior que a riqueza de espécies que nidificam no solo ( $\mathrm{n=01}$ espécie). Porém, a densidade e abundância relativa de ninhos foram maiores para uma espécie que nidifica em cavidades subterrâneas, Paratrigona subnuda $(n=4,29$ ninhos/ha; $\mathrm{n}=9$ ninhos; em ST) e não de espécies que constroem seus ninhos em árvores $(0,95$ ninho/ha; $n=2$ ninhos; em ST). A fitofisionomia das áreas ST do PEFI possibilitou não apenas uma maior oferta de substratos em árvores, mas também uma maior oferta de cavidades subterrâneas disponíveis.

Devido aos poucos ninhos encontrados em áreas SI não podemos afirmar que haja um predomínio de espécies que fazem ninhos subterrâneos (ninhos de árvores $=01$; ninhos subterrâneos=02). Pelo mesmo motivo, a equitatividade alta encontrada para a área SI $\left(J^{\prime}=0,92\right)$ não reflete muito a realidade ( 3 ninhos; $n=2$ espécies). Aparentemente, além da baixa densidade de indivíduos arbóreos, com CAPs adequados para a nidificação de espécies de meliponíneos, as áreas SI não propiciam a mesma oferta de cavidades disponíveis para a nidificação como as 
áreas ST. A estrutura da vegetação influencia diretamente a estrutura de comunidades de abelhas, ou seja, a densidade de ninhos e a riqueza específica (Banaszak, 1996). Um desses recursos é, justamente, a disponibilidade de locais para a nidificação (Kleinert, 2006), o que já foi corroborado por outros trabalhos (Inoue et al., 1993).

Os trabalhos de Peccinini (2000) e do Plano de Manejo (2005) apontam as áreas ST como áreas em que a regeneração da floresta está em estágio mais avançado, apresentando as médias de CAP e de alturas de árvores maiores que as médias das parcelas das áreas SI. Esses trabalhos também apontam maiores densidades de árvores nas áreas ST (Peccinini, 2000). Foi perceptível a diferença no dossel entre os dois estágios sucessionais, havendo maior continuidade do dossel nas parcelas ST. As diferenças entre esses estágios de vegetação, quanto ao número de ninhos encontrados em nosso trabalho, são fortes indicativos que as parcelas da área ST apresentam condições mais propícias para a nidificação de meliponíneos. Apesar de verificarmos uma diferença estatisticamente significativa entre as médias dos CAPs das duas áreas (média CAP>15 cm, em SI=36,34 $\pm 7,83$, e em $\mathrm{ST}=41,66 \pm 7,17$; média $\mathrm{CAP}>25 \mathrm{~cm}$, em $\mathrm{Sl}=47,57 \pm 9,66$, e em $\mathrm{ST}=57,40 \pm$ 12,79), essa diferença de apenas mais $10 \mathrm{~cm}$ nas áreas ST não parece ser suficiente para a nidificação de abelhas do gênero Melipona, como supunha nossa quarta hipótese. Em outro estudo com levantamento de ninhos de meliponíneos, também em áreas com diferentes estágios sucessionais de Mata Atlântica, os estágios mais avançados de regeneração apresentaram maior riqueza e diversidade de espécies (Silva et al., 2013).

Considerando as densidades dos ninhos encontrados em toda a área de estudo (3,33 ninhos/ha) e nas áreas ST (5,24 ninhos/ha), esse trabalho apresenta 
densidades superiores à média da densidade de ninhos (entre 0,89 e 2,22 ninhos/ha), encontrados em um trabalho de revisão sobre levantamentos de ninhos de meliponíneos em biomas neotropicais (Kleinert, 2006). A densidade em áreas SI (1,4 ninhos/ha) situou-se entre os valores de médias de densidade encontrados no estudo de Kleinert (2006). Ainda em relação ao mesmo estudo (Kleinert, op. cit.), se considerarmos apenas as menores áreas de levantamento (áreas correspondentes a $<5,62$ ha), os valores de densidade encontrados no PEFI continuam superiores à média de valores de densidade de ninhos dessas áreas $(1,55 \pm 3,17$ ninhos/ha, $\mathrm{n}=100$ ). Considerando-se apenas os ninhos em árvores, visto que praticamente não há, na literatura, registros de Paratrigona subnuda em ambientes naturais, no Brasil, com exceção do trabalho de Silva (2012), a densidade dos ninhos foi de 0,95 ninhos/ha, em áreas ST.

A premissa de que as áreas SI apresentariam mais ninhos subterrâneos de meliponíneos devido à maior área de solo exposta e menor densidade de árvores não pode ser corroborada. Mesmo que houvesse uma maior oferta de ninhos de formigas disponíveis para nidificação em áreas SI, deve-se considerar que, nessas áreas, conforme observações em campo, existem muitos pontos com emaranhados de bambus e samambaias, o que dificulta o encontro das cavidades pelas abelhas.

\subsection{Espécies de meliponíneos}

\subsubsection{Paratrigona subnuda: abundância dos ninhos em solo}

Paratrigona subnuda, espécie que apresenta entradas muito pequenas, com cerca de 0,7 cm de diâmetro, é comumente encontrada em ninhos abandonados de Atta, a profundidades diversas, que vão de 25 a $150 \mathrm{~cm}$ (Imperatriz-Fonseca \& Souza, 1972; Souza et al., 1993) (Anexo 6). Seus ninhos apresentam, geralmente, 
um padrão de distribuição agregado (Imperatriz-Fonseca \& Souza, 1972; Knoll et al., 1993). Apesar de nidificar no solo, também é beneficiada por uma área em que a vegetação se encontra mais regenerada. As áreas ST, que apresentam, dentre outras características, a presença de um dossel mais contínuo, podem estar ligadas diretamente à maior oferta de ninhos de formigas, como as formigas saúvas do gênero Atta, devido à presença de mais indivíduos arbóreos. Gomes et al. (2010), trabalhando em fragmentos de vegetação de Mata Atlântica, apontam que o grau de conservação da vegetação influencia mais a riqueza de espécies de formigas do que o tamanho de fragmentos ou a quantidade de vegetação ao redor das áreas remanescentes. Ao falarmos estritamente sobre a comunidade de formigas de solo, também há indícios de que a diversidade de espécies é maior em áreas com vegetação mais estratificada, solo rico em matéria orgânica e serapilheira, indicando ainda que, em estágios iniciais de sucessão, a diversidade diminui (Leal \& Lopes, 1992).

Em outros levantamentos realizados na Mata Atlântica, a taxa de encontro de ninhos de Paratrigona subnuda foi nula ou extremamente baixa (Batista et al., 2003; Silva, 2012). Silva (2012) encontrou apenas dois ninhos dessa espécie, de um total de 91 ninhos, em áreas de estágio inicial de vegetação em regeneração. No estudo de Batista et al. (2003), realizado em áreas em diferentes estágios sucessionais de Mata Atlântica, nenhum ninho dessa espécie foi registrado. Não encontramos outros registros dessa espécie em áreas naturais, no Brasil, em nosso levantamento bibliográfico.

Paratrigona subnuda também apresentou maior abundância dentre os ninhos encontrados, em um levantamento realizado em uma área aberta/urbanizada do PEFI (Sousa \& Kleinert, 2010). Em 6,85 hectares da unidade Parque Cientec (Fig. 
5), foram registrados 48 ninhos subterrâneos ( $58,4 \%$ do total de ninhos), espalhados pelos gramados e pelo solo (Fig. 19). A proximidade dessa área com as áreas naturais poderia também explicar a maior abundância dessa espécie nessa área urbana, supondo que a área natural atue como fonte de sua dispersão para essas áreas adjacentes. 


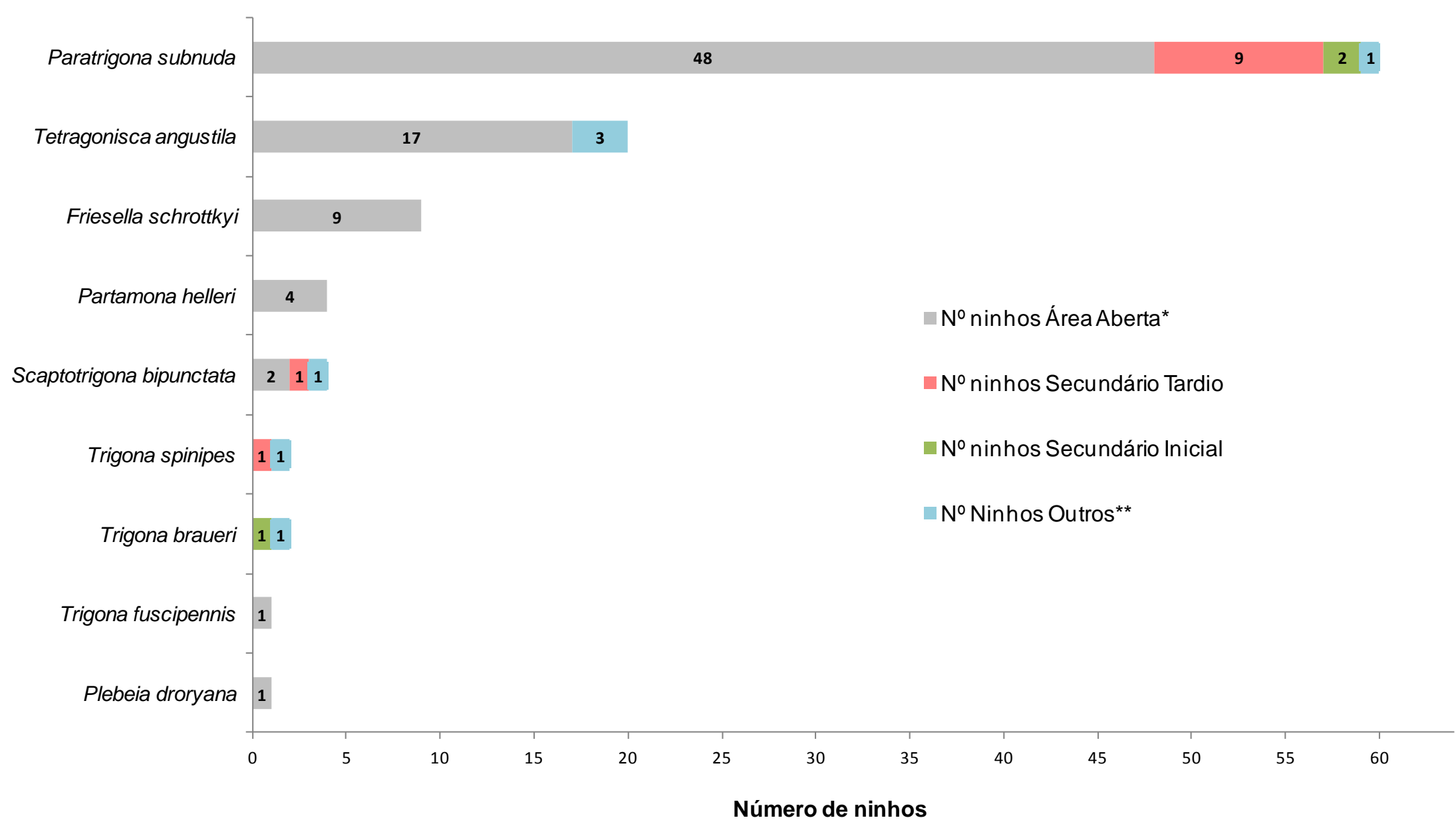

Figura 19. Número de ninhos de meliponíneos encontrados nos diferentes ambientes do PEFI, São Paulo-SP.

*- Área Aberta: ninhos encontrados em área aberta (urbanizada) do PEFI (6,85 ha, 2008-2010, Sousa \& Kleinert, 2010); ** - Outros: ninhos encontrados na mata, fora da área de amostragem. 


\subsubsection{Trigona braueri: primeiro registro em São Paulo}

Os dois ninhos de Trigona braueri encontrados nesse estudo, na área SI (ninho i2) e em uma trilha fora da área de amostragem (ninho o2), representam o primeiro registro desta espécie no estado de São Paulo (Anexo 7). Até o presente, essa espécie havia sido registrada apenas nos estados da Bahia e do Espírito Santo (Camargo \& Pedro, 2013; Sílvia M.R. Pedro, inf. pessoal). Silva (2012) encontrou um ninho dessa espécie em um fragmento de Mata Atlântica, em estágio avançado de regeneração, no estado da Bahia. Essa espécie pode utilizar mais de um tipo de substrato para nidificação, tanto cavidades em árvores, como uso das mesmas e de seus troncos como suporte, caso do ninho aéreo dessa encontrado por Silva (op. cit.). Os dois ninhos dessa espécie, encontrados no PEFI, aproveitaram as cavidades existentes na base das árvores, com alturas praticamente rentes ao nível do chão. Esse registro evidencia a importância de fragmentos florestais isolados na manutenção de populações de espécies de meliponíneos, mesmo que pequenas, como já mencionado por NogueiraNeto (2000).

\subsubsection{Trigona spinipes: ninhos aéreos}

Trigona spinipes é uma das poucas espécies de abelhas sem ferrão que constroem ninhos aéreos (Cortopassi-Laurino \& Nogueira-Neto, 2003). Esses ninhos apresentam boa capacidade termorreguladora, possibilitando a retenção de energia térmica em regiões frias (Zucchi \& Sakagami, 1972; Cortopassi-Laurino \& NogueiraNeto, 2003). Assim como Tetragonisca angustula, é comum encontrar esses ninhos pela cidade de São Paulo. O ninho dessa espécie, encontrado na área ST (ninho t6), 
encontra-se no solo há quase um ano, devido à queda da árvore que o sustentava; estava originalmente instalado nos galhos, a uma altura de mais de 15 metros. Há outros relatos de ninhos de Trigona spinipes que sobrevivem mesmo quando estão no solo, caso de uma colônia que sobrevive nas matas do Instituto de Biociências, USP (Paulo C. Fernandes, inf. pessoal). Outro ninho de Trigona spinipes (ninho 01), localizado fora da área de amostragem, em uma trilha dentro da área SI, encontrava-se a uma altura de 5,8 $\mathrm{m}$, em uma árvore com $C A P=45 \mathrm{~cm}(\mathrm{DAP}=14,5 \mathrm{~cm})$. Além do mais, como os seus ninhos são apoiados em troncos ou galhos, não necessitam necessariamente de árvores com grande CAP, havendo registro da construção de ninhos em uma árvore com CAP de apenas $18,84 \mathrm{~cm}$, ou seja, com um DAP de $6 \mathrm{~cm}$ (Kleinert, 2006).

\subsubsection{Tetragonisca angustula: presentes em área aberta e fora da área de amostragem}

Apesar de Tetragonisca angustula não ter sido registrada em nossa amostragem, foi a espécie mais abundante dentre os ninhos encontrados fora da área da amostragem ( $n=3,42,86 \%$ do total): na borda da trilha em área SI (ninho o6), na borda da trilha em área de estágio secundário médio (ninho o3), e em área com dossel aberto, ao lado de uma clareira, em área de estágio secundário médio (ninho o5) (Figs 9 e 19). Nogueira-Neto (2000) sugere que Tetragonisca angustula é encontrada principalmente em locais mais abertos, como nos cerrados e áreas urbanas. Em área aberta do PEFI, Parque Cientec, a espécie Tetragonisca angustula (Latreille, 1811) foi a segunda 
espécie mais abundante, contabilizando 17 ninhos, 20\% do total (Sousa \& Kleinert, 2010). Nessa levantamento, Tetragonisca angustula foi a única espécie que nidificou tanto em cavidades naturais ( $59 \%$ de suas colônias; $n=10)$, quanto em cavidades artificiais ( $41 \%$ de suas colônais; $n=7)$. Em outra área aberta do PEFI, espaço público de visitação do Jardim Botânico, também há registros de Tetragonisca angustula, que também nidificou tanto em cavidade de árvores, quanto em um muro de pedra.

Cabe ressaltar que, em áreas abertas do PEFI, foram registrados vários ninhos de outras espécies não localizadas em áreas de mata desse estudo: Friesella schrottkyi, Partamona helleri, além de um ninho de Plebeia droryana e um de Trigona fuscipennis (Sousa \& Kleinert, 2010).

\subsubsection{Abelhas do gênero Melipona: ausência}

O CAP médio das árvores utilizadas pelos meliponíneos na área de amostragem do PEFI foi de $139 \mathrm{~cm}(\mathrm{DAP}=44 \mathrm{~cm}, \mathrm{n}=3)$. Quando considerados também os ninhos fora da área de amostragem, o CAP médio foi de $155 \mathrm{~cm}(\mathrm{DAP}=49 \mathrm{~cm}, \mathrm{n}=9)$. Em um estudo na Mata Atlântica, Silva (2012) verificou que o CAP médio das árvores utilizadas pelos meliponíneos foi de $113 \mathrm{~cm}(\mathrm{DAP}=36 \mathrm{~cm})$, sendo que, para a única espécie do gênero Melipona encontrada, Melipona scutellaris, o CAP médio foi de $125 \mathrm{~cm}$ (DAP= 39,8 cm). Em florestas de araucárias, Lopes (2012) verificou que o CAP médio utilizado pelos meliponíneos foi de $132 \mathrm{~cm}(\mathrm{DAP}=42 \mathrm{~cm})$, sendo que a maior frequência de ninhos de Melipona bicolor schencki foi constatada em espécies arbóreas com CAP de $138 \mathrm{~cm}(\mathrm{DAP}=44 \mathrm{~cm})$. 
Em nenhuma das parcelas, foram encontrados ninhos de espécies do gênero Melipona, rejeitando nossa hipótese que previa a existência de ninhos de espécies desse gênero em áreas ST. Espécies de Melipona nidificam, geralmente, em cavidades com maiores diâmetros (Brown \& Albrecht, 2001; Antonini \& Martins, 2003; Martins et al., 2004); portanto, o tamanho das cavidades nos ocos de árvores pode limitar o desenvolvimento dos ninhos dessas espécies, especialmente em áreas de matas secundárias, onde há menor oferta desses substratos (Hubbell \& Johnson,1977; Samejima et al., 2004; Villanueva et al., 2005a apud Cortopassi-Laurino, et al., 2006).

Os levantamentos de ninhos mais recentes feitos no Brasil só vieram corroborar o fato de que espécies de Melipona são relatadas apenas em ambientes naturais (Pioker-Hara, 2011; Lopes, 2012; Siqueira et al., 2012; Barbosa, 2013; Silva, 2013), não sendo verificada sua ocorrência em ambientes urbanos (Freitas, 2001; Taura \& Laroca, 2001; Sousa et al., 2002; Souza et al., 2005; Sousa \& Kleinert, 2010; Oliveira et al., 2012). Estudos sobre a ocorrência de Melipona quadrifasciata em fragmentos urbanos e rurais (com vegetação de Mata Atlântica, cerrado e campos) indicaram haver correlação positiva significativa entre número de ninhos de $M$. quadrifasciata e densidade, diversidade e grau de preservação da vegetação (Antonini, 2002).

Silva (2012) encontrou ninhos de Melipona scutellaris tanto em estágios iniciais quanto em estágios avançados de regeneração do mesmo bioma. Isso se deve ao fato de que os fragmentos estudados por Silva (2012), mesmo os de estágio inicial de regeneração, apresentavam alta densidade de árvores vivas com grandes CAPs, que são mais adequados para a nidificação de espécies de Melipona. Apesar de Siqueira (2012) ter conduzido seu estudo em ambiente de vegetação heterogênea, com grande 
diversidade de substratos para nidificação, Melipona rufiventris foi encontrada principalmente em áreas mais preservadas, nidificando em árvores com CAP médio de $228 \mathrm{~cm}(\mathrm{DAP}=72,6 \mathrm{~cm})$ (Siqueira et al., 2007; Siqueira et al., 2012). Portanto, o fator limitante, tomando essa espécie como exemplo para as demais do mesmo gênero, pode ter sido a oferta de cavidades com tamanhos maiores.

Nesse estudo, a área de mata secundária apresentou médias de diâmetro de árvores bem abaixo daqueles utilizados pelas espécies de Melipona, o que pode explicar, em parte, a ausência de seus ninhos. Entretanto, apesar de as espécies da subtribo Trigonina nidificarem em árvores com CAPs menores do que as da subtribo Meliponina, o estudo de Kleinert (2006), que analisou um conjunto de trabalhos sobre densidade de ninhos de meliponíneos em biomas neotropicais, não revelou diferenças significativas entre os diâmetros das árvores utilizadas para nidificação por essas duas subtribos. Na caatinga, por exemplo, Martins et al. (2004) constataram que o CAP médio das árvores e troncos utilizados pelos meliponíneos foi de $65 \mathrm{~cm}$ (DAP= 20,7 $\mathrm{cm}$ ), embora a espécie mais abundante, Melipona subnitida, tenha sido encontrada nidificando em árvores com CAP médio de 55,6 cm $(\mathrm{DAP}=17,7 \mathrm{~cm})$ (semelhante às nossas áreas ST) e Melipona asilvai, a segunda mais frequente, em árvores com CAP médio de $71,3 \mathrm{~cm}(\mathrm{DAP}=22,7 \mathrm{~cm})$. Desse modo, não apenas o diâmetro das árvores parece ser relevante para a nidificação de espécies do gênero Melipona, mas também a densidade de árvores com tamanhos maiores (dado não disponível em Martins et al. 2004) e, principalmente, com ocos disponíveis, pois espécies distintas de árvores variam em relação à formação de cavidades no seu interior (Lorenzi, 1998). 


\subsubsection{Apis mellifera: abundância igual à das espécies de meliponíneos que nidificam em árvores}

Quanto aos ninhos de Apis mellifera, registrou-se apenas um em toda a área de amostragem de estudo $(0,24$ ninhos/ha), e que foi recentemente extinto. Além disso, outros três ninhos dessa espécie foram registrados fora da área de amostragem: um em região de trilha (extinto recentemente) e dois localizados no limite da mata com a área aberta do Parque (um deles estava em uma palmeira que caiu e foi recentemente extinto). Esses resultados parecem indicar que a abundância e a densidade de ninhos de Apis mellifera são iguais às das demais espécies de meliponíneos que apresentam as seguintes características: tamanho médio a grande porte (Scaptotrigona bipunctata, Trigona braueri, Trigona spinipes) e agressividade/competividade (Scaptotrigona bipunctata, e Trigona spinipes). Todas essas espécies apresentaram 1 ninho cada, 0,24 ninho/ha. Há relatos na literatura de que a fragmentação florestal pode facilitar a substituição das abelhas nativas por espécies exóticas, como Apis mellifera (Aizen \& Feinsinger, 1994). Há indícios de que essa espécie não se adapta muito bem a ambientes florestados úmidos, devido, principalmente, à pluviosidade. Oliveira \& Cunha (2005) verificaram que nenhuma operária de abelha africanizada foi vista visitando iscas de alimento no interior dos fragmentos da Floresta Amazônica, apenas em áreas desmatadas e capoeiras próximas. Em ambientes urbanos, Mello et al. (2003) encontraram correlação negativa entre as atividades das campeiras de abelhas africanizadas e seus processos de enxameagem e a umidade relativa do ar e pluviosidade. 


\subsection{Posicionamento geográfico da entrada dos ninhos e direção dos ventos}

Apesar de haver diferenças significativas em nossos resultados (teste $\chi^{2}=18$, $\mathrm{GL}=7, \mathrm{p}=0,012$ ), a preferência dos meliponíneos por um posicionamento geográfico das entradas de seus ninhos não pode ser considerada devido ao pequeno número de ninhos localizados em árvores $(n=8)$. Podemos apenas supor que há uma tendência para os ninhos de meliponíneos se orientarem preferencialmente para o sentido noroeste (NW) e leste (L) (Fig. 17). Dados da Estação Metereológica IAG/USP (2012), instalada dentro do próprio $\mathrm{PEFI}$, indicam que, em média, os ventos sopram predominantemente do sudeste (SE), além de SSE e ESE, representando $38 \%$ das direções (Fig. 18). Nenhum dos ninhos desse estudo apresentou suas entradas situadas em direção SE, SSE e ESSE. Em um estudo realizado em área aberta no PEFI (Sousa \& Kleinert, 2010), não houve diferença significativa (teste $x 2=5,5455$, $p=0,593)$ entre os posicionamentos geográficos das entradas de 33 ninhos de cavidades, apesar de $52 \%$ das entradas de ninhos orientarem-se em direção às coordenadas noroeste-norte-nordeste, contra $33 \%$ das entradas orientadas para as direções opostas sudoeste-sul-sudeste (Fig. 20). A escolha preferencial por uma determinada direção também não foi confirmada em outros estudos (Taura \& Laroca, 1991; Freitas, 2001; Pereira, 2004). Uma das possíveis explicações é que os meliponíneos ocupam as cavidades disponíveis, priorizando sua necessidade mais essencial que é a obtenção de um abrigo. Entretanto, Silva (2008) também indicou haver uma tendência das espécies de meliponíneos encontradas em sua área de estudo dirigirem suas entradas para os sentidos sudoeste (SW) e leste (E), evitando os 
sentidos norte $(\mathrm{N})$ e o nordeste $(\mathrm{NE})$ (sentido em que os ventos sopravam na sua área de estudo).

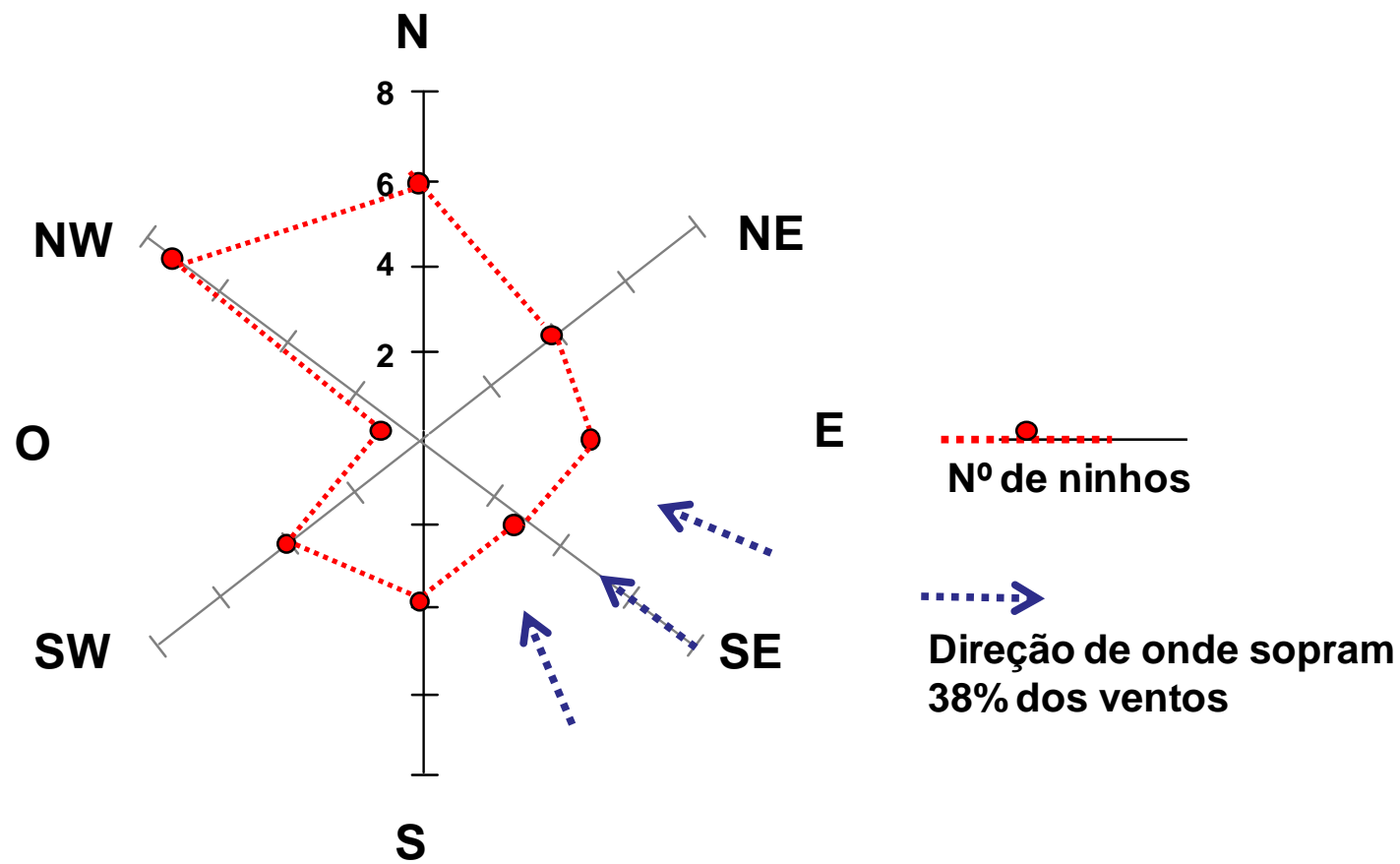

Figura 20. Número de ninhos de meliponíneos $(n=33)$ encontrados em área aberta do PEFI, plotados conforme o sentido de exposição de suas entradas.

Fonte: adaptado de Sousa \& Kleinert (2010).

\subsection{Considerações finais}

Espécies que apresentam ninhos com grande número de indivíduos, além de serem mais agressivas, tendem a ter um número menor de ninhos, ou seja, densidades menores (Knoll et al., 1993), como acontece com Trigona spinipes e Scaptotrigona bipunctata, espécies encontradas no PEFI. Essas equivalem, em termos competitivos, às espécies com populações pequenas e grande número de ninhos (densidade alta), ou seja, há um equilíbrio na partição de recursos. Trigona spinipes, espécie com indivíduos de tamanho médio $(7 \mathrm{~mm})$, apresenta uma população muito grande, que pode chegar a 
dezenas de milhares indivíduos, são agressivas, apresentam territorialidade e seus ninhos apresentam distribuição uniforme (Souza et al., 1993). Scaptotrigona sp., dentre elas S. bipunctata, apresenta hábitos e aspectos semelhantes aos de Trigona spinipes: são agressivas, apresentam tamanho individual médio $(6 \mathrm{~mm})$ e também podem apresentar uma população moderadamente grande, podendo ter até cerca de 10.000 indivíduos (Souza et al., 1993; Kleinert, 2006). Paratrigona subnuda e Tetragonisca angustula (grande abundância na área aberta do PEFI e maior número de ninhos fora da área de amostragem), diferentemente dessas outras espécies, têm tamanho pequeno, $4,0 \mathrm{~mm}$ e $5,5 \mathrm{~mm}$, respectivamente, e não apresentam uma grande população nidal (Souza et al., 1993; Mouga, 1984). A grande abundância de ninhos de Paratrigona subnuda no PEFI não é motivo de exclusão de outras espécies, pois essas abelhas não competem pelo mesmo substrato de nidificação e não são agressivas (Knoll et al., 1993). O registro de uma grande quantidade de ninhos de Tetragonisca angustula, encontrados em uma área urbana, por Fierro et al. (2012), levou esses autores a apontarem que essa população não estava submetida à uma forte competição por recursos, devido, provavelmente, à uma grande oferta de recursos alimentares. O mesmo parece ocorrer na área aberta do PEFI, tanto para Tetragonisca angustula, quanto para Paratrigona subnuda, e, para esta última, também nas áreas de mata desse estudo.

O PEFI encontra-se isolado e afastado de qualquer outro fragmento de vegetação (25 km ao norte - Parque da Cantareira; $16 \mathrm{~km}$ ao sul - Serra do Mar), além de não haver corredor ecológico conectando-o com outras áreas verdes e parques. Isso restringe a dispersão das espécies de meliponíneos, bem como diminui uma potencial 
colonização por outras novas (Araujo et al., 2004). A extinção local de uma espécie fará com que sua taxa de recolonização seja muito baixa, ou até mesmo nula. Araujo et al. (2004) mostraram que a distância máxima de vôo para os meliponíneos pequenos não passa de $1.000 \mathrm{~m}$. Por exemplo, Plebeia droryana, Trigona spinipes e Tetragonisca angustula, espécies já registradas no PEFI, atingiriam, no máximo, uma distância de 540, 840 e 951 m, respectivamente. Abelhas do gênero Melipona, por apresentarem um tamanho maior, podem atingir distâncias em torno de 2.000 m (Roubik \& Aluja, 1983 ; Araujo et al., 2004; Kuhn-Neto et al., 2009), mesmo assim sendo inviável e improvável sua dispersão de outras áreas verdes para o PEFI. Abelhas do gênero Melipona necessitariam de grandes fragmentos para persistirem, pois além da falta de oferta de cavidades adequadas em pequenos fragmentos e/ou degradados, os efeitos da homozigose poderiam levar à sua extinção. Kerr \& Vencovsky (1982) estimaram que populações inferiores a 20 colônias levariam à eliminação total de colônias de Melipona quadrifasciata, ressaltando que apenas um número superior a 44 colônias evitaria esse problema. Entretanto, Nogueira-Neto (2000) argumenta que, em muitos casos, é viável a expansão de populações pequenas de meliponíneos, desde que haja condições adequadas para isso, tais como oferta de recursos e cavidades disponíveis.

Pequenas populações de meliponíneos, apesar de correrem risco maior de serem eliminadas pela ação de predadores e por condições ambientais desfavoráveis, podem sobreviver, sem maiores problemas (Nogueira-Neto, 2000). As espécies persistem em fragmentos pequenos e isolados devido à influência de outros fatores, tais como a abundância de recursos alimentares e a oferta de cavidades adequadas (Araujo et al., 2004), o que acreditamos ser o que ocorre para as registradas no PEFI, 
em especial, Paratrigona subnuda. A pressão urbana, a destruição dos ninhos, a fragilidade e a extrema exposição dos ninhos aéreos, podem dificultar a expansão de várias espécies em direção a outros fragmentos distantes. A manutenção das populações de meliponíneos em áreas fragmentadas depende da capacidade das espécies em transitar entre os fragmentos da vegetação. Porém, não se pode considerar apenas a distância das colônias em relação aos recursos florais, mas também a distância em relação a novos sítios de nidificação. O processo peculiar de enxameagem dos meliponíneos implica em um contato por até vários meses (dependendo da espécie) entre colônia mãe e filha, limitando o número de locais passíveis de serem colonizados (Michener, 1979; Roubik, 1989; Nogueira-Neto, 1997).

Kleinert (2006) verificou que os valores de densidade e número de ninhos, além da riqueza de espécies, foram maiores nos ambientes de áreas abertas e modificadas, quando comparados com aqueles de ambientes florestados. A área aberta do PEFI apresentou maiores valores de densidade, número de ninhos e riqueza de espécies (10,51 ninhos/ha; $n=72$ ninhos; $n=7$ espécies) (Sousa \& Kleinert, 2012) do que os obtidos nesse estudo ( $n=14$ ninhos; 3,33 ninhos/ha; $n=4$ espécies). Em áreas florestadas, por sua vez, devemos considerar que há uma subestimativa da densidade de ninhos devido às dificuldades de sua localização. Além disso, há muitos mais trabalhos em áreas urbanas, o que poderia resultar em um viés na análise de dados (Kleinert, 2006). Os ambientes urbanos acabam oferecendo mais opções de cavidades, que são aproveitadas por algumas espécies (Friesella schrotkyi, Plebeia sp., Tetragonisca angustula). A disponibilidade de cavidades não acaba sendo um recurso limitante para elas, mas sim os recursos florais. Porém, conforme a localização das 
áreas abertas/urbanizadas, a oferta do alimento pode ser compensada pelas floradas de matas próximas, como pelos recursos oferecidos pelos jardins. Do mesmo modo, a área de vegetação do PEFI é adjacente a reflorestamentos de eucaliptos, dentro do próprio parque, e próxima a outras fontes adicionais de alimento: o Instituto Jardim Botânico (seus jardins) e a área da Fundação Parque Zoológico.

Dessa forma, os principais fatores limitantes na área estudada do PEFI para a presença de outras espécies e para uma maior abundância das espécies encontradas, em especial daquelas que nidificam em árvores, são a baixa densidade de árvores com CAPs maiores, associada, provavelmente, à baixa oferta de ocos e ao fato dessa área ser um fragmento isolado.

\section{Desdobramentos atuais e futuros desse estudo: sua ampliação e relação com a educação ambiental}

O PEFI, apesar de ser um importante fragmento isolado de mata secundária na cidade de São Paulo, é praticamente desprovido de pesquisas relacionadas à sua fauna, incluindo artrópodes (Lopes \& Bicudo, 2002). A partir desse trabalho, pretendemos, futuramente, relacionar as espécies encontradas nesse fragmento/ilha com espécies presentes em outras manchas e áreas de preservação da grande São Paulo. Essas áreas, situadas a quilômetros de distância do PEFI, são: o Parque Estadual da Serra da Cantareira, ao norte, $25 \mathrm{~km}$; as matas da região da Serra do Mar e da Represa Billings, ao sul, cerca de $16 \mathrm{~km}$; outros possíveis parques urbanos da cidade de São Paulo. Outro ponto a ser destacado, é que os resultados desse trabalho 
fornecem importantes dados e subsídios para os trabalhos realizados na área de educação ambiental em algumas unidades desse parque setorial, como o Parque de Ciência e Tecnologia da USP (Parque Cientec) e Instituto Jardim Botânico. Já realizamos palestras e atividades educativas ambientais com os funcionários dessas unidades, além de termos atingindo um público externo, os visitantes. Ecoamos os dizeres de Nogueira-Neto (2000), sobre a importância da preservação do maior número possível de pequenos fragmentos florestais isolados, pois estes permitem a manutenção de muitas espécies na ausência de maiores estresses. 


\section{CONCLUSÕES}

- As áreas em estágio secundário tardio (ST) apresentaram condições mais propícias para a nidificação de meliponíneos, mostrando uma densidade maior de ninhos, quando comparadas às áreas de estágio secundário inicial (SI).

- Ao contrário do que esperávamos, a maior abundância de ninhos subterrâneos de meliponíneos ocorreu em áreas ST, ao invés de áreas SI. A fitofisionomia das áreas ST do PEFI proporcionou não apenas uma maior oferta de substratos em árvores, mas também uma maior oferta de cavidades subterrâneas disponíveis.

- Devido aos poucos ninhos encontrados em áreas SI, não podemos afirmar que há um predomínio de espécies que fazem ninhos subterrâneos (ninhos de árvores=01; ninhos subterrâneos=02 em SI).

- Considerando os valores de densidade de ninhos encontrados em toda a área de estudo (3,33 ninhos/ha), e nas áreas ST (5,24 ninhos/ha), esse estudo mostra valores superiores à média de densidade de ninhos (entre 0,89 e 2,22 ninhos/ha) encontrada em um trabalho de revisão sobre levantamentos de ninhos de meliponíneos, em biomas neotropicais (Kleinert, 2006).

- Não foram encontrados ninhos de espécies do gênero Melipona, refutando assim uma de nossas hipóteses, que previa o encontro de ninhos de espécies desse gênero em áreas de estágio secundário tardio.

- As médias dos valores de CAP das árvores estão bem abaixo daqueles utilizados pelas espécies de Melipona, na maior parte dos biomas estudados, o que pode explicar, em parte, a ausência de ninhos de espécies desse gênero. 
- A grande abundância de ninhos de Paratrigona subnuda, que nidifica em cavidades subterrâneas, no PEFI, não é motivo de exclusão de outras espécies, pois essas abelhas não competem pelo mesmo substrato de nidificação e não são agressivas.

- Constatamos que a abundância e a densidade de Apis mellifera é igual à das demais espécies de meliponíneos que nidificam em árvores e que apresentam as seguintes características: tamanho individual médio (Scaptotrigona bipunctata, Trigona braueri, Trigona spinipes) e agressividade/competividade (Scaptotrigona bipunctata, e Trigona spinipes).

- Os dois ninhos de Trigona braueri, encontrados no PEFI, representam o primeiro registro dessa espécie no estado de São Paulo. Ressalta-se com isso a importância de estudos em pequenos fragmentos florestais, que atuam como locais para a manutenção de muitas espécies de meliponíneos, muitas delas ainda não registradas em estudos já realizados.

- Provavelmente, os principais fatores limitantes no PEFI para a presença de outras espécies, e para uma maior abundância das espécies encontradas, em especial daquelas que nidificam em árvores, como as do gênero Melipona, são a baixa densidade de árvores com CAPs maiores, associada, provavelmente, à baixa oferta de ocos e ao fato dessa área ser um fragmento isolado. 


\section{REFERÊNCIAS BIBLIOGRÁFICAS}

AGUIAR, O.T. 2003. Comparação entre os métodos de quadrantes e parcelas na caracterização da composição florística e fitossociológica de um trecho de floresta ombrófila densa no Parque Estadual "Carlos Botelho"- São Miguel Arcanjo, São Paulo. USP. Dissertação (Mestrado). Piracicaba. 120 p.

AIZEN, M.A. \& FEINSINGER, P. 1994. Habitat fragmentation, native insect pollinators, and feral honey-bees in Argentine Chaco Serrano. Ecological Applications 4: 378392.

ANDENA,S.R.; BEGO, L.R. \& MECHI, M.R. 2005. A Comunidade de abelhas (Hymenoptera, Apoidea) de uma área de cerrado (Corumbataí, SP) e suas visitas às flores. Juiz de Fora, Revista brasileira Zoociências 7 (1): 55-91.

ANDERSSON, E.; BARTHEL, S. \& AHRNE. K. 2007. Measuring Social Ecological Dynamics Behind the Generation of Ecosystem Services. Ecological Applications 17(5): 1267-1278.

ANTONINI, Y. 2002. Efeitos de variáveis ecológicas na ocorrência de Melipona quadrifasciata (Apidae: Meliponini) em fragmentos urbanos e rurais. UFMG.Tese (Doutorado). Belo Horizonte.

ANTONINI, Y. \& MARTINS, R.P. 2003. The value of a tree species (Caryocar brasiliense) for stingless bee Melipona quadrifasciata quadrifasciata. Journal of Insect Conservation 3: 164-167.

ARAÚJO, E. D.; COSTA, M.; CHAUD-NETTO, J. \& FOWLER, H. G. 2004. Body side and flight distance in stingless bees (Hymenoptera: Meliponini): interference of flight range and possible ecological implication. Brazilian Journal of Biology 64(3B): 563-568.

BARBOSA, L.M.; POTOMATI, A. \& PECCININI, A.A. 2002. O PEFI: histórico e legislação. p.15-28. In: Parque Estadual das Fontes do Ipiranga (PEFI): Unidade de Conservação que resiste a Urbanização de São Paulo. Editora Imprensa Oficial do Estado de São Paulo.

BARBOSA, M.M. 2013. Ecologia de nidificação e diversidade genética de Melipona subnitida em uma área do Parque Nacional dos Lençóis Maranhenses. Dissertação (Mestrado) - Universidade Federal do Maranhão, Programa de PósGraduação em Biodiversidade e Conservação. 56p.

BATISTA, M.A.; RAMALHO, M. \& SOARES, A.E.E. 2003. Nesting sites and abundances of Meliponini (Hymenoptera: Apidade) in heterogeneous habitats of the Atlantic Rain Forest, Bahia, Brazil. Lundiana 4(1): 19-23. 
BANASZAK, J. 1996. Ecological bases of conservation of wild bees. In: MATHESON, A.; BUCHMANN, S. L.; O'TOOLE, C. ET AL (Ed). The conservation of bees. London: Academic Press. 254p.

BROWN J.C. \& ALBRECHT C. 2001. The effect of tropical deforestation on stingless bees of the genus Melipona (Insecta: Hymenoptera: Apidae: Meliponini) in central Rondonia, Brazil. Journal of Biogeography 28: 623-634.

CAMARGO, J. M. F \& PEDRO, S. R. M. 2013. Trigona braueri . In: Moure, J. S., Urban, D. \& Melo, G. A. R. (Orgs). Catalogue of Bees (Hymenoptera, Apoidea) in the Neotropical Region - online version. http://www.moure.cria.org.br/catalogue/catalogue?id=34818 Acessado em 21 de junho de 2013

CANE, J.H. 2001. Habitat fragmentation and native bees: a premature veredict? Conservation Ecology 5(1): 3. [online] URL: http://www.consecol.org/vol5/iss1/art3/ Acessado em 10 de maio de 2011.

CAPOBIANCO, J P R (org.). 2004. Quem faz o que pela Mata Atlântica - 1990-2000: Projeto Avaliação dos Esforços de Conservação, Recuperação e Uso Sustentável dos Recursos Naturais da Mata Atlântica. São Paulo: Instituto Socioambiental. $64 \mathrm{p}$.

CARVALHO, C.A.L. \& MARCHINI, L.C. 1999. Abundância de ninhos de Meliponinae (Hymenoptera: Apidae) em biótopo urbano no município de Piracicaba-SP. Revista de Agricultura 74 (1): 35-44.

CASTRO, M.S. 2001. A comunidade de abelhas (Hymenoptera, Apoidea) de uma área

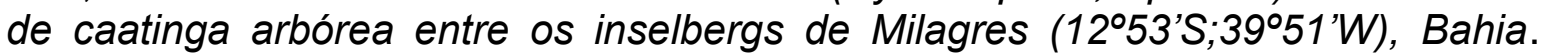
USP. Tese (Doutorado). São Paulo. 191p.

CORTOPASSI-LAURINO \& M. NOGUEIRA-NETO, P. 2003. Notas sobre a bionomia de Tetragonisca weyrauchi SCHWARZ, 1943 (APIDAE, MELIPONINI). Acta Amazonica 33(4): 643-650.

CORTOPASSI-LAURINO, M.; IMPERATRIZ-FONSECA, V.L.; ROUBIK, D.W.; DOLLIN, A.; HEARD, T.; AGUILAR, I.; VENTURIERI, G.C.; EARDLEY, C. \& NOGUEIRANETO, P. 2006. Global meliponiculture: challenges and opportunities. Apidologie 37: 275-292.

COSTA, M. A.; DEL LAMA, M. A.; MELO, G. A. R. \& SHEPPARD, W. S. 2003. Molecular phylogeny of the stingless bees (Apidae, Apinae, Meliponini) inferred from mitochondrial 16S rDNA sequences. Apidologie 34: 73-84.

ELTZ, T.; BRUHL, C.A.; KAARS, S. VAN DER \& LINSENMAIR; K.E. 2002. Determinants of stingless bee nest density in lowland dipterocarp forests of Sabah, 
Malaysia. Oecologia 131: 27-34.

ELTZ, T.; BRÜHL, C. A.; IMIYABIR, Z. \& LINSENMAIR, K. E. 2003. Nesting and nest trees of stingless bees (Apidae: Meliponini) in lowland dipterocarp forests in Sabah, Malaysia, with implications for forest management. Forest Ecology and Management 172: 301-313.

FERNANDES, A.J; REIS, L.A.M \& CARVALHO, A. 2002. Caracterização do Meio Físico. p. 49-62. In: Parque Estadual das Fontes do Ipiranga (PEFI): Unidade de Conservação que resiste a Urbanização de São Paulo. Editora Imprensa Oficial do Estado de São Paulo.

FIERRO, M.M.; CRUZ-LÓPEZ, L.; SÁNCHES, D.; VILLANUEVA-GUTIÉRREZ, R. \& VANDAME, R. 2012. Effect of Biotic Factors on the Spatial Distribution of Stingless Bees (Hymenoptera: Apidae, Meliponini) in Fragmented Neotropical Habitats. Neotropical Entomology 41: 95-104.

FIGUEIREDO-MECCA, G..; BEGO, L.R. \& NASCIMENTO, F.S. 2013. Foraging behavior of Scaptotrigona depilis (Hymenoptera, Apidae, Meliponini) and its relationship with temporal and abiotic factors. Sociobiology 60(3): 277-282.

FREITAS, G. S. 2001 Levantamento de ninhos de meliponíneos (Hymenoptera, Apidae) em área urbana: Campus da USP, Ribeirão Preto/SP. Ribeirão Preto, USP. Dissertação (Mestrado). Faculdade de Filosofia, Ciências e Letras, Ribeirão Preto. $84 p$.

GALINDO-LEAL, C \& CÂMARA, I. G. 2005. Status do hotspot Mata Atlântica: uma síntese. In: GALINDO-LEAL, C \& CÂMARA, I. G. (orgs.). Mata Atlântica: biodiversidade, ameaças e perspectivas. São Paulo: Fundação SOS Mata Atlântica. Belo Horizonte: Conservação Internacional.

GOMES, J.P.; IANNUZZI, L.; LEAL \& I.R. 2010. Resposta da Comunidade de Formigas aos Atributos dos Fragmentos e da Vegetação em uma Paisagem da Floresta Atlântica Nordestina. Neotropical Entomology 39(6): 898-905.

HAMMER, O.; HARPER, D.A.T. \& Ryan, P.D. 2001. PAST: Paleontological Statistics software package for education and data analysis. Palaeontologia Electronica 4(1): $9 \mathrm{p}$.

HEARD, T. 1999. The role of stingless bees in crop pollination. Annual Review Entomology 44: 183-206.

HILÁRIO, S.D.; RIBEIRO, M.F. \& IMPERATRIZ-FONSECA, V.L. 2007a. Efeito do vento sobre a atividade de vôo de Plebeia remota (Holmberg, 1903) (Apidae, Meliponini). Biota Neotropica 7 (3): 225-232. 
HILÁRIO, S.D.; RIBEIRO, M.F. \& IMPERATRIZ-FONSECA, V.L. 2007b. Impacto da precipitação pluviométrica sobre a atividade de vôo de Plebeia remota (Holmberg, 1903) (Apidae, Meliponini). Biota Neotropica $7 \quad$ (3). http://www.biotaneotropica.org.br/v7n3/pt/abstract?article+bn02307032007

HUBBELL, S.P. \& JOHNSON, L.K. 1977. Competition and nest spacing in a tropical stingless bee community. Ecology 58: 949-963.

IAG/USP. 2012. Boletim Climatológico Anual da Estação Meteorológica do IAG/USP/ Seção Técnica do Serviço Meteorológico - Instituto de Astronomia, Geofísica e Ciências Atmosféricas da Universidade de São Paulo - v 16, 2012 - São Paulo: IAG/USP. 63p.

IMPERATRIZ-FONSECA, V. L. ; SOUZA, S. C. F. 1972 . Subterranean nest structure of stingless bee (Paratrigona subnuda Moure) (Meliponinae, Apidae, Hymenoptera). Ciência e Cultura (SBPC), v. 24, n.7, p. 662-666

IMPERATRIZ-FONSECA, V.L. \& KLEINERT, A.M.P. 1998. Worker reproduction in the Stingless Bee Species Friesella schrottkyi (Hymenoptera, Apidae, Meliponini). Entomol Gen 23 (3): 169-175.

INOUE, T.; NAKAMURA, K.; SALMAH, S. \& ABBAS, I. 1993. Population dynamics of animals in unpredictably-changing tropical environments. Journal of Biosciences. Vol. 18 (4): 425-455

IWAMA, S. 1977. A influência dos fatores climáticos na atividade externa de Tetragonisca angustila (Apidae, Meliponinae). Boletim Zoologia, Univ. S. Paulo, 2: 189-201.

KAJOBE, R. \& ROUBIK, D. W. 2006. Honey-making bee colony abundance and predation by apes and humans in a Uganda forest reserve. Biotropica 38(2): 210218.

KERR, W.E.; SAKAGAMI, S.F.; ZUCCHI, R.; PORTUGAL ARAÚJO, V. \& CAMARGO, J.M.F. 1967. Observações sobre a arquitetura dos ninhos e comportamento de algumas espécies de abelhas sem ferrão das vizinhanças de Manaus, Amazonas (Hymenoptera, Apoidea). Atas do simpósio sobre a biota Amazônica 5: 255-309.

KERR, W. E. \& VENCOVSKY, R., 1982, Melhoramento genético em abelhas. Efeito do número de colônias sobre o melhoramento. Brazilian Journal of Genetics 2: 279285.

KLEINERT, A.M.P. 2006. Demografia de ninhos de meliponíneos em biomas neotropicais. USP. Tese (Livre Docência). Instituto de Biociências. 93 p. 
KNOLL, F.R.N.; BEGO, L.R. \& IMPERATRIZ-FONSECA, V.L. 1993. As abelhas em áreas urbanas - Um estudo no Campus da Universidade de São Paulo. p.31-42. In: Flores e Abelhas em São Paulo. Pirani, J.R. \& Cortopassi-Laurino, M. (coord.) São Paulo: Edusp/FAPESP.

KUHN-NETO, B., CONTRERA, F.A.L., CASTRO, M.S., NIEH, J.C., 2009. Long distance foraging and recruitment by a stingless bee, Melipona mandacaia. Apidologie 40: 472-480.

LEAL, I.R. \& LOPES, B.C. 1992. Estrutura das comunidades de formigas (Hymenoptera: formicidae) de solo e vegetação no Morro da Lagoa da Conceição, Ilha de Santa Catariana, SC. Biotemas 5(1): 107-122.

LOPES, I.M.S.; BICUDO, C.E.M. 2002. Publicações no PEFI. In: Parque Estadual das Fontes do Ipiranga (PEFI): Unidade de Conservação que resiste a Urbanização de São Paulo. Editora Imprensa Oficial do Estado de São Paulo. p.319-351.

LOPES, L.A. 2012. Abelhas sem ferrão em fragmentos preservados de floresta com Araucária em Cambará do Sul, RS, com ênfase em Melipona bicolor schencki. USP. Tese (Doutorado). FFLCH-RP. Ribeirão Preto. 107 p.

LORENZI, H. 1998. Árvores Brasileiras. Vol.2. Editora Plantarum, Nova Odessa-SP, $368 \mathrm{p}$.

MANTOVANI, M.S.M \& MASSAMBANI, O. 2004. Ciência e Tecnologia no Parque. São Paulo, Edusp. 136 p.

MARTINS, C.F.; CORTOPASSI-LAURINO, M.; KOEDAM, D. \& IMPERATRIZFONSECA, V.L. 2004. Espécies arbóreas utilizadas para nidificação por abelhas sem ferrão na caatinga (Seridó, PB; João Câmara, RN). Biota Neotropica 4 (2): 8p. Disponível em:

http://www.biotaneotropica.org.br/v4n2/pt/abstract?article+BN0010402204

MELLO, M.H.S.H.; SILVA, E.A. \& NATAL, D. 2003. Abelhas africanizadas em área metropolitana do Brasil: abrigos e influências climáticas. Revista Saúde Pública 37(2): 237-241.

MICHENER, C. D. 1979. Biogeography of bees. Annals of the Missouri Botanical Garden 66(3): 277-347.

MICHENER, C. D. 2000. The bees of the World. John Hopkins University Press, Baltimore. 913p.

MOUGA, D.M.D.S. 1984. Atividade de coleta de Paratrigona subnuda (Moure) (Apidae, Meliponinae). São Paulo. USP. Dissertação (Mestrado). Instituto de Biociências, Departamento de Zoologia. 117p. 
MOUGA, D.M.D.S. 2004. As comunidades de abelhas (Hymenoptera, Apoidea) em Mata Atlântica na região nordeste do estado de Santa Catarina, Brasil. São Paulo. USP. Tese (Doutorado). Instituto de Biociências. Departamento de Zoologia. 253p.

NOGUEIRA-NETO, P.; IMPERATRIZ-FONSECA, V. L.; KLEINERT-GIOVANNINI, A.; VIANA B.F. \& CASTRO, M. S. 1986. Biologia e manejo das abelhas sem ferrão. São Paulo, SP, Editora Tecnapis. 54 p.

NOGUEIRA-NETO, P. 1997. Vida e criação de abelhas indígenas sem ferrão. Editora Nogueirapis. 446p.

NOGUEIRA-NETO, P. 2000. Uma conversa sobre fragmentos florestais, pequenas populações e abelhas indígenas. IV Encontro sobre Abelhas. Anais. Ed. M.M.G. Bitondi, K. Hartfelder et al. Ribeirão Preto. p.27-34.

OLIVEIRA M.L., MORATO E.F. \& GARCIA, M.V.B. 1995. Diversidade de espécies e densidade de ninhos de abelhas sociais sem ferrão (Hymenoptera, Apidae, Meliponinae) em floresta de terra firma na Amazônia central. Revista Brasileira de Biologia 12: 13-24.

OLIVEIRA, M.L. \& CUNHA, J.A. 2005. Abelhas africanizadas Apis mellifera scutellata Lepeletier, 1836 (Hymenoptera: Apidae: Apinae) exploram recursos na floresta amazônica?. Acta Amazonica 35(3): 389 - 394.

OLIVEIRA, R.C.; MENEZES, C.; SOARES, A.E.E. \& IMPERATRIZ-FONSECA, V.L. 2012. Trap-nests for stingless bees (Hymenoptera, Meliponini). Apidologie 44(1): 29-37.

PEDRO, S.R.M. \& CAMARGO, J.M.F. 1999. Apoidea apiformes, p. 193 - 211. In: C. R. F BRANDÃO \& E. M. CANELLO (Eds.). Biodiversidade do Estado de São Paulo: síntese do conhecimento ao final do século XX, Invertebrados terrestres - São Paulo, FAPESP, vol 5.

PECCININI, A.A. 2000. Caracterização de fragmentos de Mata Atlântico no Parque Estadual das Fontes do Ipiranga - PEFI: subsidios para a Conservação Ecológica. USP. Dissertação (Mestrado). Instituto de Biociências, Dep. Ecologia. 114 p.

PEREIRA, U.C.R. 2004. Ninhos de Meliponinae (Hymenoptera, Apidae) do Parque Municipal do Bacaba, Nova Xavantina - MT. Trabalho de Conclusão de Curso. Universidade do Estado do Mato Grosso, Campus de Nova Xavantina. 40 p.

PIELOU, E.C. 1977. Mathematical ecology. $2^{\text {nd }}$ ed. New York, Willey-Interscience publication, John Wiley and Sons. 385 p. 
PINHEIRO-MACHADO, C.A. \& KLEINERT, A.M.P. 1993. Abundância relativa e distribuição de ninhos de meliponíneos (Apidae, Meliponinae) numa área urbana

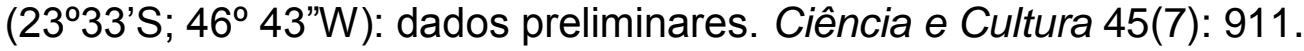

PIOKER-HARA, F.C. 2011. Determinantes da densidade e distribuição de ninhos e diversidade de espécies de meliponíneos (Apidade, Meliponini) em áreas de cerrado e Itirapina, SP. Tese (Doutorado). Instituto de Biociências da Universidade de São Paulo. Departamento de Ecologia. 232 p.

PIVELLO, V.R. \& PECCININI, A.A. 2002. A vegetação do PEFI. In: Parque Estadual das Fontes do Ipiranga (PEFI): Unidade de Conservação que resiste à Urbanização de São Paulo. Editora Imprensa Oficial do Estado de São Paulo. 351 p.

PLANO DE MANEJO DO PARQUE ESTADUAL DAS FONTES DO IPIRANGA (PEFI). 2005. Diagnóstico dos Estudos Socio-econômico-ecológico e legislativo para caracterização, zoneamento e implantação do Plano de Manejo do PEFI e do seu programa de eco-desenvolvimento. São Paulo, Arquivo do Instituto de Botânica.

RÊGO, M. \& BRITO, C. 1996. Abelhas sociais (Apidae: Meliponini) em um ecossistema de cerrado S.L. (Chapadinha - MA, BR): Distribuição dos ninhos. In: Encontro sobre abelhas.. Anais. Ribeirão Preto, SP: 238-247.

ROUBIK, D.W., Aluja, M., 1983. Flight ranges of Melipona and Trigona in tropical forest. Journal of Kansas Entomological Society 56: 217-222.

ROUBIK, D., 1989. Ecology and natural history os tropical bees. Cambridge Tropical Biology series. Cambridge University Press. 514p.

ROUBIK, D.W. 2006. Stingless bee nesting biology. Apidologie 37: 124-143.

SAKAGAMI, S.F. 1982. Stingless bees. In: Herman H.H. (Ed.). Social insects. Academic Press, New York, 3: 361-423p.

SAMEJIMA, H.; MARZUKI, M.; NAGAMITSU, T.\& NAKASHIZUKA, T. 2004. The effects of human disturbance on a stingless bee community in a tropical rainforest. Biological Conservation 120: 577-587.

SANTOS, I. A. 2002. A vida de uma abelha solitária. Ciência Hoje 179, jan. Disponível em: < http://eco.ib.usp.br/beelab/solitarias.htm $/>$.

Acessado em: 10 de maio de 2011.

SANTOS, P.M \& FUNARI, F.L. 2002. Clima local. In: In: Parque Estadual das Fontes do Ipiranga (PEFI): Unidade de Conservação que resiste a Urbanização de São Paulo. Editora Imprensa Oficial do Estado de São Paulo. p.29-48. 
SCHAFFER, W.B. \& PROCHNOW, M. 2002. A Mata Atlântica e você: como preservar, recuperar e se beneficiar da mais ameaçada floresta brasileira. Brasília: APREMAVI, $156 \mathrm{p}$.

SERRA, B.D.V.; DRUMMOND, M.S.; LACERDA, L.M. \& AKATSU, I.P. 2009. Abundância, distribuição espacial de ninhos de abelhas Meliponina (Hymenoptera, Apidae, Apini) e espécies vegetais utilizadas para nidificação em áreas de cerrado do Maranhão. Iheringia 99(1):12-17.

SIQUEIRA, E.N.L; MARTINES, R.B.; NOGUEIRA-FERREIRA, F.H. 2007. Ninhos de abelhas sem ferrão (Hymenoptera, Meliponina) em uma região do Rio Araguari, Araguari-MG. Bioscience Journal 23 (1): 38-44.

SIQUEIRA, E.N.L; BARTELLI, A.R.T.N. \& NOGUEIRA-FERREIRA, F.H. 2012. Diversity and Nesting Substrates of Stingless Bees (Hymenoptera, Meliponina) in a Forest Remnant. Psyche Article ID 370895, 9 pages, 2012. doi:10.1155/2012/370895.

SILVA, D.A.T. 2008. Caracterização da distribuição e riqueza de ninhos de Apini (Hymenoptera, Apidae) Eussociais no contexto de um remanescente de floresta ombrófila mista, Estação Experimental do Canguiri, Pinhais-PR. UFPR. Dissertação (Mestrado). Ciências Agrárias. 101 p.

SILVA, M.D. 2012. Comunidade de abelhas sociais Meliponina (Apidae; Hymenoptera) em fragmentos de ata Atlântica da Reserva Ecológica da Michelin, Ituberá-Bahia. Universidade Federal da Bahia (UFBA). Tese (Doutorado). $190 \mathrm{p}$.

SILVA, M.D.; Ramalho, M. \& Monteiro, D. 2013. Diversity and habitat use by stingless bees (Apidae) in the Brazilian Atlantic Forest. Apidologie 44: 699-707.

SILVEIRA, F. A.; MELO, G.A.R. \& ALMEIDA, E.A.B. 2002. Abelhas Brasileiras Sistemática de Identificação. Belo Horizonte, 253 p.

SOUSA, L.A.; PEREIRA, T.O.; PREZOTO, F. \& FARIA-MUCCI, G.M. 2002. Nest foundation and diversity of Meliponini (Hymenoptera, APIDAE) in na urban area of the municipality of Juiz de Fora, MG, Brazil. Bioscience Journal 18 (2): 59-65.

SOUSA, V. C. \& KLEINERT, A. M. P. 2010. Identificação de ninhos de meliponíneos (Apidae, Meliponini) em área aberta do Parque de Ciência e Tecnologia da USP. In: IX Encontro sobre Abelhas, 2010, Ribeirão Preto. Resumos. IX Encontro sobre Abelhas. Ribeirão Preto: USP/RP. v. 1.

SOUZA, V.C.; CORTOPASSI-LAURINO-M.; SIMÃO-BIANCHINI, R.; PIRANI, J.R.; AZOUBEL, M.L.; GUIBU, L.S. \& GIANNINI, T.C. 1993. Plantas apícolas de São Paulo e arredores. In: Flores e Abelhas em São Paulo. Pirani, J.R. \& CortopassiLaurino, M. (coord.) São Paulo: Edusp/FAPESP, 1993. p.43-67. 
SOUZA, S.G.X.; TEIXEIRA, A.F.R.; NEVES, E.L. \& MELO, A.M.C. 2005. As abelhas sem ferrão (APIDAE: MELIPONINA) residentes no Campus/Federação/Ondina da Universidade Federal da Bahia, Salvador. Candombá - Revista Virtual 1(1): 57-69.

SOUZA, V.C. \& KLEINERT, A.M.P. 2006. Razão sexual em Friesella schrottkyi (Apidae, Meliponini): Uma análise preliminar. Anais. VII Encontro sobre Abelhas. Ribeirão Preto. CDROM.

TAURA, H. M. \& LAROCA, S. 1991. Abelhas altamente sociais (Apidae) de uma área restrita em Curitiba (Brasil): Distribuição dos ninhos e abundância relativa. Acta Biologica Paranaensis 20: 85-101.

TAURA, H.M.; LAROCA, S. 2001. A associação de abelhas silvestres de um biótopo urbano de Curitiba (Brasil), com comparações espaço-temporais: abundância relativa, fenologia, diversidade e exploração de recursos (Hymenoptera, Apoidea). Acta Biológica Paranaensis 30 (n. 1,2,3,4): 35-137.

TEIXEIRA, A. F. R. \& B. F. VIANA. 2005. Distribuição e densidade dos sítios nidificados pelos meliponíneos (Hymenoptera:Apidae) das Dunas do Médio São Francisco, Ibiraba, Barra-Bahia. Revista Nordestina de Zoologia 2 (1): 5-20.

TEIXEIRA, L.V. \& CAMPOS, F.N.M. 2005. Início da atividade de vôo em abelhas sem ferrão (Hymenoptera, Apidae): influência do tamanho da abelha e da temperatura ambiente. Revista brasileira de Zoociências 7 (2): 195-202.

VIANA, V.M.; TABANEZ, A.J. \& BATISTA, L.F. 1997. Dynamics and Restoration of Forest Fragments in the Brazilian Atlantic Moist Forest. In: Laurance, W.F. \& Bierregaard, R.O.(orgs). Tropical Forest Remnants: Ecology, Management and Conservation of Fragmented Communities. University of Chicago Press. $616 \mathrm{p}$.

ZANETTE, L. R. S.; MARTINS, R. P. \& RIBEIRO, S. P. 2005. Effects of urbanization on Neotropical wasp and bee assemblages in a Brazilian metropolis. Landscape and Urban Planning 71: 105-121.

ZAR, J. H. 1999. Biostatistical analysis. 4a ed. New Jersey, Prentice Hall. 663 p.

ZUCCHI, R. \& SAKAGAMI, S.F. 1972. Capacidade termo-reguladora em Trigona spinipes e em algumas outras espécies de abelhas sem ferrão (Hymenoptera, Apidae, Meliponinae). In: Cruz-Landim, C. et al. (Eds). Homenagem a Warwick E Kerr. Rio Claro, SP: 301-309 p. 
Anexo 1

A

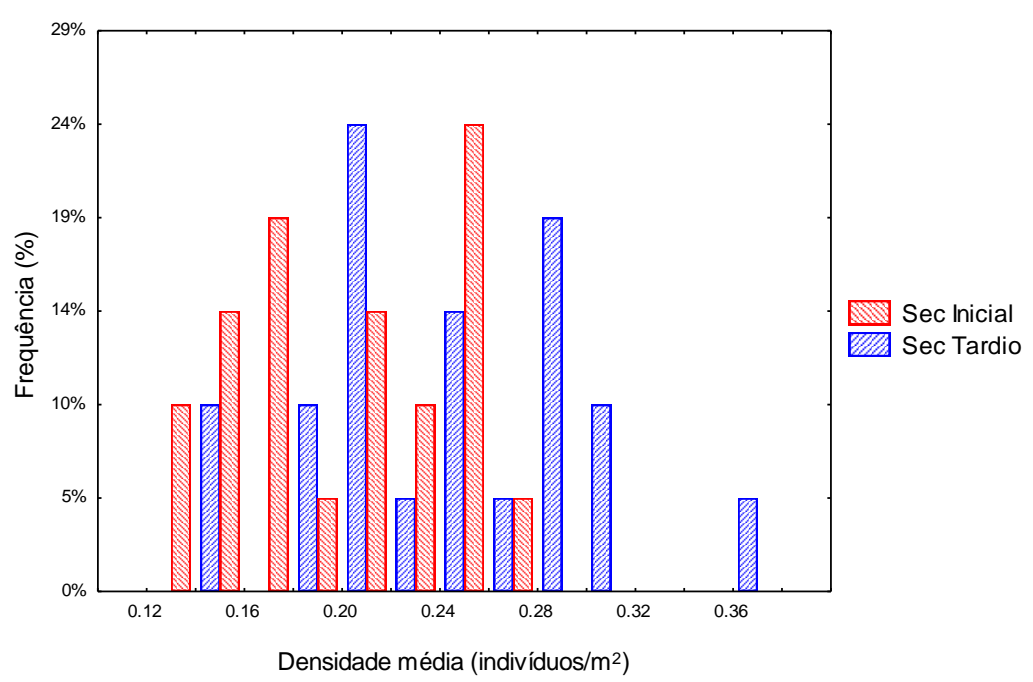

B

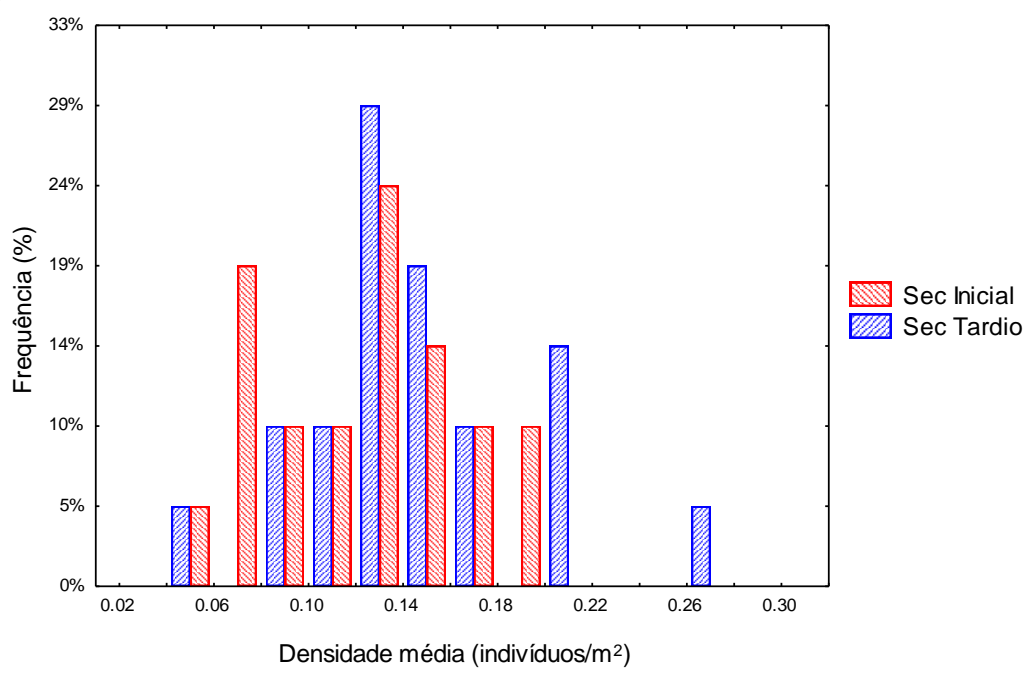

Figura 1. Distribuição das densidades médias de indivíduos arbóreos amostrados nas parcelas em áreas de secundário inicial e secundário tardio com CAP $>15 \mathrm{~cm}(\mathrm{~A}) \mathrm{e}$ com CAP>25 cm (B). 
Anexo 2

A

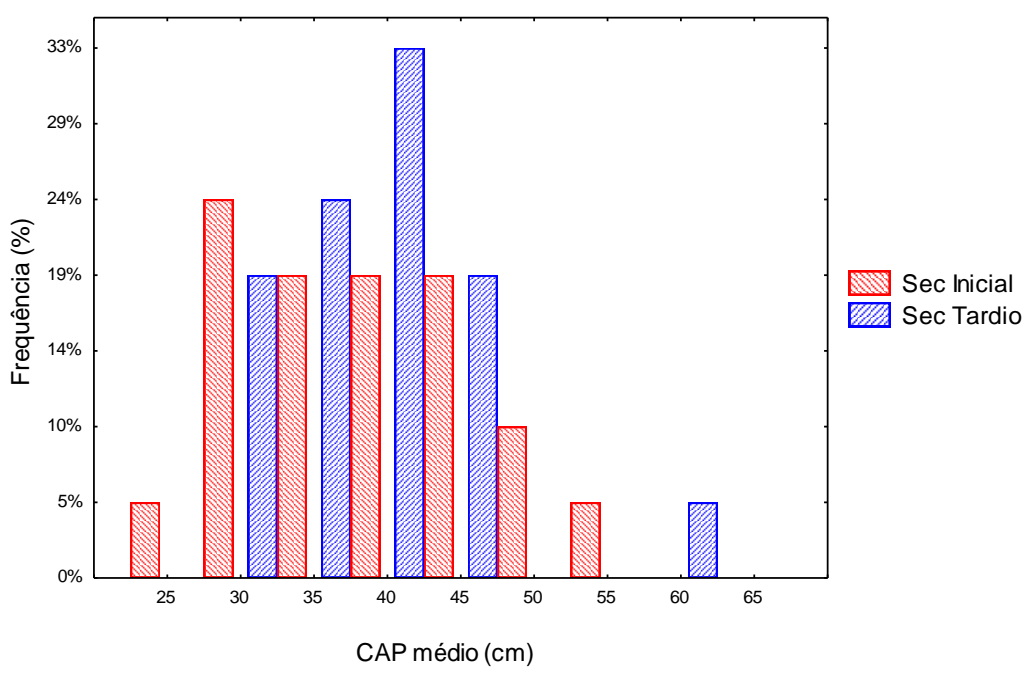

$\mathrm{B}$

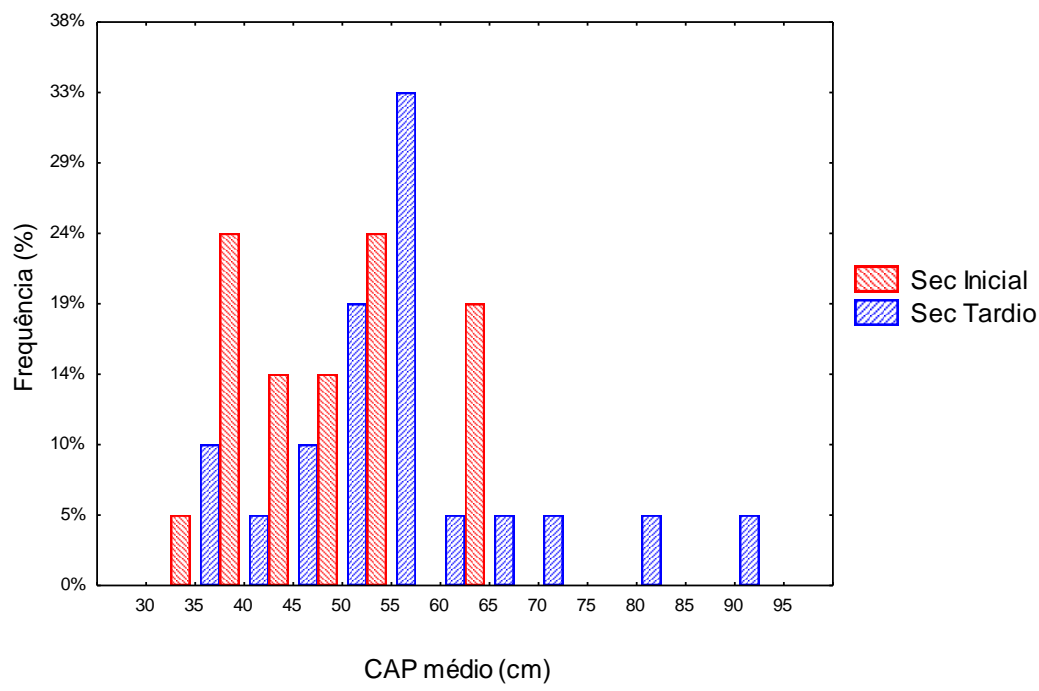

Figura 2 - Distribuição das médias dos CAPs (cm) de indivíduos arbóreos amostrados nas parcelas em áreas de secundário inicial e secundário tardio com CAP >15 cm (A) e com CAP>25 cm (B). 


\section{Anexo 3}
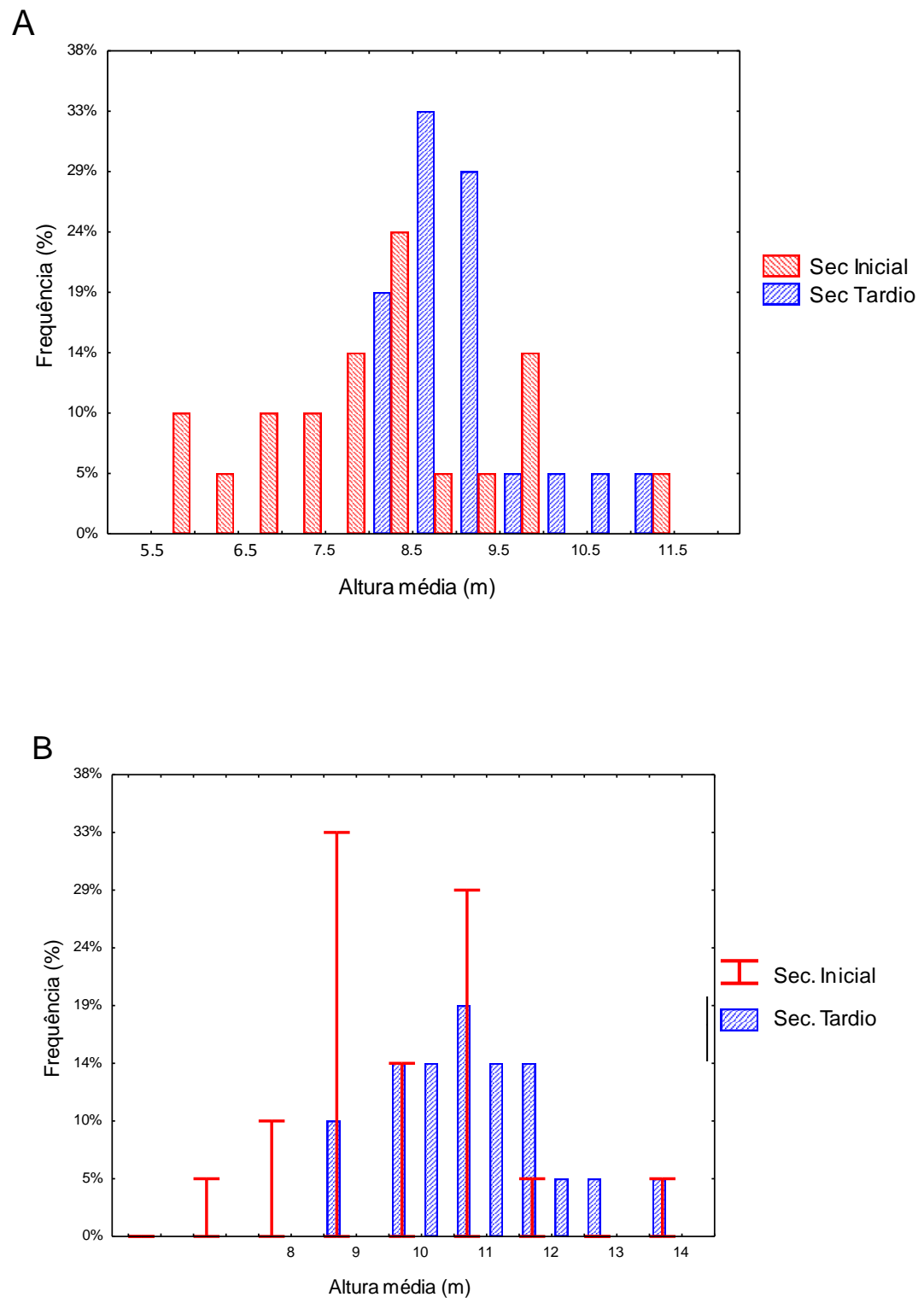

Figura 3. Distribuição das médias da altura $(\mathrm{m})$ de indivíduos arbóreos amostrados nas parcelas em áreas de secundário inicial e secundário tardio com CAP $>15 \mathrm{~cm}(\mathrm{~A}) \mathrm{e}$ com CAP>25 cm (B). 
Anexo 4

Tabela 1. Pontos, coordenadas geográficas e os estágios sucessionais da localização dos ninhos encontrados nas áreas de amostragem do PEFI.

\begin{tabular}{|c|c|c|c|c|}
\hline Ninhos & Pontos & Longitude (X) & Latitude $(\mathrm{Y})$ & Estágio \\
\hline Paratrigona subnuda & $\mathrm{t} 1$ & $46^{\circ} 37^{\prime} 22,2 " W$ & $23^{\circ} 39^{\prime} 09,6^{\prime \prime S}$ & Tardio \\
\hline Paratrigona subnuda & t3 & $46^{\circ} 37^{\prime} 24,4 " \mathrm{~W}$ & $23^{\circ} 39^{\prime} 11,8^{\prime \prime S}$ & Tardio \\
\hline Paratrigona subnuda & t4 & $46^{\circ} 37^{\prime} 18,0^{\prime \prime W}$ & $23^{\circ} 39^{\prime} 16,2 " \mathrm{~S}$ & Tardio \\
\hline Paratrigona subnuda & $\mathrm{t} 5$ & $46^{\circ} 37^{\prime} 23,8^{\prime \prime W}$ & $23^{\circ} 39^{\prime} 25,4^{\prime \prime S}$ & Tardio \\
\hline Paratrigona subnuda & t6 & 463'23,2"W & $23^{\circ} 39 ' 30,9 " S$ & Tardio \\
\hline Paratrigona subnuda & $\mathrm{t} 7$ & $46 \div 37^{\prime} 22,0 " \mathrm{~W}$ & $23^{\circ} 39^{\prime} 30,8 " S$ & Tardio \\
\hline Paratrigona subnuda & $\mathrm{t} 9$ & $46^{\circ} 37^{\prime} 23,7^{\prime \prime W}$ & $23^{\circ} 39^{\prime} 31,7^{\prime \prime S}$ & Tardio \\
\hline Paratrigona subnuda & $\mathrm{t} 10$ & $46^{\circ} 37^{\prime} 21,5^{\prime \prime} \mathrm{W}$ & $23^{\circ} 39^{\prime} 31,7 " S$ & Tardio \\
\hline Paratrigona subnuda & $\mathrm{t} 11$ & $46 \div 37^{\prime} 17,0 " W$ & 23ํ39'22,0"S & Tardio \\
\hline Paratrigona subnuda & i1 & $46^{\circ} 37^{\prime} 52,4 " \mathrm{~W}$ & $23^{\circ} 39^{\prime} 28,8^{\prime \prime S}$ & Inicial \\
\hline Paratrigona subnuda & i3 & $46^{\circ} 37^{\prime} 35,0^{\prime \prime W}$ & $23^{\circ} 39^{\prime} 26,1 " \mathrm{~S}$ & Inicial \\
\hline Scaptotrigona bipunctata & t2 & $46^{\circ} 37^{\prime} 24,2 " W$ & $23^{\circ} 39^{\prime} 11,1 " \mathrm{~S}$ & Tardio \\
\hline Trigona braueri & i2 & $46^{\circ} 37^{\prime} 51,4 " W$ & $23^{\circ} 39^{\prime} 33,2 " S$ & Inicial \\
\hline Trigona spinipes & t8 & $46^{\circ} 37^{\prime} 24,2 " \mathrm{~W}$ & $23^{\circ} 39^{\prime} 31,3^{\prime \prime S}$ & Tardio \\
\hline
\end{tabular}


Anexo 5

Tabela 2. Pontos, coordenadas geográficas e os estágios da localização dos ninhos encontrados fora das áreas de amostragem do PEFI.

\begin{tabular}{|c|c|c|c|c|}
\hline Ninhos & Pontos & Longitude (X) & Latitude (Y) & Estágio \\
\hline Paratrigona subnuda & 07 & $46 \div 37^{\prime} 41,6 " \mathrm{~W}$ & 2339'20,9"S & Degradada* \\
\hline Scaptotrigona bipunctata & 04 & $46^{\circ} 37^{\prime} 26,0^{\prime \prime} \mathrm{W}$ & $23^{\circ} 39^{\prime} 16,4^{\prime \prime S}$ & Inicial/Médio** \\
\hline Tetragonisca angustula & 03 & $46^{\circ} 37^{\prime} 34,4^{\prime \prime W}$ & $23^{\circ} 39^{\prime} 08,5^{\prime \prime S}$ & Médio \\
\hline Tetragonisca angustula & 05 & $46^{\circ} 37^{\prime} 20,5^{\prime \prime W}$ & $23^{\circ} 39^{\prime} 14,9 " S$ & Médio \\
\hline Tetragonisca angustula & 06 & $46^{\circ} 37^{\prime} 15,8^{\prime \prime} \mathrm{W}$ & $23^{\circ} 39^{\prime} 33,8 " S$ & Inicial \\
\hline Trigona braueri & 02 & $46^{\circ} 37^{\prime} 47,7^{\prime \prime} \mathrm{W}$ & $23^{\circ} 39^{\prime} 06,2^{\prime \prime S}$ & Inicial/Médio** \\
\hline Trigona spinipes & 01 & $46^{\circ} 37^{\prime} 52,9 " \mathrm{~W}$ & $23^{\circ} 39^{\prime} 14,3^{\prime \prime S}$ & Inicial \\
\hline
\end{tabular}

* - área sem árvores, pois sofreu um incêndio em anos anteriores

** - ninhos localizados nas áreas limítrofes desses estágios 


\section{Anexo 6}

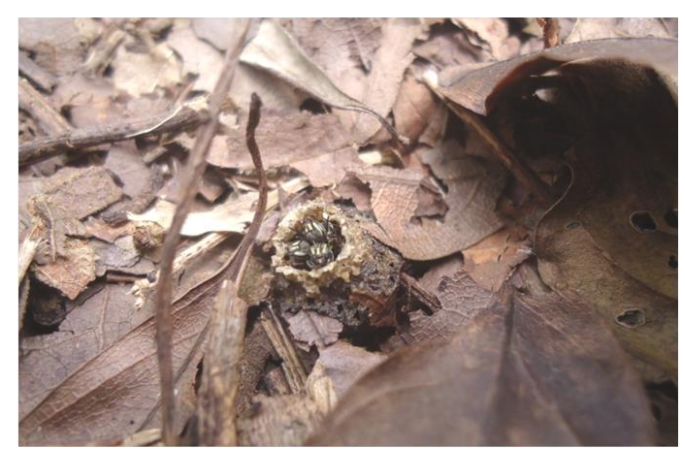

Ninho 07, área degradada, fora da área de amostragem.

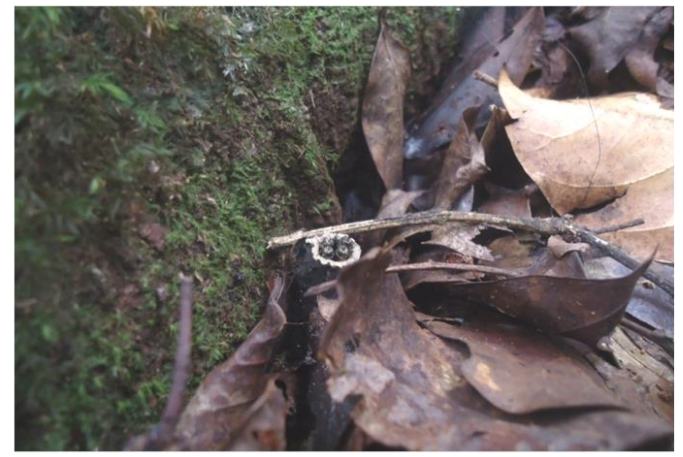

Ninho t5, área ST.

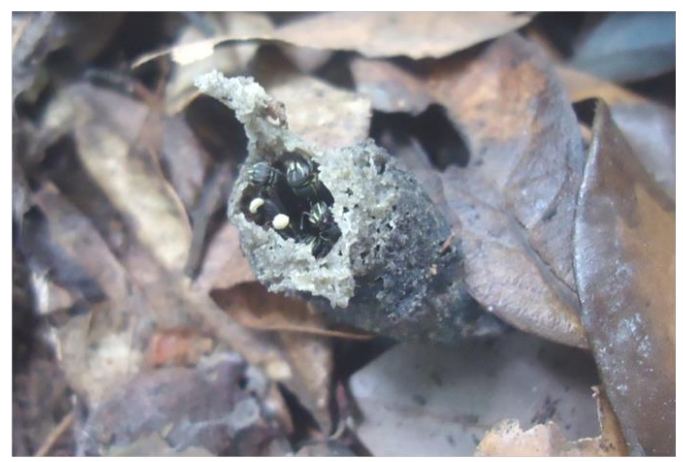

Ninho t4, área ST. Operária com pólen em suas corbículas.

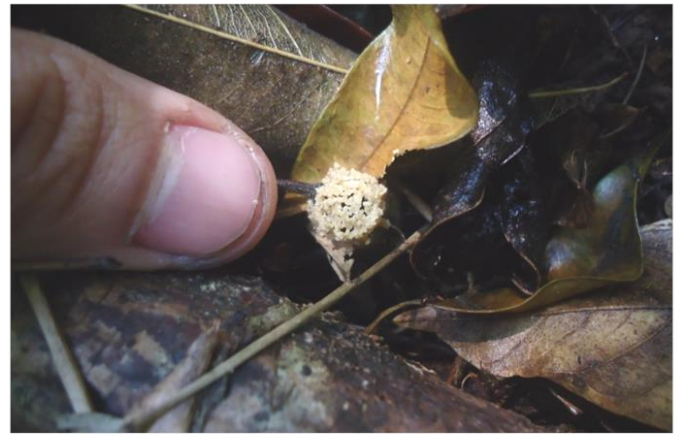

Entrada fechada em um dia chuvoso..

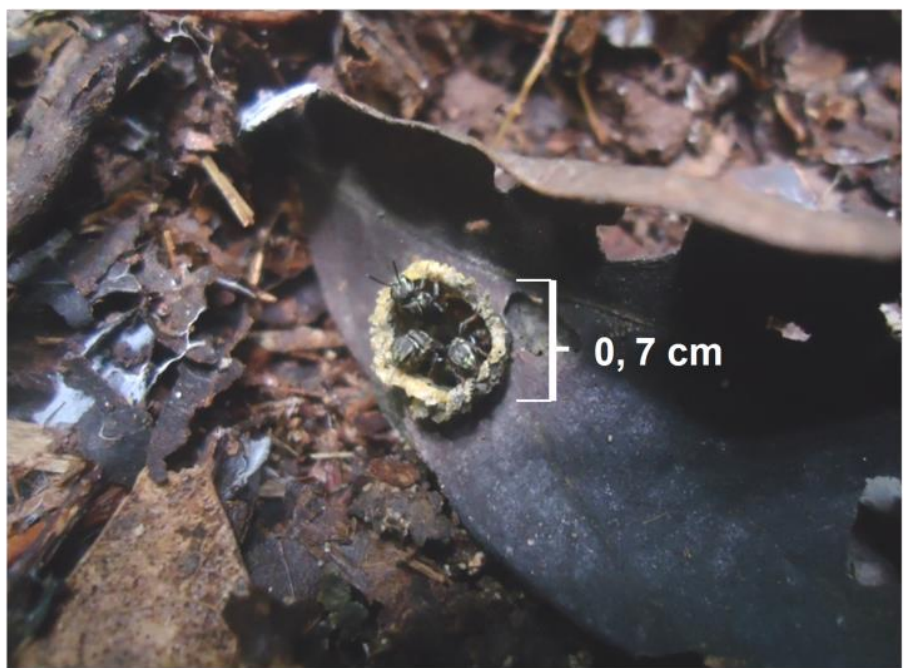

Figura 4. Entrada dos ninhos de de Paratrigona subnuda encontrados no PEFI. 
Anexo 7

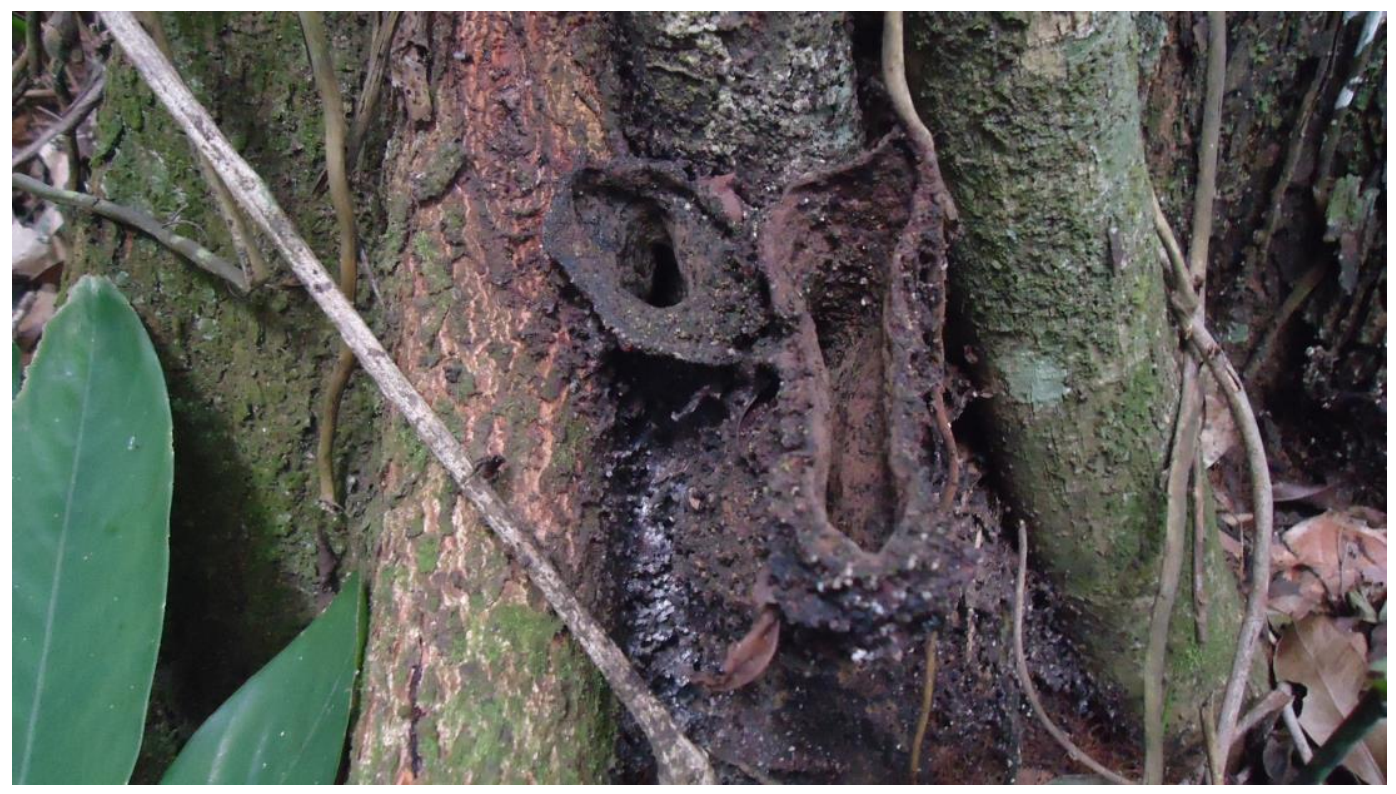

Trigona braueri, ninho o2, em área de trilha, fora da área de amostragem.

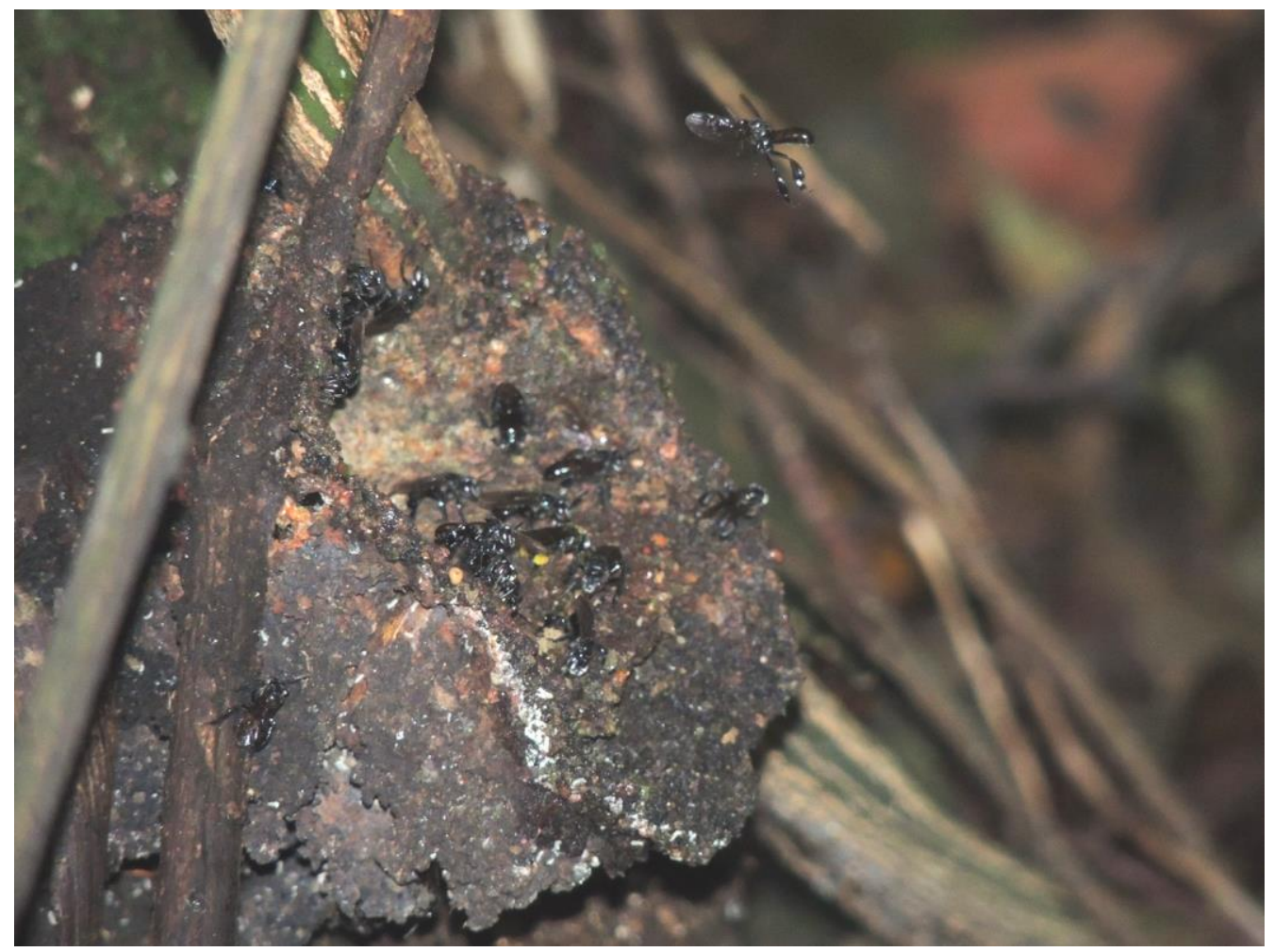

Trigona braueri, ninho i2, em área Secundária Inicial.

Figura 5. Entradas de ninho de Trigona braueri nas matas do PEFI. 